\title{
The Department of the Interior Southeast Climate Science Center Synthesis Report, 2011-15: Projects, Products, and Science Priorities
}

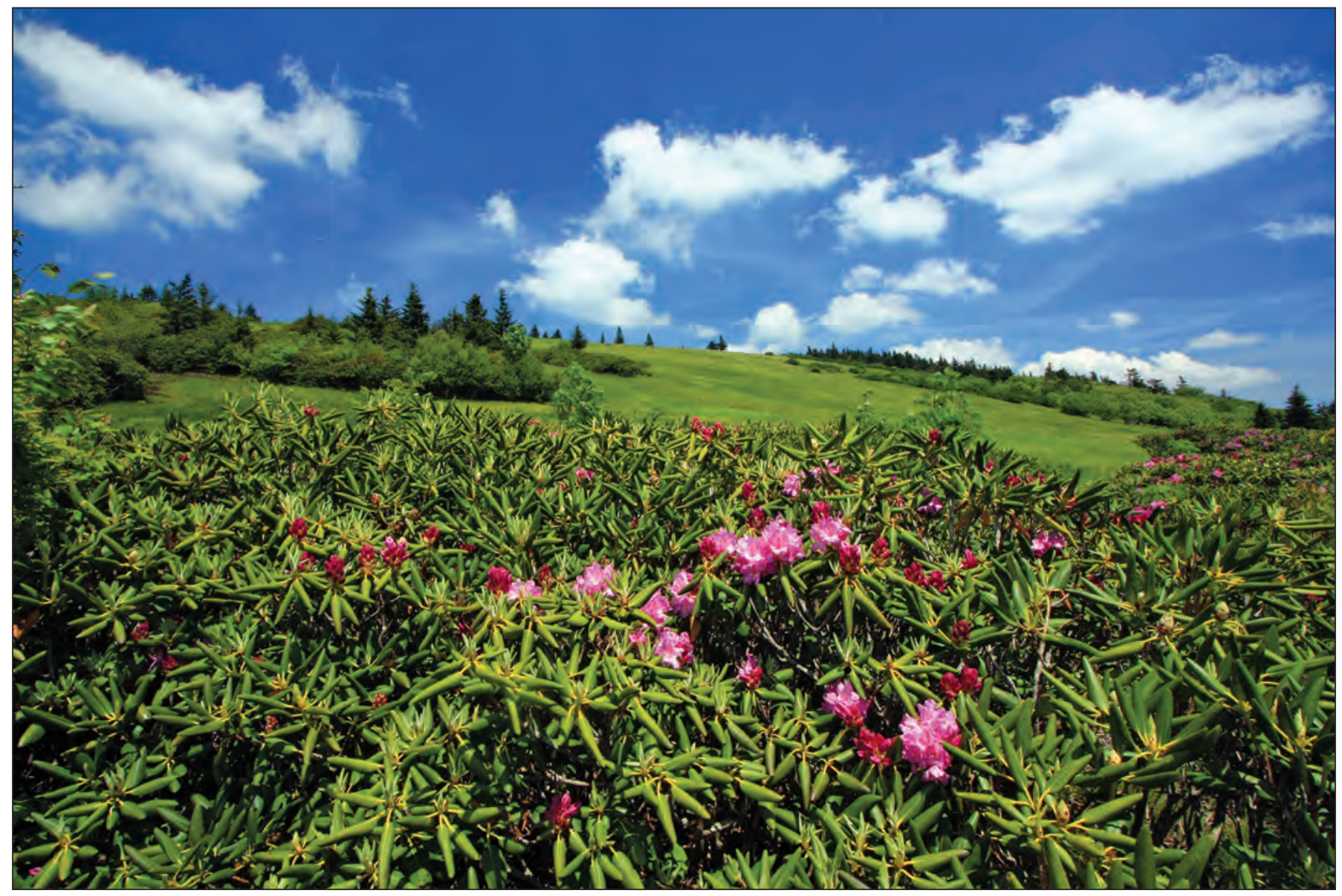

Open-File Report 2016-1133

U.S. Department of the Interior

U.S. Geological Survey 
Cover. Rhododendron catawbiense, Round Bald, Pisgah National Forest, Mitchell County, North Carolina, and Cherokee National Forest, Carter County, Tennessee. Photograph by Alan M. Cressler, USGS. 


\section{The Department of the Interior Southeast Climate Science Center Synthesis Report, 2011-15: Projects, Products, and Science Priorities}

By Elda Varela Minder, Aranzazu R. Lascurain, and Gerard McMahon

Open-File Report 2016-1133 


\title{
U.S. Department of the Interior SALLY JEWELL, Secretary
}

\section{U.S. Geological Survey Suzette M. Kimball, Director}

\author{
U.S. Geological Survey, Reston, Virginia: 2016
}

For more information on the USGS - the Federal source for science about the Earth, its natural and living resources, natural hazards, and the environment—visit http://www.usgs.gov or call 1-888-ASK-USGS.

For an overview of USGS information products, including maps, imagery, and publications, visit http://store.usgs.gov.

Any use of trade, firm, or product names is for descriptive purposes only and does not imply endorsement by the U.S. Government.

Although this information product, for the most part, is in the public domain, it also may contain copyrighted materials as noted in the text. Permission to reproduce copyrighted items must be secured from the copyright owner.

Suggested citation:

Varela Minder, Elda, Lascurain, A.R., and McMahon, Gerard, 2016, The Department of the Interior Southeast Climate Science Center synthesis report 2011-15-Projects, products, and science priorities: U.S. Geological Survey OpenFile Report 2016-1133, 59 p., http://dx.doi.org/10.3133/ofr20161133.

ISSN 2331-1258 (online) 


\section{Contents}

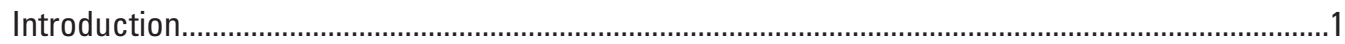

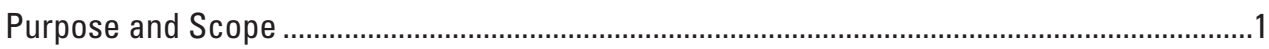

SE CSC “Actionable Science” Agenda ..........................................................................................1

Goal 1: Decision-Focused, Co-Produced, Research-Based

Global Change Science ........................................................................................2

Goal 2: Convener of Conversations About Global Change and Its Impact in the Southeast.......................................................................................

Goal 3: Capacity Building of Academics and Professionals................................................4

Development and Implementation of SE CSC Science Plan, 2012-15 ...............................................4

Southeast Climate Science Center Projects by Science Theme ..........................................................5

Science Theme 1: Develop Climate Projections and Determine Appropriate

Projections to Use for Resource Management.................................................................5

Science Theme 2: Land Use and Land Cover Change Projections ............................................5

Science Theme 3: Impacts of Climate Change on Water Resources .........................................6

Science Theme 4: Ecological Research and Modeling..........................................................6

Science Theme 5: Impacts of Climate Change on Coastal and Nearshore Marine

Environments...........................................................................................................................

Science Theme 6: Impacts of Climate Change on Cultural-Heritage Resources .....................7

SE CSC Project Descriptions and Products ....................................................................................

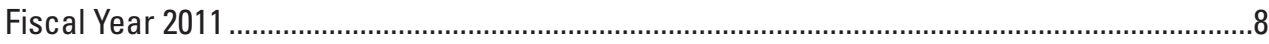

Southeast Regional Assessment Project (SERAP) .......................................................8

Developing Long-Term Urbanization Scenarios for the Appalachian and Gulf Coastal Plain and Ozarks LCCs as Part of SERAP ........................................10

Developing Long-Term Urbanization Scenarios for the Caribbean LCC as Part of the SERAP ............................................................................................ 10

Impact of Ocean Warming and Acidification on Growth of Reef-Building Corals..........11

Integrating the Effects of Global and Local Climate Change on Wildlife in

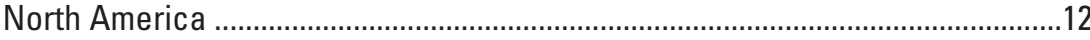

Predicting Vulnerability of Southeastern Sea Turtle Nesting Beaches to Climate Change .............................................................................................................. 13

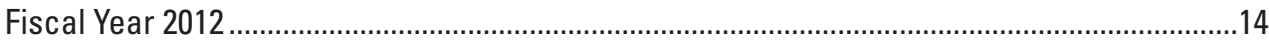

A Handbook for Resource Managers to Understand and Utilize Sea-Level Rise and Coastal Wetland Models for Ecosystem Management Under Future Conditions .............................................................................................. 14

Assessing Climate-Sensitive Ecosystems in the Southeastern U.S. ................................15

Assessment of Terrestrial and Aquatic Monitoring Programs in the Southeastern U.S. ............................................................................................ 16

Communicating and Using Uncertain Scientific Information in the Production of "Actionable Science" ...................................................................17

Connectivity for Climate Change in the Southeastern U.S. ............................................18

Ecological Implications of Mangrove Forest Migration in the Southeastern U.S. .........19

Hydrological Modeling for Flow-Ecology Science in the Southeastern U.S..................20

Synthesis of Climate Model Downscaling Products for the Southeastern U.S. .............20 


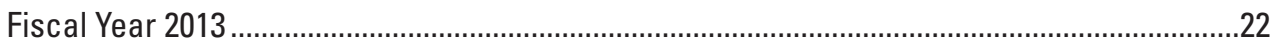

Actionable Science: Decision Analysis and Science Communication.............................22

An Adaptive Landscape Planning and Decision Framework for Gopher Tortoise (Gopherus polyphemus) Conservation ...............................................................22

Developing Multi-Model Ensemble Projections of Ecologically Relevant Climate Variables for Puerto Rico and the U.S. Caribbean ..................................23

Development of a SECAS Conservation Decision Guidance Library ...............................24

Dynamic Reserve Design in the Face of Climate Change and Urbanization ..................25

Evaluation and Downscaling of CMIP5 Climate Simulations for the Southeast U.S..........26

Structured Decision Making to Facilitate Multi-Stakeholder Coastal Conservation and Restoration Under Climate Change Uncertainties: Case Study on Barrier Islands of the Northern Gulf of Mexico .........................................................27

Tree Eaters: Predicting the Response of Herbivores to the Integrated Effects of Urban and Global Change ...............................................................................28

Understanding Conservation Management Decisions in the Face of Sea-Level Rise Along the U.S. Atlantic Coast ........................................................................29

Fiscal Year 2014

Forests of the Future: Integrated Assessment of Climate Change and Ecosystem Diversity .30

The Global Change Monitoring Portal 30

Hydrologic Modeling for Gulf Coastal Plains and Ozarks LCC ...31

Gulf of Mexico Avian Monitoring Network: A Forum to Facilitate Integrated and Complementary Data Collection for Avian Populations and Their Habitats.......31

Fiscal Year 2015. 32

Climate Change Adaptation for Coastal National Wildlife Refuges 32

Connecting Landscape Adaptation and National Cultural Resource Policy to Climate Change and Cultural Resource Adaptation Decisions.

Consequences of Urbanization and Climate Change on Human and Ecosystem Health

Conservation Adaptation Planning for Landscape and Climate Changes in the Southeast.

Implementing a Values-Based Approach to Landscape Conservation Design in the U.S. Caribbean

Climate Change and Patch Dynamics: Implications for the Conservation of Amphibians in Tropical Environments.

Conclusion

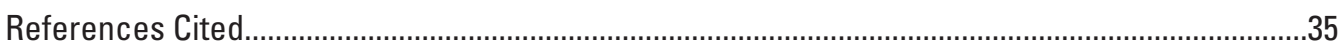

Appendix 1. SE CSC Projects and Timeline of Events......................................................................

Appendix 2. Southeast Climate Science Center Global Change Fellows........................................42

Appendix 3. FY12 SE CSC Science Priorities.....................................................................................47

Appendix 4. FY13/14 SE CSC Science Priorities ...............................................................................50

Appendix 5. FY15 SE CSC Science Priorities.................................................................................51

Appendix 6. Southeast Climate Science Center Science Planning Meeting ................................56 


\section{Figure}

1. Map of the DOI Climate Science Center regions and consortia .2

\section{Abbreviations}

ACC anthropogenic climate change

ACCCNRS Advisory Committee on Climate Change and Natural Resource Science

AM adaptive management

AOGCM atmosphere-ocean general circulation model

AR5 Assessment Report 5

CLCC Caribbean LCC

CPAS co-produced actionable science

CSC Climate Science Center

CMIP5 Coupled Model Intercomparison Project phase 5

DM decision network model

DOI U.S. Department of the Interior

EHNWR Everglades Headwaters National Wildlife Refuge

el CAMPO Caribbean Atlas for Management and Planning Options

FY Fiscal Year

GCF Global Change Fellows

GCM global climate models

HCCVI Habitat Climate Change Vulnerability Index

IPCC Intergovernmental Panel on Climate Change

LCC Landscape Conservation Cooperative

LCD landscape conservation design

MsCIP Mississippi Coastal Improvement Program

NCCWSC National Climate Change and Wildlife Science Center

NCSU North Carolina State University

NOAA National Oceanic and Atmospheric Administration

NPS National Park Service

NW CSC Northwest Climate Science Center

PI principal investigator 


$\begin{array}{ll}\text { PNW } & \text { Pacific Northwest U.S. } \\ \text { PRMS } & \text { Precipitation-Runoff Modeling System } \\ \text { RISA } & \text { Regional Integrated Sciences and Assessments } \\ \text { SAC } & \text { Stakeholder Advisory Council } \\ \text { SC } & \text { Steering Committee } \\ \text { SDM } & \text { structured decision making } \\ \text { SE CSC } & \text { Southeast Climate Science Center } \\ \text { SECAS } & \text { Southeast Conservation Adaptation Strategy } \\ \text { SEAFWA } & \text { Southeastern Association of Fish and Wildlife Agencies } \\ \text { SERAP } & \text { Southeast Regional Assessment Project } \\ \text { SIP } & \text { Science Implementation Panel } \\ \text { SNTemp } & \text { Stream Temperature Network } \\ \text { Sr/Ca } & \text { strontium-to-calcium } \\ \text { SST } & \text { sea surface temperature } \\ \text { USFWS } & \text { U.S. Fish and Wildlife Service } \\ \text { USGS } & \text { U.S. Geological Survey }\end{array}$




\title{
The Department of the Interior Southeast Climate Science Center Synthesis Report, 2011-15: Projects, Products, and Science Priorities
}

\author{
By Elda Varela Minder, Aranzazu R. Lascurain, and Gerard McMahon
}

\section{Introduction}

In 2009, the U.S. Department of the Interior (DOI) Secretary Ken Salazar established a network of eight regional Climate Science Centers (CSCs) (fig. 1) that, along with the Landscape Conservation Cooperatives (LCCs), would help define and implement the Department's climate adaptation response (Jones and Dalton, 2012). The Southeast Climate Science Center (SE CSC) was established at North Carolina State University (NCSU) in Raleigh, North Carolina, in 2010, under a 5-year cooperative agreement with the U.S. Geological Survey (USGS), to identify and address the regional challenges presented by climate change and variability in the Southeastern United States. All eight regional CSC hosts, including NCSU, were selected through a competitive process.

Since its opening, the focus of the SE CSC has been on working with partners in the identification and development of research-based information that can assist managers, including cultural and natural resource managers, in adapting to global change processes, such as climate and land use change, that operate at local to global scales and affect resources important to the DOI mission. The SE CSC was organized to accomplish three goals:

1. Provide co-produced, researched based, actionable science that supports transparent global change adaptation decisions.

2. Convene conversations among decision makers, scientists, and managers to identify key ecosystem adaptation decisions driven by climate and land use change, the values and objectives that will be used to make decisions, and the research-based information needed to assess adaptation options.

3. Build the capacity of natural resource professionals, university faculty, and students to understand and frame natural resource adaptation decisions and develop and use research-based information to make adaptation decisions.

\section{Purpose and Scope}

The purpose of this report is to provide an overview of the SE CSC and the projects developed by the SE CSC since its inception. Projects are identified by SE CSC science planning theme and the fiscal year the project began. Brief summaries of each project are provided along with a list of the projects' products and links to electronic copies of the products. Summaries are drawn from previously published information from SE CSC and NCCWSC Web sites and from project reports and publications; in effect, this report is a synthesis of information from a variety of sources combined into a single document intended to enable SE CSC stakeholders to gain an overview of SE CSC activities and easily access specific project information. This synthesis is necessarily a snapshot at a given moment in time (projects funded through fiscal year 2015 and products reported through July 2016); however, projects and products will evolve over time.

An important goal of the report is to provide a framework for understanding the evolution of the SE CSC science agenda, which has evolved over the first 5 years of the Center's operation to include the support of research as well as a broader set of activities - such as convening conversations and capacity building for students and professionals - that can be thought of as actionable science.

\section{SE CSC “Actionable Science" Agenda}

Actionable science is the outcome of a knowledge production process that informs or fosters adaptation action by those with an interest in the effects of global change processes. The Report to the Secretary of the Interior Advisory Committee on Climate Change and Natural Resource Science (ACCCNRS, 2015) authored by the Advisory Committee on Climate Change and Natural Resource Science (ACCCNRS), the de facto federal advisory group of the CSC network, noted that the "co-production of actionable science is the core programmatic focus of the NCCWSC- (National Climate 


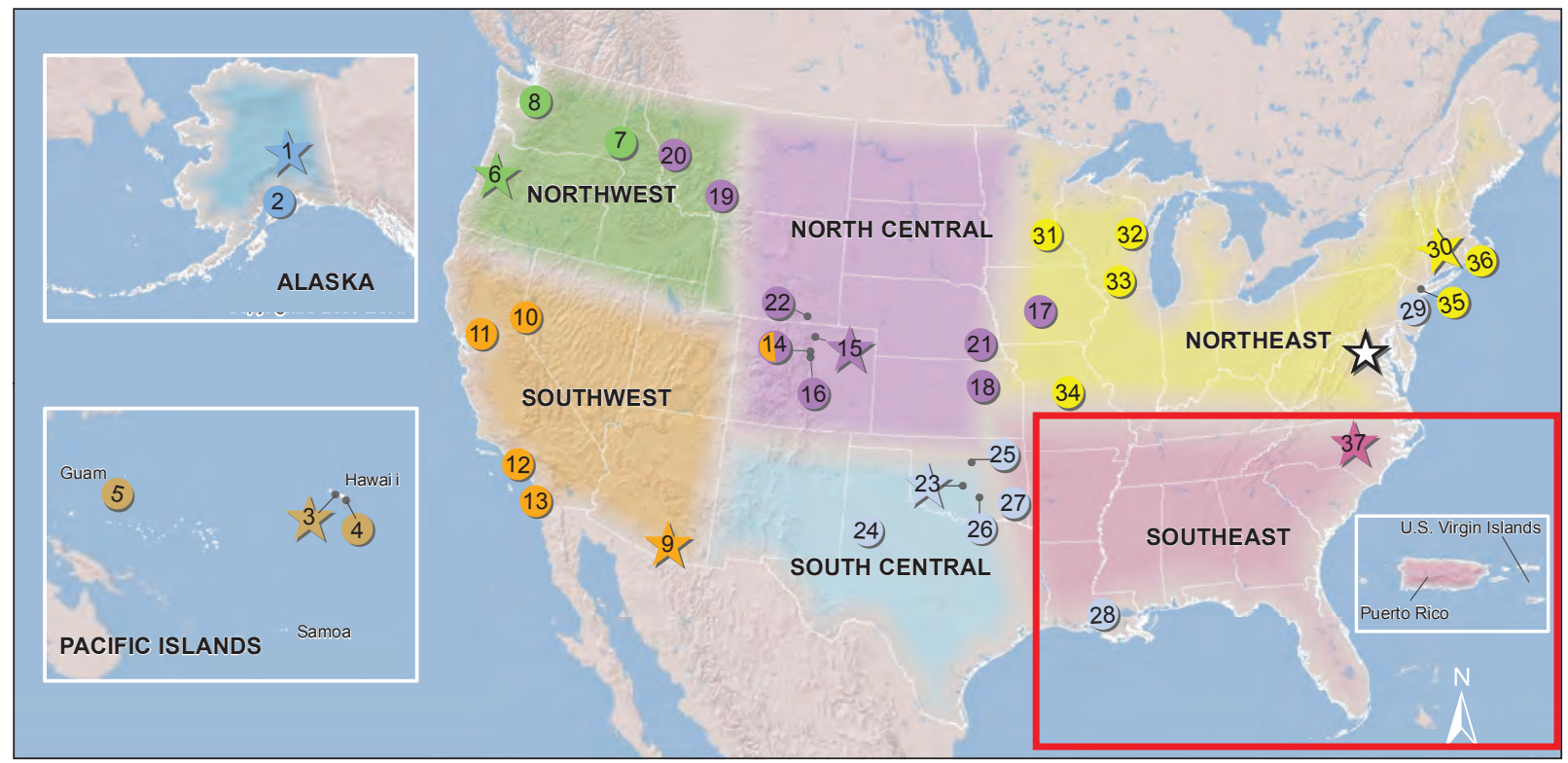

Base from ESRI, 2009, Albers Equal Area Conic Projection North American Datum of 1983

\section{EXPLANATION}

National Climate Change and Wildlife Science Center

CSC lead institutions

2) CSC institutions

Alaska CSC

1. University of Alaska Fairbanks

2. University of Alaska Anchorage

Pacific Islands CSC

3. University of Hawaì i at Mānoa

4. University of Hawai i at Hilo

5. University of Guam

Northwest CSC
6. Oregon State University
7. University of Idaho
8. University of Washington
Southwest CSC
9. University of Arizona
10. Desert Research Institute (Nevada)
11. University of California, Davis
12. University of California, Los Angeles
13. Scripps Institute of Oceanography
14. University of Colorado

Sout

rth Central CSC

14. University of Colorado

15. Colorado State University

16. Colorado School of Mines

17. lowa State University

18. Kansas State University

19. Montana State University

20. University of Montana

21. University of Nebraska, Lincoln

22. University of Wyoming

South Central CSC

23. University of Oklahoma

24. Texas Tech University

25. Oklahoma State University

26. Chickasaw Nation

27. Choctaw Nation of Oklahoma

28. Louisiana State University

29. NOAA Geophysical Fluid Dynamics Laboratory

Figure 1. Map of the DOI Climate Science Center regions and consortia. The Southeast Climate Science Center is outlined in red (source: https://nccwsc.usgs. gov/about-nccwsc).

Change and Wildlife Science Center), the USGS program that manages the eight regional CSCs, CSC enterprise." Co-production involves collaborations between scientists, decision makers, and other stakeholders to frame research questions, decide how to answer the questions, execute needed science activities, and communicate the findings (Lemos and Morehouse, 2005; Meadow and others, 2015). The SE CSC considers this collaboration of central importance in addressing the science needs of the Southeast Region (fig. 1) and considers actionable science and co-production to be at the core of meeting the SE CSC's goals.

\section{Goal 1: Decision-Focused, Co-Produced, Research-Based Global Change Science}

Co-produced actionable science (CPAS) includes activities that can be viewed along two continuums, one related to the degree to which research-based information is decision focused and another related to the degree to which the science can be viewed as "co-produced." At one end of the research-based information continuum are the many SE CSC colleagues/partners are still trying to understand what global change will look like and what the footprint of global change 
will mean for the things that matter to them. The research objective here is to provide a science-based understanding of unfamiliar global change phenomena. Research-based science helps stakeholders and decision makers understand global change in a way that may help decision makers and other stakeholders to eventually frame an adaptation decision problem associated with global change. At the other end of the research continuum, decision makers may have accepted that global change processes and impacts exist, but they may be uncertain about what the right management decision is in the face of these processes and impacts; science supported by the SE CSC at this end of the continuum is explicitly focused on framing the decision problem correctly and providing information that helps decision makers assess the impacts of potential actions or action portfolios on well specified adaptation objectives.

Over the first 5 years of the SE CSC (cycle 1 funding), synthesis and background information projects helped develop global change "basic information infrastructure" that enabled organizations and individuals to understand what global change processes look like (now and in the future) at a variety of scales and begin to understand the implications of these global change processes for places and resources that have value for them. These include projects focused on land cover and climate projections. Several applied research activities, such as the Tree Eater projects and the Connectivity for Climate Change project, are not necessarily connected with a specific management decision identified by the LCCs, but these projects are "pre-decisional" in the sense that they help managers (and individuals) "get their head around" the footprint of global change and begin to become aware of and understand potential decision problems brought about by this global change footprint. Building a basic global change information infrastructure has been a primary emphasis of SE CSC cycle 1 project funding.

For the SE CSC, the few projects that are explicitly decision focused have also been projects at the high end of the co-production continuum. These projects, including the Climate Change Adaptation for Coastal National Wildlife Refuges, involve stakeholders in many or all phases of specification of the problem and major elements of the research approach; at this end of the continuum, the science effort tends to involve co-specification of the project elements among both scientists and decision makers and stakeholders. Cycle 1 SE CSC experience suggests that science projects at the decision specific end of the continuum require both convening and background/overview activities; these activities may need to occur before the decision project can begin (that is, stakeholders need to talk with each other and also learn more about global change processes before a climate adaptation problem/decision can be fully articulated).

The SE CSC receives guidance in developing this actionable science agenda from several sources:
- A Stakeholder Advisory Council (SAC) is composed of senior-level Federal and State government agency executives in the Southeast Region who guide the development and periodic updating of the SE CSC science and operational plan.

- A Science Implementation Panel (SIP) provides the SE CSC with annual guidance on specific science priorities associated with the Science Plan and is responsible for developing a biannual call for project proposals that respond to the determined science priorities, identifying potential directed projects (that is, projects where the SE CSC is investing money to explore issues of interest to the SIP where there is not yet enough information to issue a general call for proposals), and conducting a peer review of all proposed projects and making funding recommendations to the SE CSC Director. Staff from the LCCs and other Federal agencies interested in adaptation to global change serves on the SIP.

- NCSU faculty affiliates ${ }^{1}$ include faculty from the SE CSC's host institution, NCSU, who work on behalf of the SE CSC's objectives and provide input on the SE CSC's involvement within the university community. Participating faculty members are eligible to respond to SE CSC requests for proposals and are also eligible to nominate their students for the SE CSC Global Change Fellows Program.

This guidance has molded the development of the SE CSC. An overview of the SE CSC-supported projects and key milestones since establishment of the CSC in 2009 is shown in a timeline in Appendix 1.

\section{Goal 2: Convener of Conversations About Global Change and Its Impact in the Southeast}

The second SE CSC goal is for the SE CSC, along with LCCs, the U.S. Department of Agriculture Climate Southeast Hub, and the three National Oceanographic and Atmospheric Administration (NOAA) Southeast Regional Integrated Sciences and Assessments (RISAs), is to convene conversations among resource managers and other interested parties at many scales about adapting to global change; these conservations are the foundation for SE CSC actionable science activities. No single organization in the Southeast Region has the responsibility to carry out this convening function, and the lack of communication and coordination among these diverse partners remains one of the biggest challenges to effective and efficient climate adaptation activities. By convening these conversations, the SE CSC and its partners have three goals:

\footnotetext{
${ }^{1}$ A list of the NCSU faculty affiliates can be found at https://globalchange. ncsu.edu/secsc/faculty-affiliates/.
} 
1. Build awareness among diverse management partners about each other's existence and key goals and values;

2. Encourage the development of networks among partners who may not have been aware of each other or have worked together before; and

3. Foster a general understanding of global climate processes, the spatial and temporal footprint of these processes, and the resources needed to learn more about them, including what might be thought of as "information concierge" activities.

\section{Goal 3: Capacity Building of Academics and Professionals}

The third SE CSC goal is to provide or coordinate training and professional development activities that increase the capabilities of academics (students and faculty) and professionals to understand global change processes and their impacts, in general, and also bring these abilities to their own research or professional work domains. The SE CSC has supported $45 \mathrm{NCSU}$ graduate and post-doctoral Global Change Fellows (GCF) (Appendix 2) and has also supported training for professionals, including science communication training for NCSU faculty and climate change communication training for journalists and broadcast meteorologists.

\section{Development and Implementation of SE CSC Science Plan, 2012-15}

The SE CSC actionable science agenda began evolving in 2012, when Acting SE CSC Director Sonya Jones and staff scientist Melinda Dalton, with input from regional partners and stakeholders, including the SAC, developed the "U.S. Department of the Interior Southeast Climate Science Center Science and Operational Plan" (Jones and Dalton, 2012). This science and operational plan outlines the direction and goals of the SE CSC. The objectives of the plan are stated as

"The Southeast CSC will use long-term and new observational records as well as understanding of biological and physical processes that can be expressed in quantitative models to describe the consequences of global change on natural resources; provide scientifically valid information and tools that can be used to adapt resource management to changing environmental conditions; and apply these tools to produce regional assessments that are widely used by policy makers, resource managers, and the public."

The plan provides the strategic context for SE CSC efforts related to climate and land use change in the
Southeastern U.S., identifying six major science themes and potential operational activities needed to address these strategic themes.

- Science Theme 1: Develop climate projections and determine appropriate projections to use for resource management,

- Science Theme 2: Land use and land cover change projections,

- Science Theme 3: Impacts of climate change on water resources,

- Science Theme 4: Ecological research and modeling,

- Science Theme 5: Impacts of climate change on coastal and nearshore marine environments, and

- Science Theme 6: Impacts of climate change on cultural-heritage resources.

With these six themes providing the strategic direction during the first 5 years of the SE CSC operation, the SE CSC operational emphasis, especially the emerging importance of a continuum of actionable science activities and the practical challenges of co-production, has emerged in an annual science planning process conducted by the SE CSC staff and the SIP (Appendixes 3, 4, and 5) that are met through the USGS coordinated call for project proposals. Science plans for federal fiscal year 2012 (FY12; October 2011-September 2012) were defined during a 2-day meeting (Appendix 6) in St. Petersburg, Florida, in February 2012 among approximately 40 participants from USGS, NCSU, and LCC staff and scientists. This meeting was the initial gathering of the SE CSC SIP where panel members were able to identify major science priorities for FY12. Beginning with the FY12 call for proposals, the SIP emphasized the development of decision-focused science that supports LCC management activities and future investment of CSC and (or) LCC dollars with the expectation that funded investigators would collaborate with the LCCs in the identification of priority information needs. The FY12 call for proposals (Appendix 3) identified five priority science needs and reflects a sense of the annual planning team that decisionfocused science exists along a continuum as described above; that is, actionable science can be both pre-decisional (for example, state of the science projects that help stakeholders understand what is known about a global change process) as well as decision focused:

- Synthesis of the state of the science regarding six topics important to the LCC efforts to manage sustainable landscapes: regional downscaling of global climate models (GCMs), ecohydrology, sea-level rise, modeling of urban growth, unique climate-vulnerable and climate-sensitive ecosystems, and the communication of scientific uncertainty to decision makers.

- Terrestrial connectivity analysis across the entire Southeast region. 
- Conceptual model for regional-scale sustainable landscapes.

- Impact of mangrove migration on coastal ecosystems.

- Snowfall and snow depth projections for the Eastern United States.

FY13 SE CSC annual science priorities were developed by the SIP in a series of conference calls during the winter of 2012-13. The two priorities were conservation and water governance, and local-scale climate adaptation (Appendix 4). The SIP also identified several topics for directed projects, including dynamic downscaling in Puerto Rico; urban warming effects on biodiversity; resource allocation decision making in the face of climate change; and the impacts of global change on coastal U.S. Fish and Wildlife Service (USFWS) National Wildlife Refuges.

A formal FY14 science planning effort did not identify any themes for a call for proposals, because most FY14 SE CSC science funding was committed to projects that started in FY13 and continued into FY14. Therefore, there was no call for proposals in FY14.

FY15 SE CSC annual science priorities were focused on development of a Southeast Conservation Adaptation Strategy (SECAS), use of reserve design approaches for assisting coastal National Wildlife Refuges in responding to climate and land use threats to their missions, and climate change adaptation decisions associated with managing cultural resources (Appendix 5). Each of these priorities reflects an emphasis on decision support and long-term climate change adaptation conservation priorities of Federal, State, local, private, and nongovernmental organizations.

\section{Southeast Climate Science Center Projects by Science Theme}

Since 2010, the SE CSC has provided more than $\$ 5$ million in research funding through 30 research awards to scientists at NCSU and the USGS; more than 90 publications have been produced by projects supported by the SE CSC. These projects can be viewed through the lens of six SE CSC science themes and tasks, established by partners in the southeastern conservation community, to address information gaps that can inform the conservation science and resource management needs of ecoregional conservation partnerships, such as the LCCs. These themes are presented in detail in the "U.S. Department of the Interior Southeast Climate Science Center Science and Operational Plan," (Jones and Dalton, 2012). In this section of the report, each science theme is briefly summarized followed by a list of the SE CSC-funded science projects that respond to that theme. Detailed information about each project is contained in the "SE CSC Project Descriptions and Products" section of this report.

\section{Science Theme 1: Develop Climate Projections and Determine Appropriate Projections to Use for Resource Management}

Theme 1 tasks include identification of climate information gaps; characterization and use of global climate projections; and development of climate scenarios for SE CSC impacts, vulnerability, and adaptation assessments. Project names and initial funding year are listed below.

- Southeast Regional Assessment Project (SERAP) (FY11)

- Synthesis of climate model downscaling products for the Southeastern U.S. (FY12)

- Actionable science: Decision analysis and science communication (FY13)

- Communicating and using uncertain scientific information in the production of "actionable science" (FY12)

- Developing multi-model ensemble projections of ecologically relevant climate variables for Puerto Rico and the U.S. Caribbean (FY13)

- Evaluation and downscaling of CMIP5 climate simulations for the Southeast U.S. (FY13) (CMIP5 is the Coupled Model Intercomparison Project Phase 5)

- Climate change adaptation for coastal National Wildlife Refuges (FY15)

- Conservation adaptation planning for landscape and climate changes in the Southeast (FY15)

- Implementing a values-based approach to landscape conservation design in the U.S. Caribbean (FY15)

- Linking climate change and patch dynamics: Implications for the conservation of amphibians in tropical environments (FY15)

\section{Science Theme 2: Land Use and Land Cover Change Projections}

Theme 2 tasks include researching land use and land cover change rates, causes, and consequences; researching droughts, floods, water availability, and biological responses under changing land use and climate; and developing land cover and habitat projections for the Southeastern U.S. Project names and initial funding year are listed below.

- Developing long-term urbanization scenarios for the Appalachian and Gulf Coastal Plain and Ozarks LCCs as part of SERAP (FY11)

- Integrating the effects of global and local climate change on wildlife in North America (FY11)

- Southeast Regional Assessment Project (SERAP) (FY11) 
- Assessing climate-sensitive ecosystems in the Southeastern U.S. (FY12)

- Connectivity for climate change in the Southeastern U.S. (FY12)

- Developing long-term urbanization scenarios for the Caribbean LCC as part of the Southeast Regional Assessment Project (FY12)

- Actionable science: Decision analysis and science communication (FY13)

- An adaptive landscape planning and decision framework for gopher tortoise (Gopherus polyphemus) conservation (FY13)

- Dynamic reserve design in the face of climate change and urbanization (FY13)

- Understanding conservation management decisions in the face of sea-level rise along the U.S. Atlantic Coast (FY13)

- Forests of the future: Integrated assessment of climate change and ecosystem diversity (FY14)

- Climate change adaptation for coastal National Wildlife Refuges (FY15)

- Connecting landscape adaptation and national cultural resource policy to climate change and cultural resource adaptation decisions (FY15)

- Consequences of urbanization and climate change on human and ecosystem health (FY15)

- Conservation adaptation planning for landscape and climate changes in the Southeast (FY15)

- Implementing a values-based approach to landscape conservation design in the U.S. Caribbean (FY15)

\section{Science Theme 3: Impacts of Climate Change on Water Resources}

Theme 3 tasks include developing predictive hydrologic conditions models of groundwater, surface water, and water quality; improving our knowledge of existing hydrologic processes models; supporting Web-based access to a suite of hydrologic models, common climatic datasets, and calibration data; and supporting SE CSC partners in producing waterrelated vulnerability assessments. Project names and initial funding year are listed below.

- Impact of ocean warming and acidification on growth of reef-building corals (FY11)

- Southeast Regional Assessment Project (SERAP) (FY11)
- Assessment of terrestrial and aquatic monitoring programs in the Southeastern U.S. (FY12)

- Ecological implications of mangrove forest migration in the Southeastern U.S. (FY12)

- Hydrological modeling for flow-ecology science in the Southeastern U.S. (FY12)

- Actionable science: Decision analysis and science communication (FY13)

\section{Science Theme 4: Ecological Research and Modeling}

Theme 4 tasks include developing species and population distribution maps, and population and phenology models; studying whether the predicted responses of species to climate and land use change match observed changes; documenting organismal responses to climate change; identifying species interactions impact on community structure and ecosystem function; and assessing new strategies to conserve natural communities and ecosystems. Project names and initial funding year are listed below.

- Integrating the effects of global and local climate change on wildlife in North America (FY11)

- Predicting vulnerability of southeastern sea turtle nesting beaches to climate change (FY11)

- Southeast Regional Assessment Project (SERAP) (FY11)

- A handbook for resource managers to understand and utilize sea-level rise and coastal wetland models for ecosystem management under future conditions (FY12)

- Assessment of terrestrial and aquatic monitoring programs in the Southeastern U.S. (FY12)

- Connectivity for climate change in the Southeastern U.S. (FY12)

- Ecological implications of mangrove forest migration in the Southeastern U.S. (FY12)

- Actionable science: Decision analysis and science communication (FY13)

- An adaptive landscape planning and decision framework for gopher tortoise (Gopherus polyphemus) conservation (FY13)

- Developing multi-model ensemble projections of ecologically relevant climate variables for Puerto Rico and the U.S. Caribbean (FY13) 
- Development of a SECAS conservation decision guidance library (FY13) (SECAS is Southeast Conservation Adaptation Strategy)

- Dynamic reserve design in the face of climate change and urbanization (FY13)

- Tree eaters: Predicting the response of herbivores to the integrated effects of urban and global change (FY13)

- Understanding conservation management decisions in the face of sea-level rise along the U.S. Atlantic Coast (FY13)

- Global Change Monitoring Portal (FY14)

- Conservation adaptation planning for landscape and climate changes in the Southeast (FY15)

- Climate change and patch dynamics: Implications for the conservation of amphibians in tropical environments (FY15)

\section{Science Theme 5: Impacts of Climate Change on Coastal and Nearshore Marine Environments}

Theme 5 tasks include establishing ecological baseline conditions and describing current climate trends and impacts in coastal systems; developing scenarios of coastal landform and habitat change; describing how estuaries and marine resources will be affected by climate change; and assessing potential impacts on highly vulnerable coastal and marine habitats and potential management responses. Nine funded projects have addressed this theme. Project names and initial funding year are listed below.

- Impact of ocean warming and acidification on growth of reef-building corals (FY11)

- Predicting vulnerability of southeastern sea turtle nesting beaches to climate change (FY11)

- Southeast Regional Assessment Project (SERAP) (FY11)

- A handbook for resource managers to understand and utilize sea-level rise and coastal wetland models for ecosystem management under future conditions (FY12)

- Ecological implications of mangrove forest migration in the Southeastern U.S. (FY12)

- Actionable science: Decision analysis and science communication (FY13)

- Development of a SECAS conservation decision guidance library (FY13)
- Understanding conservation management decisions in the face of sea-level rise along the U.S. Atlantic Coast (FY13)

- Structured decision making to facilitate multistakeholder coastal conservation and restoration under climate change uncertainties: Case study on barrier islands of the northern Gulf of Mexico (FY13)

- Climate change adaptation for coastal National Wildlife Refuges (FY15)

\section{Science Theme 6: Impacts of Climate Change on Cultural-Heritage Resources}

Theme 6 tasks include developing inventory and monitoring plans for cultural-heritage resources; supporting SE CSC partners in assessing the vulnerability of culturalheritage resources to climate change; facilitating paleoecological and paleoclimate research for cultural-heritage resources; and supporting cultural-heritage resources climatechange planning.

- Actionable science: Decision analysis and science communication (FY13)

- Connecting landscape adaptation and national cultural resource policy to climate change and cultural resource adaptation decisions (FY15)

\section{SE CSC Project Descriptions and Products}

This section of the report summarizes information for each project started by the NCCWSC (FY09-FY10) and the SE CSC (FY11-FY15). Project summaries are drawn from materials developed by the project teams and available on the SE CSC and NCCWSC Web sites. Each summary includes the project title, the name and affiliation of the principal investigator (PI), the project completion date, a project summary, and a list of publications and other products, through July 2016, along with links to electronic copies of the products. It should be noted that publications and other products have been completed after the formal project end date, reflecting the sometimes lengthy process necessary for completing scientific publications. 


\section{Fiscal Year 2011}

\section{Southeast Regional Assessment Project (SERAP) \\ PI: Brian Hughes (USGS Georgia Water Science Center)}

\section{Project Completion: March 2013}

\section{Project Summary}

In 2009, prior to the establishment of the CSCs, the USFWS and the USGS National Climate Change and Wildlife Science Center (NCCWSC) supported and coordinated a large-scale, multidisciplinary project, the Southeast Regional Assessment Project (SERAP), to provide regional-scale information and tools to the resource management community in the Southeast. The SERAP subsequently was incorporated into the SE CSC research program in 2011. The SERAP team produced assessments of climate change, impacts on land cover and ecosystems, and priority species in the region. SERAP investigations and products can be organized into the following themes or categories: aquatic habitat; downscaling; hydrology; land use change; sea-level rise; and terrestrial species. Specific products associated with these themes are listed below, including links to the actual products.

Key terms: conservation planning; system drivers; climate and land use change; physiology

\section{Products}

- Publication:

- Southeast Regional Assessment Project for the National Climate Change and Wildlife Science Center, U.S. Geological Survey (Dalton and Jones, 2010)

\section{Additional SERAP products were grouped according to the following seven themes:}

\section{SERAP: The Effects of Climate Change on Aquatic Species and Habitat in the Southeast}

\section{- Publications:}

- Effects of climate and land cover on hydrology in the Southeastern U.S.: Potential impacts on watershed planning (LaFontaine and others, 2015)

- Stream classification of the Apalachicola-Chattahoochee-Flint River System to support modeling of aquatic habitat response to climate change (Elliott and others, 2014)

- An evaluation of the relations between flow regime components, stream characteristics, species traits, and meta-demographic rates of warm-water-stream fishes: Implications for aquatic resources management (Peterson and Shea, 2015)

- Linking river management to species conservation using dynamic landscape-scale models (Freeman and others, 2013)

- Misidentification of freshwater mussel species (Bivalvia:Unionidae): Contributing factors, management implications, and potential solutions (Shea and others, 2011)

\section{SERAP: Comprehensive Web-Based Climate Change Projections: Downscaled Maps and Data}

- Publications:

- CMIP5 projected changes in spring and summer drought and wet conditions over North America (Swain and Hayhoe, 2015)

- CMIP5 climate model analyses: Climate extremes in the United States (Wuebbles and others, 2014)

- Regional and large-scale influences on seasonal to interdecadal variability in Caribbean surface air temperature in CMIP5 simulations (Ryu and Hayhoe, 2014)

- Toward enhanced understanding and projections of climate extremes using physics-guided data mining techniques (Ganguly and others, 2014)

- An asynchronous regional regression model for statistical downscaling of daily climate variables (Stoner and others, 2013) 
- The Practitioner's dilemma - How to assess the credibility of downscaled climate projections?

(Barsugli and others, 2013)

- Understanding the sources of Caribbean precipitation biases in CMIP3 and CMIP5 simulations

(Ryu and Hayhoe, 2013)

- Inferring likelihoods and climate system characteristics form climate models and multiple tracers (Bhat and others, 2012)

- Climate projections using Bayesian model averaging and space-time dependence (Bhat and others, 2011)

- Description and testing of the Geo Data Portal: A data integration framework and web processing services for environmental science collaboration (Blodgett and others, 2011)

- Computer model calibration with multivariate spatial output: A case study in climate parameter learning (Bhat and others, 2010)

\section{SERAP: Modeling of Hydrologic Systems}

- Publications:

- Application of the Precipitation-Runoff Modeling System (PRMS) in the Apalachicola-Chattahoochee-Flint River basin in the Southeastern U.S. (LaFontaine and others, 2013)

- Effects of climate and land cover on hydrology in the Southeastern U.S.: Potential impacts on watershed planning (LaFontaine and others, 2015)

- P2S-Coupled simulation with the Precipitation-Runoff Modeling System (PRMS) and the Stream Temperature Network (SNTemp) models (Markstrom, 2012)

- Hydrologic effects of urbanization and climate change in the Flint River Basin, Georgia (Viger and others, 2011)

- Effects of including surface depressions in the application of the Precipitation-Runoff Modeling System in the Upper Flint River Basin, Georgia (Viger and others, 2010)

\section{SERAP: Modeling of Global and Land Use Change Impacts}

\section{- Publications:}

- Modeling climate change, urbanization, and fire effects on Pinus palustris ecosystems of the Southeastern U.S. (Costanza and others, 2015)

- Small reservoir distribution, rate of construction, and uses in the upper and middle Chattahoochee Basins of the Georgia piedmont, USA, 1950-2010 (Ignatius and Jones, 2014)

- The southern megalopolis: Using the past to predict the future of urban sprawl in the Southeast U.S. (Terando and others, 2014)

- Simulating the effects of southern pine beetle on regional dynamics 60 years into the future (Costanza and others, 2012)

- What is the skill of ocean tracers in reducing uncertainties about ocean diapycnal mixing and projections of the Atlantic Meridional Overturning Circulation? (Goes and others, 2010)

- Data:

- Urban growth modeling for the SAMBI designing sustainable landscapes project (Belyea and Terando, 2013)

\section{SERAP: Modeling Global and Land Use Change}

\section{- Publication:}

- The southern megalopolis: Using the past to predict the future of urban sprawl in the Southeast U.S. (Terando and others, 2014)

\section{- Data:}

- Dataset for urban growth projection for Southeast Regional Assessment Project (Belyea, 2012)

- Dataset for developing long-term urbanization scenarios for the Caribbean LCC as part of the Southeast Regional Assessment Project (Collazo, 2012) 
6. SERAP: Assessment of Shoreline Retreat in Response to Sea-Level Rise

- Publication:

- A Bayesian network to predict coastal vulnerability to sea level rise (Gutierrez and others, 2011)

- Data:

- Sea-level rise visualization for Alabama, Mississippi, and Florida (Wilson, 2011)

7. SERAP: Assessment of Climate and Land Use Change Impacts on Terrestrial Species

- Publications:

- Use of occupancy models to evaluate expert knowledge-based species-habitat relationships (Iglecia and others, 2012)

- Modeling habitat dynamics accounting for possible misclassification (Veran and others, 2012)

- Data:

- Urban growth modeling for the SAMBI designing sustainable landscapes project (Belyea and Terando, 2013)

Developing Long-Term Urbanization Scenarios for the Appalachian and Gulf Coastal Plain and Ozarks LCCs as Part of SERAP (Part 1, funded in FY11)

Developing Long-Term Urbanization Scenarios for the Caribbean LCC as Part of the SERAP (Part 2, funded in FY12)

\section{PI: Jaime Collazo (USGS North Carolina Cooperative Fish and Wildlife Research Unit)}

\section{Project Completion: March 2013}

\section{Project Summary}

These land cover datasets were developed to complement and extend the spatial extent of the original SERAP land cover projections. Part 1 of this project was devoted to modeling the land cover and Part 2 the production of a dataset.

Key terms: scenario planning; modeling; urbanization; corridors

\section{Products}

- Publication:

- The southern megalopolis: Using the past to predict the future of urban sprawl in the Southeast U.S. (Terando and others, 2014)

- Data:

- Dataset for developing long-term urbanization scenarios for the Caribbean LCC as part of the Southeast Regional Assessment Project (Collazo, 2012) 


\section{Impact of Ocean Warming and Acidification on Growth of Reef-Building Corals}

\section{PI: Ilsa B. Kuffner (USGS St. Petersburg Coastal and Marine Science Center)}

\section{Project Completion: January 2013}

\section{Project Summary}

Increasing ocean surface temperatures and decreasing ocean acidification are two significant contributing factors to the degradation of coral reef ecosystems. This study focused on differences in climate vulnerability among three important reef-building coral species. Strontium-to-calcium ratios $(\mathrm{Sr} / \mathrm{Ca})$ were measured on the skeletal matrix of a core sample from a colony of the massive coral Siderastrea sidereal collected in Coral Bay, St. John, U.S. Virgin Islands. Details presented from the St. John S. sidereal core indicate that terrestrial inputs of sediment and freshwater can disrupt the chemical balance and subsequently complicate the utility of $\mathrm{Sr} / \mathrm{Ca}$ in reconstructing historical sea surface temperature (SST). An approximately 44-year-long record of $\mathrm{Sr} / \mathrm{Ca}$ shows that an annual SST signal is recorded in the $S$. siderea core but with an increasing $\mathrm{Sr} / \mathrm{Ca}$ trend from 1980 to present, which is likely the result of runoff from the mountainous terrain of St. John.

Key terms: coral; ocean temperature; ocean $\mathrm{pH}$

\section{Products}

\section{- Publication:}

- Calcification rates of the massive coral Siderastrea siderea and crustose coralline algae along the Florida Keys (USA) outer-reef tract (Kuffner and others, 2013)

- Complexity of nearshore strontium-to-calcium ratio variability in a core sample of the massive coral Siderastrea siderea obtained in Coral Bay, St. John, U.S. Virgin Islands (Reich and others, 2013)

- Methods for monitoring corals and crustose coralline algae to quantify in-situ calcification rates (Morrison and others, 2013)

- Web site:

- http://coastal.er.usgs.gov/crest/

\section{- Map viewer:}

- http://olga.er.usgs.gov/coreviewer/ 


\title{
Integrating the Effects of Global and Local Climate Change on Wildlife in North America
}

\section{PI: Rob Dunn, Steve Frank, Nick Haddad, Nadia Singh, and other researchers (North Carolina State University)}

\author{
Project Completion: July 2014. This project was expanded in Tree Eaters: Predicting the response
} of herbivores to the integrated effects of urban and global change.

\section{Project Summary}

Climate in the Southeastern U.S. is predicted to be changing at a slower rate than in other parts of North America; however, land use change associated with urbanization is having a significant effect on wildlife populations and habitat availability. The research team sought to understand the effect of global warming on both beneficial and pest insects of trees. The team used urban warming as a proxy representation of global warming since many cities have already warmed as much, due to heat island effects, as they are expected to warm due to climate change by 2050 or even 2100 . The team was able to develop good predictive models of how warming influences beneficial and pest insects for cities in the Southeastern U.S. and generally across the east coast. They also were able to predict how tree health will respond to these changes in insect communities. In addition, by comparing the results to those garnered from herbarium specimens (many insects can be found on herbarium specimens), the researchers could show that the effects of urban warming match those of climate change through time. In short, a subset of pests is likely to get far worse with warming and this effect is likely to be most pronounced in the Southeastern U.S. Building on these findings, additional work was carried out to evaluate how to protect trees and forests from the pests that thrive with warming. Work continues to be focused on the importance of which trees are present (or planted) and the diversity of those trees.

Key terms: land use change; urbanization; modeling; warming; tree pests; species distribution

\section{Products}

\section{- Publications:}

- Do growing degree days predict phenology across butterfly species? (Cayton and others, 2015)

- Do cities simulate climate change? A comparison of herbivore response to urban and global warming (Youngsteadt and others, 2014)

- The effects of urban warming on herbivore abundance and street tree condition (Dale and Frank, 2014a)

- Foraging by forest ants under experimental climatic warming: A test at two sites (Stuble and others, 2013)

- A physiological trait-based approach to predicting the responses of species to experimental climate warming (Diamond, Nichols, and others, 2012)

- Bad neighbors: Urban habitats increase cankerworm damage to non-host understory plants (Frank, 2014)

- Clinal variation in colony breeding structure and level of inbreeding in the subterranean termites Reticulitermes flavipes and R. grassei (Vargo and others, 2013)

- Common garden experiments reveal uncommon responses across temperatures, locations, and species of ants (Pelini and others, 2012)

- Mycangia of ambrosia beetles host communities of bacteria (Hulcr and others, 2012)

- Species loss on spatial patterns and composition of zoonotic parasites (Harris and Dunn, 2013)

- Upward ant distribution shift corresponds with minimum, not maximum, temperature tolerance (Warren and Chick, 2013)

- Urban warming drives insect pest abundance on street trees (Meineke and others, 2013)

- Urban warming trumps natural enemy regulation of herbivorous pests (Dale and Frank, 2014b)

- Using physiology to predict the responses of ants to climatic warming (Diamond and others, 2013)

- Who likes it hot? A global analysis of the climatic, ecological, and evolutionary determinants of warming tolerance in ants (Diamond, Sorger, and others, 2012)

- Every species is an insect (or nearly so): On insects, climate change, extinction, and the biological unknown (Dunn and Fitzpatrick, 2012)

- Final memorandum - Integrating the effects of global and local climate change on wildlife in North America and Tree eaters: Predicting the response of herbivores to the integrated effects of urban and global change (Dunn and others, 2015) 


\section{Predicting Vulnerability of Southeastern Sea Turtle Nesting Beaches to Climate Change}

\section{PI: Kristen M. Hart (USGS Southeast Ecological Science Center)}

\section{Project Completion: April 2014}

\section{Project Summary}

The goal of this project was to produce a vulnerability assessment of coastal habitats representing important nesting grounds specifically for federally threatened loggerhead sea turtles (Caretta caretta). Because some of the same nesting beaches are also important for other endangered sea turtles (for example, Kemp's ridleys [Lepidochelys kempii], green turtles [Chelonia mydas], and leatherbacks [Dermochelys coriacea]), this project represents a vulnerability assessment of coastal nesting habitats for multiple sea turtle species of national conservation significance. Project results demonstrate that female loggerhead turtles in the northern Gulf of Mexico subpopulation express significantly less nest-site fidelity and make larger movements during the inter-nesting period than previously reported for this species.

Key terms: sea-level rise; nesting habitat; foraging habitat; listed species; vulnerability assessment; phenology; maps

\section{Products}

- Publications:

- Habitat use of breeding green turtles Chelonia mydas tagged in Dry Tortugas National Park: Making use of local and regional MPAs (Hart, Zawada, and others, 2013)

- Movements and habitat-use of loggerhead sea turtles in the northern Gulf of Mexico during the reproductive period (Hart, Lamont, and others, 2013) 


\section{Fiscal Year 2012}

\section{A Handbook for Resource Managers to Understand and Utilize Sea-Level Rise and Coastal Wetland Models for Ecosystem Management Under Future Conditions}

\section{PI: Thomas W. Doyle (USGS National Wetlands Research Center)}

\section{Project Completion: March 2015}

\section{Project Summary}

A handbook for resource managers was produced to describe the science and simulation models for understanding the dynamics and impacts of sea-level rise on our coastal ecosystems. The focus of the handbook is to categorize and describe the suite of data, methods, and models, as well as their design, structure, and application, useful for hindcasting and forecasting the potential impacts of sea-level rise in coastal environments. Basic illustrations of the components of the Earth's hydrosphere and effects of plate tectonics, planetary orbits, and glaciation are explained to understand the long-term cycles of historical sea-level rise and fall. Discussion of proper interpretation of contemporary sea-level rates and trends from tide gauge stations and satellite altimetry missions are presented to show their complementary aspects and value for understanding variability in eustasy and land motion for different coastal reaches of the U.S. Examples of the different types and classes of hydrology and ecosystem models used to predict potential effects of future sea-level rise at local and regional scale applications are presented. Coastal land managers, engineers, and scientists will benefit from this synthesis of tools and models that have been developed for projecting causes and consequences of sea-level change on the landscape and seascape.

Key terms: handbook; decision-support tools; simulation models; sea-level rise

\section{Products}

\section{- Publications:}

- Sea-level rise modeling handbook - Resource guide for coastal land managers, engineers, and scientists: U.S. Geological Survey Professional Paper 1815 (Doyle and others, 2015)

- Final project memorandum-A handbook for resource managers to understand and utilize sea-level rise and coastal wetland models for ecosystem management under future conditions (Doyle, 2015)

\section{- Webinar:}

- Sea-level rise modeling handbook: Resource guide for coastal land managers, engineers, and scientists by Thomas W. Doyle, Ecologist, U.S. Geological Survey, National Wetlands Research Center, Lafayette, Louisiana (2014) 


\section{Assessing Climate-Sensitive Ecosystems in the Southeastern U.S.}

\section{PI: Jaime Collazo (USGS North Carolina Cooperative Fish and Wildlife Research Unit), and William J. Wolfe (USGS Tennessee Water Science Center)}

\section{Project Completion: December 2013}

\section{Project Summary}

The Southeastern U.S. contains a unique diversity of ecosystems that provide important benefits, including habitat for wildlife and plants, water quality, and recreation opportunities. As climate changes, a better understanding of how these ecosystems will be affected is vital for identifying strategies for protecting them. The research team assessed climate change vulnerability for 12 ecosystems in the Southeastern U.S. and Caribbean. The team synthesized data and literature related to three components of vulnerability: climate sensitivity, climate change exposure, and adaptive capacity. They also summarized all information into a qualitative vulnerability rating for each ecosystem. On the basis of the available information, the team identified critical management actions for reducing the vulnerability of each ecosystem. Next, for 2 of the 12 ecosystems, they used NatureServe's Habitat Climate Change Vulnerability Index (HCCVI) framework as an alternative approach for assessing vulnerability. Using the HCCVI, the research team developed a numeric vulnerability rating for the two ecosystems. Of the 12 ecosystems assessed in the first approach, 5 were rated as having high vulnerability, 6 had moderate vulnerability, and 1 had low vulnerability. For the two ecosystems assessed with both approaches, vulnerability ratings generally agreed. Important conservation strategies identified to reduce vulnerability and improve adaptive capacity for the ecosystems included maintaining connectivity, restoring or maintaining disturbance processes, and minimizing the effects of urbanization. The synthesis of this information for key ecosystems across the entire Southeast and Caribbean will enable regional decision makers to prioritize current efforts and plan future research and monitoring for conservation of these important ecosystems.

Key Terms: conservation strategies; research and monitoring

\section{Products}

- Publications:

- Final project memorandum-Assessing climate-sensitive ecosystems in the Southeastern U.S. (Collazo, 2014) Modeling climate change, urbanization, and fire effects on Pinus palustris ecosystems of the Southeastern U.S. (Costanza and others, 2015)

- Insular ecosystems of the southeastern United States-A regional synthesis to support biodiversity conservation in a changing climate (Cartwright and Wolfe, 2016)

- Assessing climate-sensitive ecosystems in the southeastern United States (Costanza and others, 2016)

- Webinar:

- Climate-sensitive, insular ecosystems of the Southeastern U.S.: The state of the science and a case study of limestone cedar glades in the central basin of Tennessee (2014)

\section{- Data:}

- Climate sensitivity, exposure, and adaptive capacity results for twelve ecosystems in the Southeastern U.S. (Costanza, 2014a)

- Habitat Climate Change Vulnerability Index (HCCVI) analysis results for two ecosystems in the Southeastern U.S. (Costanza, 2014b) 


\section{Assessment of Terrestrial and Aquatic Monitoring Programs in the Southeastern U.S.}

\section{PI: Damian Shea, Ryan Boyles, and Cari Furiness (North Carolina State University)}

\section{Project Completion: June 2015. This project, Phase I, has now been completed. Phase II is now known as The Global Change Monitoring Portal.}

\section{Project Summary}

Detecting change in ecosystems requires observations of living and non-living components over time. Many different organizations make observations that are relevant to understanding global change processes, but the data often are not easily accessible by other interested scientists and managers. Climate scientists require information about the status of ecological systems that may be influenced by climate change. The need is especially acute for reliable and complete information about monitoring networks maintained by government and nongovernmental organizations and associated data. Although many organizations monitor one or more aspects of aquatic and terrestrial ecosystems, these monitoring programs are seldom coordinated, and information about both the networks and the associated data are not always readily available. The DOI SE CSC is participating in an effort by multiple Federal, State, and other organizations to develop a comprehensive and integrated assessment of monitoring networks associated with atmospheric, stream, and terrestrial ecosystems. This project has compiled information about many of these observational networks into a centrally accessible online database. A publicly available online portal was developed that provides a means to discover, search, and connect to many types of environmental and biological data collected in the Southeastern U.S. that are relevant to characterizing potential effects of climate and land use change on land, water, and wildlife. The Global Change Monitoring Portal (GCMP) consolidates information about data resources from research and monitoring done by Federal, State, Tribal, local, and nongovernmental organizations; it provides opportunities for discovery by users who are land managers, scientists, Tribal and other leaders, decision makers, and citizens. Data resources can be visualized and searched by categories of measurements made and (or) by specific geographic criteria such as State, ecoregion, hydrologic unit, and Landscape Conservation Cooperative. The GCMP provides a mechanism to increase the usefulness of important data-collection efforts by a broad range of organizations by making the data more accessible to users. By November 2015, a publicly available database had been developed containing metadata, including monitoring site and data access information, about atmospheric, terrestrial, and aquatic measurements collected in the Southeastern U.S. for observational networks, and a Web application that allows the database to be queried and displayed using four geographic categories and several measurement classification categories was developed and released at https://my.usgs.gov/gcmp. Using an evolving list of monitoring programs of more than 300 programs, we gathered and sought program metadata and site information, and populated the database with entries as information was developed and reviewed. At the end of this phase of the project, about 100 programs were in the database associated with about 220,000 measurement sites. We also continued to identify other observational networks for potential inclusion.

Key terms: monitoring network coordination

\section{Products}

- Publication:

- Final memorandum-Assessment of terrestrial and aquatic monitoring programs in the Southeastern U.S. [Global Change Monitoring Portal Phase 1] (Shea, 2015)

\section{- Web site:}

- Southeast Global Change Monitoring Portal

\section{- Webinar:}

- Development of a global change monitoring portal: Pilot project for the Southeastern U.S. (2014) 


\section{Communicating and Using Uncertain Scientific Information in the Production of "Actionable Science"}

\section{PI: Brian Irwin (USGS Georgia Cooperative Fish and Wildlife Research Unit)}

\section{Project Completion: June 2016}

\section{Project Summary}

Conservation practitioners must navigate many challenges to advance effective natural resource management in the presence of multiple uncertainties. Numerous climatic and ecological changes remain on the horizon, and the eventual consequences of these changes are not completely understood. Even so, the influences of these changes are expected to impact important resources and the people that depend on these resources across local, regional, and sometimes global scales. Although forecasts of future conditions are almost always imperfect, decision makers are increasingly expected to communicate and use uncertain information when making policy choices that affect multiple user groups. The degree to which management objectives are met can depend on (1) how critical uncertainties are identified and accounted for and (2) effective communication among user groups, scientists, and resource managers. The objective of this project is to help facilitate strategic decision support and synthesize the state of the science related to communicating and using uncertain information in conservation decision making. By providing a forum on the communication of scientific uncertainty, the project will traverse traditional disciplinary boundaries with a focus on climate change in the Southeastern U.S. It is expected that this process will generate transferable guidance that will directly assist resource managers across agencies to identify common goals and shared research priorities.

A project workshop, titled Communicating and Using Uncertain Information in Conservation Decision Making, was held February 27-28, 2013, on the campus of the University of Georgia. The workshop consisted of four sessions: (1) problem scoping; (2) definitions and treatment of uncertainty; (3) the role of science in decision making; and (4) developing recommendations. The workshop was intended, in part, to identify research and strategic-planning needs for effective delivery of regional conservation policy, with an emphasis on providing science-based decision support in the presence of uncertainty and climate change. The plenary session included two presenters-Drs. J. Marshall Shepherd (University of Georgia) and Michael Runge (USGS).

Key terms: communication; uncertainties; workshop

\section{Products}

\section{- Publication:}

- Consideration of reference points for the management of renewable resources under an adaptive management paradigm (Irwin and Conroy, 2013)

- Fact Sheet: Turning uncertainty into useful information for conservation decisions (Irwin and others, 2016)

- Webinar:

- Communicating and using uncertain information in conservation decision making project workshop (2013) 


\section{Connectivity for Climate Change in the Southeastern U.S.}

\section{PI: Nick Haddad (North Carolina State University)}

\section{Project Completion: March 2015}

\section{Project Summary}

The objective of this project was to identify key connections in the Southeastern U.S. that would provide a template for reconnecting landscapes in the face of a changing climate. The focus was on the region of the U.S. within the Southeastern Association of Fish and Wildlife Agencies (SEAFWA) borders. Three focal species inhabiting one habitat type - bottomland hardwoods - were chosen for study on the basis of suggestions from LCC partners: black bear (Ursus americanus), Rafinesque's big-eared bat (Corynorhinus rafinesquii), and timber rattlesnake (Crotalus horridus). For each species, researchers measured connectivity using three types of resistance layers (niche models, expert opinion, empirical movement data) and three different algorithms (Linkage Mapper, Circuitscape, Connecivity Analysis Toolkit). Lack of available data for some factor levels resulted in 21 unique combinations of resistance estimate, algorithm, and species. This research achieved the goal of assessing regional connectivity with results that can be used by managers and regional landscape planners to determine where conservation efforts could be focused to maintain connectivity in the future. Although researchers were able to successfully model connectivity for each individual species, there was not a high degree of overlap among combinations of models for each species. Ensemble estimates of landscape connectivity resulting from the intersection of all 21 models showed estimates of high connectivity were largely concentrated at mid elevations of the Appalachian Mountains in eastern Tennessee. The data suggest limited capacity for "umbrella" resistance estimates, algorithms, or species to generalize the results of one connectivity model to other conditions. On the basis of the observation that predictions from connectivity models are largely contingent on methodological considerations, managers may find that a suite of modeling approaches provide the best means for estimating landscape connectivity. Incorporation of climate change predicted that, on average under future conditions, the mean suitability of links will decrease compared to current conditions. Overall, modeled links for black bear showed the smallest decreases in suitability, while Rafinesque's big-eared bat and timber rattlesnake both showed similar, larger decreases in suitability under climate change. The geographic distribution of changes in suitability also varies by species. These results will be important for local and regional conservation and land management, and provide a basis for future work examining connectivity in other habitats and with other species.

Key terms: connectivity; wildlife; modeling; adaptation

\section{Products}

- Publications:

- Habitat fragmentation and its lasting impact on earth's ecosystems (Haddad and others, 2015)

- Final memorandum - Connectivity for climate change in the Southeastern United States (Haddad, 2015)

\section{- Webinar:}

- 6-week seminar series on corridor connectivity (2013)

\section{- Web sites:}

- Conservation Corridor

- Connectivity Modeling Web page 


\section{Ecological Implications of Mangrove Forest Migration in the Southeastern U.S.}

\section{PI: Michael Osland (USGS National Wetlands Research Center)}

\section{Project Completion: September 2014}

\section{Project Summary}

Winter climate change has the potential to have a large impact on coastal wetlands in the southeastern U.S. Warmer winter temperatures and reductions in the intensity of freeze events would likely lead to mangrove forest range expansion and salt marsh displacement in parts of the U.S. Gulf of Mexico and Atlantic coast. The objective of this research was to better evaluate the ecological implications of mangrove forest migration and salt marsh displacement. The potential ecological impacts of mangrove migration are diverse, ranging from important biotic impacts (such as coastal fisheries, land bird migration; colonial nesting wading birds) to ecosystem stability (such as response to sea-level rise and drought; habitat loss; coastal protection) to biogeochemical processes (such as carbon storage; water quality). This research investigated the impact of mangrove forest migration on coastal wetland soil processes and the consequent implications for coastal wetland responses to sea-level rise and carbon storage.

Collectively, results from this project indicate that interactions between winter temperatures and rainfall influence the above- and belowground ecological implications of poleward mangrove forest expansion and development in the northern Gulf of Mexico. More broadly, these findings reinforce the importance of considering interactions between multiple climatic drivers when attempting to predict the ecological implications of climate-induced ecological transitions, especially those that involve woody plants encroaching into grass-dominated ecosystems. The data and publications from this work can help environmental managers and decision makers plan and prepare for future change in coastal wetland ecosystems.

Key terms: mangrove forest; salt marsh; migration; displacement

\section{Products}

\section{Publications:}

- Salt marsh-mangrove ecotones: using structural gradients to investigate the effects of woody plant encroachment on plant-soil interactions and ecosystem carbon pools (Yando and others, 2016)

- Freshwater availability and coastal wetland foundation species: Ecological transitions along a rainfall gradient (Osland, Enwright, and Stagg, 2014)

- Aboveground allometric models for freeze-affected black mangroves (Avicennia germinans): equations for a climate sensitive mangrove-marsh ecotone (Osland, Day, and others, 2014)

- How mangrove forests adjust to rising sea level (Krauss, McKee, Lovelock, and others, 2014)

- Final memorandum-Ecological implications of mangrove forest migration in the Southeastern U.S. (Osland, 2014)

- Water use characteristics of black mangrove (Avicennia germinans) communities along an ecotone with marsh at a northern geographical limit (Krauss, McKee, and Hester, 2014)

- Winter climate change and coastal wetland foundation species: Salt marshes versus mangrove forests in the Southeastern U.S. (Osland and others, 2013)

- Mangrove expansion and salt marsh decline at mangrove poleward limits (Saintilan and others, 2014)

- Vegetation's importance in regulating surface elevation in a coastal marsh facing elevated rates of sea-level rise (Baustian and others, 2012)

\section{- Webinars:}

- Climate change and tidal wetland foundation species: mangroves, marches and salt flats (2014)

Data:

- All datasets produced by project are available at: https://www.sciencebase.gov/catalog/ item/505b584be4b08c986b30c22d 
Hydrological Modeling for Flow-Ecology Science in the Southeastern U.S.

\section{PI: Jonathan Kennen (USGS New Jersey Water Science Center)}

\section{Project Completion: July 2013}

\section{Project Summary}

Assessing the impact of flow alteration on aquatic ecosystems has been identified as a critical area of research nationally and in the Southeastern U.S. This project aimed to address the Ecohydrology Priority Science Need of the SE CSC FY12 Annual Science Work Plan by developing an inventory and evaluation of current efforts and knowledge gaps in hydrological modeling for flow-ecology science in global change impact studies across the Southeast. To accomplish this goal, researchers completed a thorough synthesis and evaluation of hydrologic modeling efforts in the Southeast region (including all states of the Southeastern Association of Fish and Wildlife Agencies [SEAFWA] - Alabama, Arkansas, Florida, Georgia, Kentucky, Louisiana, Mississippi, Missouri, North Carolina, Oklahoma, South Carolina, Tennessee, Texas, Virginia, and West Virginia) and Puerto Rico. Because this modeling synthesis was performed comprehensively and using a consistent methodology, it will provide landscape conservation cooperatives (LCCs) and other resource managers with a useful database of who is doing what, where, how, and how well in terms of hydrological modeling for global change impact studies across the Southeast region.

Key terms: hydrology; streamflow; modeling

\section{Products}

- Publications:

- A comparison of hydrologic models for ecological flows and water availability (Caldwell and others, 2015)

- Final memorandum-Hydrological modeling for flow-ecology science in the Southeastern U.S. (Kennen and others 2015)

\section{Synthesis of Climate Model Downscaling Products for the Southeastern U.S.}

\section{PI: Ryan P. Boyles and Adrienne Wootten (North Carolina State University)}

\section{Project Completion: August 2014}

\section{Project Summary}

Climate change is likely to impact natural ecosystems in the Southeast by way of warming temperatures, ocean acidification, sea-level rise, and changes to rainfall and evapotranspiration. To better assess how these changes could influence multiple sectors, including ecosystems, climatologists have created numerous downscaled climate projections (or downscaled datasets) that contain information translated from GCMs to regional and local scales. The process for creating these downscaled datasets, known as downscaling, can be carried out with a broad range of statistical and numerical modeling techniques. The proliferation of techniques in recent years has led to the production of a large number of downscaled datasets, presenting challenges for scientists and decision makers for assessing the vulnerability of a species or ecosystem to climate change. This project focused on several specific questions that users of downscaled datasets have with regard to how to choose a downscaled dataset (or datasets) to use and the accuracy of those datasets. (1) How do these downscaled datasets compare to each other? (2) Which variables are available, and are certain downscaled datasets more 
appropriate for assessing the vulnerability of a particular species? Given the desire to use these downscaled datasets and the lack of comparison between them, the main goal of the project was to synthesize the available information in these downscaled datasets and provide guidance to scientists and natural resource managers with specific interests in ecological modeling and conservation planning related to climate change in the Southeast U.S. At the start of the project, no current literature was available that evaluated downscaled datasets with regard to these applications. There also was no current literature available that offered a comparison of the structure of these downscaled datasets with regard to the needs of ecologists in the Southeast U.S. The project itself thus became twofold. First, synthesize the available literature and information from a subset of downscaled datasets that cover the Southeastern U.S. Second, using this synthesis, evaluate this same subset of downscaled datasets to make recommendations regarding the use of the downscaled climate projections and future work needed to make these datasets more useful for ecological modeling and decision making. This project was not intended to evaluate all the projections available, but synthesize the important aspects of downscaled datasets that should be considered when a decision maker or ecologist in the Southeast uses downscaled datasets for their applications. For the first part of the project an extensive literature review (including both climatological and ecological studies) was performed to assess the connections between the downscaled datasets and the needs of the ecological community as a whole. This was augmented by a workshop held in May 2013 in Raleigh, N.C., and discussions with a select group of stakeholders from the Landscape Conservation Cooperatives (LCCs) across the Southeast. In addition to providing added knowledge to the literature review, these activities furthered the engagement between the climate and ecology communities in the Southeast U.S. For the second part of the project, an initial evaluation of six available downscaled datasets for the Southeast U.S. was performed by using the knowledge gained from the prior aspect to focus specifically on climate information needs of ecologists in the Southeast. In prior literature, the focus has been on the specific differences between GCMs, but this evaluation was the first in the Southeast to focus specifically on the differences between the downscaled datasets (and their corresponding downscaling techniques). The project produced a report, which was written to serve as a guide for the ecological community in the Southeast, on the basics of climate modeling, downscaling, and how to choose appropriate downscaled datasets to use based on their metadata and accuracy. This guide was written with extensive contribution and review by a group of advisors, and the project as a whole furthered the engagement between the climate and ecology communities in the Southeast by connecting climatologists with ecologists and decision makers. The conclusions drawn from the project highlight the need for ecologists and decision makers to consider carefully how downscaled datasets are created in addition to the accuracy of the datasets for variables of interest. In addition, the conclusions highlight the benefits to climatologists involved in the development of downscaled datasets to be aware of the needs of the ecological community and conservation decision makers as new downscaled datasets are created.

Key Terms: downscaling; model comparisons

\section{Products}

\section{- Publications:}

- Evaluating the fidelity of downscaled climate data on simulated wheat and maize production in the southeastern U.S. (Cammarano and others, 2013)

- Final memorandum-Synthesis of climate model downscaling products for the Southeastern U.S. (Boyles, 2015)

- Downscaled climate projections for the Southeast U.S.: Evaluation and use for ecological applications (Wootten and others, 2014)

- Fact Sheet: Downscaled climate projections for the Southeast: Evaluation and use for ecological applications (Wootten and Furiness, 2015) 


\title{
Fiscal Year 2013
}

\section{Actionable Science: Decision Analysis and Science Communication}

\author{
PI: Damian Shea and Ryan Boyles (North Carolina State University)
}

\section{Project Completion: September 2017}

\section{Project Summary}

Two great challenges are faced by scientists in responding to science and policy issues associated with global change. The first challenge is ensuring science activities of project design, data collection, and data analysis result in information of use to decision makers with responsibilities for mitigating and adapting to global change processes. The second challenge is developing the understanding and capabilities to communicate sometimes complex, science-based information to audiences with varying levels of scientific understanding. This project supports participatory training of SE CSC graduate students in the use of decision analysis and science communication concepts and tools, including support for travel to decision analysis training at the USFWS National Conservation Training Center in August 2013, 2014, and 2015, and has also supported communication training activities in 2014 and 2015. A grant has supported SE CSC staff activities related to coordination and implementation of actionable science activities (especially outreach to convening conversations among CSC staff and stakeholders and producing education and outreach materials) at the Southeast and Northeast Climate Science Centers and has provided research coordination activities on related projects for the SE CSC and National CSC enterprise. Finally the grant has been used to support training for NCSU scientists (Summer 2015) to communicate effectively with journalists who are inquiring about climate change as well as training for broadcast meteorologists and print journalists who report on climate change (Fall 2015).

Key terms: training; decision analysis; science communication

\section{An Adaptive Landscape Planning and Decision Framework for Gopher Tortoise (Gopherus polyphemus) Conservation}

\section{PI: Clint Moore (USGS Georgia Cooperative Fish and Wildlife Research Unit)}

\section{Project Completion: June 2017}

\section{Project Summary}

The gopher tortoise (Gopherus polyphemus) is a familiar species across the southeastern coastal plain, but its population has declined significantly over the decades. One reason for its decline is that much of its primary habitat—sparse stands of mature pine - has been replaced by development or agriculture. Another reason for the decline is that periodic ground fires, which are important for providing needed forage, have been largely suppressed on the landscape. The gopher tortoise is a "keystone" species, meaning that its disappearance from the landscape would jeopardize the existence of many other species that make use of its underground burrows. In addition to tortoise habitat, the uplands of the coastal plain contain isolated seasonal wetlands that are important for the life cycles of many amphibian species. The State of Georgia would like to conserve more of the landscape for the statewide protection of the gopher tortoise and associated natural communities. Steps that could be taken include conservation partnerships formed with private landowners and land purchases as opportunities arise. Determining the best approach is challenging because of uncertainties about tortoise population ecology and future patterns of urbanization. The goal of this research is to provide tools to arrive at the most efficient means toward building a more sustainable landscape under these uncertainties.

Key terms: gopher tortoise; "keystone" species; urbanization; uncertainty 
Developing Multi-Model Ensemble Projections of Ecologically Relevant Climate Variables for Puerto Rico and the U.S. Caribbean

\section{PI: Ryan Boyles (North Carolina State University) and Adam Terando (U.S. Geological Survey)}

\section{Project Completion: September 2016}

\section{Project Summary}

Global increases in surface air temperature are the most widespread and direct consequence of anthropogenic climate change (ACC). Although 21st century temperatures are projected to increase in Puerto Rico and the broader U.S. Caribbean (the geography of both is contained within the Caribbean LCC, or CLCC), the low variability and high annual average temperatures indicate that the largest climate-related impact on ecosystems and water resources is likely to be through changes in the timing, pattern, and availability of moisture. Although numerous perturbed climate simulations are available through model intercomparison projects, the development of adaptation strategies that respond to ACC for the CLCC, and particularly for Puerto Rico, is currently hindered by the lack of local-scale climate scenarios that resolve the complex topographical and mesoscale climate features that will mediate the island-wide response to the global anthropogenic climate forcing. Project researches plan to address these issues by developing a suite of dynamically downscaled, nonhydrostatic climate model projections for Puerto Rico and the U.S. Caribbean.

Key terms: adaptation strategies; modeling; downscaling; projections; Puerto Rico; U.S. Caribbean 


\section{Development of a SECAS Conservation Decision Guidance Library}

\section{PI: Nils Peterson and Fred Cubbage (North Carolina State University)}

\section{Project Completion: June 2015}

\section{Project Summary}

A priority of the SE CSC is to support the planning and implementation of a Southeast Conservation Adaptation Strategy (SECAS). The objectives of this project are to (1) develop a better understanding of the management decision context for important SECAS resource management themes by using restoration of open pine ecosystems as a case study; (2) describe and synthesize management objectives related to this resource management theme; (3) improve understanding of how management decisions are being made and how this decision-making process can be improved; and (4) design a questionnaire to evaluate sociostructural drivers of decision making associated with SECAS. Project researchers examined the decision-making context, decision-making process, and management planning associated with the restoration of open pine ecosystems in the Southeast. To better understand the planning practice associated with this system, the quality of 35 management plans from Federal, State, and nongovernmental agencies were assessed. Newer plans scored higher than older plans, suggesting agencies may be learning to develop better plans over time and indicating older plans should be prioritized for revision. Plans from Federal and State agencies scored higher than plans from nongovernmental agencies, reflecting differences in agency missions and resources. The fact base scored high across most plans, whereas actions and implementation scored lower. Although agencies tended to perform best on fact base, our results suggest having a strong fact base has little influence on other components. To improve actions and implementation, planners should consider incorporating more stakeholder participation to help them develop better actions and implementation indirectly through improved problem and objective statements. Project researchers also investigated how decisions were being made and what barriers, if any, faced decision makers. To gain this insight, 24 semi-structured interviews were conducted with key decision makers and stakeholders; findings emphasized the challenge of collaboration between individuals, governmental organizations, and nongovernmental organizations. Discrepancies were found between groups on everything from objectives and goals, to how decisions are made, the barriers groups are facing, information that is used to make those decisions, and where information comes from as well as differences in decision-making timing and frequency. Agency managers had firm objectives while landowners/private land managers had flexible objectives that changed on the basis of new goals, knowledge, and information. In the same vein, agency managers said it was hard to change their management plans, but landowners/private land managers said that their management plans were constantly changing to meet their shifting objectives. Agency managers reported that they had access to all of the information they needed to make "good" decisions while landowners/private managers said that they wanted and needed more information, specifically better economic and growth data. And although agency managers said climate change was a factor when making decisions, landowners/private land managers said that climate change was not a factor in the decision making. To bridge the gap between the two groups and increase information sharing, a library of regulatory requirements, scientific data, personal experiences, and fiscal information may be a way to align management objectives and goals. Lastly, a questionnaire was developed as part of the project that may be used in future research projects to evaluate how sociostructural drivers and the personas of decision makers influence their decision making.

Key terms: Southeast Conservation Adaptation Strategy (SECAS); guide; sociostructural drivers

\section{Products}

\section{- Publication:}

- Final memorandum-Development of a SECAS conservation decision guidance library (Peterson and Cubbage, 2015) 


\section{Dynamic Reserve Design in the Face of Climate Change and Urbanization}

\section{PI: Stephanie S. Romanach (USGS Southeast Ecological Science Center)}

\section{Project Completion: August 2015}

\section{Project Summary}

Reserve design is a process that must address many ecological, social, and political factors to successfully identify parcels of land in need of protection to sustain wildlife populations and other natural resources. Making land acquisition choices for a large, terrestrial protected area is difficult because it occurs over a long timeframe and may involve consideration of future conditions such as climate and urbanization changes. Decision makers need to consider factors including the order of parcel purchasing given budget constraints, future uncertainty, potential future landscape-scale changes from urbanization, and climate. In central Florida, two new refuges and the expansion of a third refuge are in various stages of USFWS planning. The new refuges were strategically located for both species adaptation from climate change impacts as well as currently hosting a number of important threatened and endangered species and habitats. For this study project researchers combined a structured decision-making framework, optimal solution theory, and output from urbanization models that provide forecasts of population growth that might be expected due to climate change, and provide guidance for Everglades Headwaters National Wildlife Refuge (EHNWR) reserve design. Utilizing a structured decision making (SDM) approach and optimal solution theory, stakeholder-determined objectives were used to design optimal configurations for the refuge and help USFWS in land acquisition prioritization. The approach relied heavily on the Marxan with Zones (Marxan) conservation planning software package to find near-optimal solutions to a set of stakeholder objectives, which consisted of protecting specific amounts of five target habitats and allocating these targets among two zones representing different methods of protection: fee-simple purchase (up to 50,000 acres) and conservation easement agreements (up to 100,000 acres). County appraiser estimates of parcel property values were used as input to Marxan to generate cost estimates of different reserve configurations. Researchers varied the proportion of habitat targets allocated between the fee and easement zones, and examined the differences in reserve costs. A substantial increase in costs was found as the proportion of fee-simple purchases was increased. Scenarios also were run to investigate how the Marxan "connectivity" parameter changed the spatial configuration of reserves. The reserve configurations changed very little with increased connectivity values. Researchers explored dynamic aspects of the reserve design problem using Marxan in an "ad hoc" manner on the basis of projections of urban models that represent dynamic loss of habitat due to urbanization. These projections provided an indicator of how climate change could affect the study area by simulating how urbanization associated with "coastal retreat" might affect the availability of parcels for inclusion in the reserve design. Marxan scenarios were run, excluding the parcels forecasted for development, and the resulting reserve designs were compared with those obtained without urbanization, focusing on differences such as reserve costs, number of real estate transactions, and ability to meet targets. It was found that the cost of reserves increased substantially due to urbanization, and some habitat targets could not be met in the urbanization scenarios. A dynamic-heuristic approach was developed that operates on a yearly time step to select parcels on the basis of an annual budget and the probability of desirable parcels being lost over time to development. This method offers a much higher degree of realism than the Marxan analysis but requires data that are not currently available for the study area.

Key terms: reserve design; urbanization; Everglades Headwaters National Wildlife Refuge (EHNWR); species adaptation; threatened and endangered species; structured decision making; modeling; optimal solution theory

\section{Products}

\section{- Publication:}

- Final memorandum-Dynamic reserve design in the face of climate change and urbanization (Romañach, 2015) 


\section{Evaluation and Downscaling of CMIP5 Climate Simulations for the Southeast U.S.}

\section{PI: Phil Mote (Oregon State University), John Abatzoglou (University of Idaho), and David Rupp (Oregon State University)}

\section{Project Completion: October 2014}

\section{Project Summary}

This project generated a series of freely available datasets that provide projections of climate change at appropriate spatial scales that can directly address specific management questions. These climate change projections are the result of "downscaling" output from GCMs that formed the basis of many conclusions in the Intergovernmental Panel on Climate Change (IPCC) Assessment Report 5 (AR5) (IPCC, 2014). The datasets include projections of climate variables, in addition to daily temperature and precipitation such as surface winds, humidity, and solar radiation, that are needed in hydrologic and ecological modeling. Two products, one at a 4-kilometer resolution, the other at a 6-kilometer resolution, that cover the continental United States have been completed.

Moreover, an evaluation was done of how well the GCMs reproduce the historical climate of the Southeastern U.S. and surrounding region. This evaluation can be used as one source of information when a user is faced with selecting a small number of climate projections from the larger set of available projections for an impacts assessment. Collectively, the guidance on the credibility of GCMs over the Southeastern U.S. and the downscaled datasets provide necessary information and data to develop strategies for coping with climate change.

Key terms: future scenarios; CMIP5; global climate models; downscaling; southeast

\section{Products}

- Publications:

- Final memorandum-Evaluation and downscaling of CMIP5 climate simulations for the Southeast U.S. (Mote and others, 2015)

- An evaluation of 20th century climate for the Southeastern United States as simulated by Coupled Model Intercomparison Project Phase 5 (CMIP5) global climate models (Rupp, 2016)

\section{Data:}

- Multivariate adaptive constructed analogs (MACA) statistical downscaling method (2015) 


\section{PI: Gregory D. Steyer (USGS National Wetlands Research Center)}

\section{Project Completion: May 2015}

\section{Project Summary}

Barrier islands protect mainland coasts from waves and provide valuable habitat; thus, islands that have lost acreage may be targeted for restoration by resource managers. Because of the dynamic nature of barrier islands, there is a possibility that restoration projects could be damaged during construction. Decisions must then be made on how to meet project objectives while managing limited funding and resources. The goal of this study was to use a collaborative, structureddecision-making approach to develop two Bayesian decision network models (DMs) for restoration at Ship Island, Mississippi, where sand will be used to close an extensive breach. The team identified what damage may occur during construction, and the DMs guided decisions within the confines of limited sand and funding to select actions that minimized adverse impacts to project objectives. DM input was derived from expert elicitation and augmented with inundation data. The first DM determined that sand was more limiting than funds, and unrepaired major breaching would negatively impact project objectives. The second DM addressed if, how, and when to repair minor damage, depending on the extent to which it is more cost effective to repair immediately than risk more damage to the weakened project. The goals were met by identifying specific management actions from the decision guidance that will be implemented under the Mississippi Coastal Improvement Program (MsCIP) long-term monitoring and adaptive management (AM) program (http://coastal.la.gov/ wp-content/uploads/2014/03/Appendix_F_Implementation-and-AM.pdf). This SDM application highlights uncertainty about barrier island physical processes that limit the ability of managers to make robust decisions and demonstrates the potential for direct incorporation of process-based models in a formal adaptive management decision model. More importantly, this research is a prototype for using collaborative structured decision making in dynamic environments where mid-construction decisions may arise. With numerous barrier island construction projects planned in the northern Gulf of Mexico, this innovative mid-construction application of SDM has regional relevance.

Key terms: structured decision making; Gulf of Mexico; coastal conservation; restoration

\section{Products}

\section{- Publication:}

- Final memorandum - Structured decision making to facilitate multi-stakeholder coastal conservation and restoration under climate change uncertainties: Case study on barrier islands of the northern Gulf of Mexico (Steyer, 2015) 


\title{
Tree Eaters: Predicting the Response of Herbivores to the Integrated Effects of Urban and Global Change
}

\section{PI: Rob Dunn and Steve Frank (North Carolina State University)}

\author{
Project Completion: September 2015. This project expands on work initiated under Integrating the effects \\ of global and local climate change on wildlife in North America.
}

\section{Project Summary}

Climate in the Southeastern U.S. is predicted to be changing at a slower rate than in other parts of North America; however, land use change associated with urbanization is having a significant effect on wildlife populations and habitat availability. A team of North Carolina State University researchers sought to understand the effect of global warming on both beneficial and pest insects of trees. They used urban warming as a proxy for global warming in as much as many cities have already warmed as much, due to heat island effects, as they are expected to warm due to climate change by 2050 or even 2100. Researchers were able to develop good predictive models of how warming influences beneficial and pest insects for cities in the Southeast and generally across the east coast. They were also able to predict how tree health will respond to these changes in insect communities. In addition, by comparing their results to those they garnered from herbarium specimens (many insects can be found on herbarium specimens), they could show that the effects of urban warming match those of climate change through time. In short, a subset of pests is likely to get far worse with warming and this effect is likely to be most pronounced in the Southeastern U.S. A second body of work builds on these discoveries to consider how to protect trees and forests from the pests that thrive with warming. Work continues to be focused on the importance of which trees are present (or planted) and the diversity of those trees.

Key terms: pests; urbanization; trees; modeling; diversity; composition

\section{Products}

\section{- Publications:}

- Final memorandum - Integrating the effects of global and local climate change on wildlife in North America and Tree eaters: Predicting the response of herbivores to the integrated effects of urban America and global change (Dunn and others, 2015)

- Habitat and species identity, not diversity, predict the extent of refuse consumption by urban arthropods (Youngsteadt and others, 2015)

- Stable isotopes reveal links between human food inputs and urban ant diets (Penick and others, 2015)

- Ant-mediated seed dispersal in a warmed world (Stuble and others, 2014)

- Early pest development and loss of biological control are associated with urban warming (Meineke and others, 2014)

- High diversity in an urban habitat: are some animal assemblages resilient to long-term anthropogenic change? (Guénard and others, 2015)

- Bad neighbors: Urban habitats increase cankerworm damage to non-host understory plants (Frank, 2014)

- Changes in ant community composition caused by 20 years of experimental warming vs. 13 years of natural climate shift (Menke and others, 2014)

- Interactions in a warmer world: Effects of experimental warming, conspecific density, and herbivory on seedling dynamics (Burt and others, 2014)

- The effects of urban warming on herbivore abundance and street tree condition (Dale and Frank, 2014a)

- Unexpected phenological responses of butterflies to the interaction of urbanization and geographic temperature (Diamond and others, 2014)

- Microbial communities respond to experimental warming, but site matters (Cregger and others, 2014)

- Urban warming trumps natural enemy regulation of herbivorous pests (Dale and Frank, 2014b)

- Urban warming drives insect pest abundance on street trees (Meineke and others, 2013) 


\section{Understanding Conservation Management Decisions in the Face of Sea-Level Rise Along the U.S. Atlantic Coast}

\section{PI: Damian Shea (North Carolina State University), and Fred Johnson (USGS Southeast Ecological Science) Center, Mitchell Eaton (DOI Southeast Climate Science Center)}

\section{Project Completion: September 2014}

\section{Project Summary}

Coastal ecosystems in the Eastern U.S. have been severely altered by processes associated with human development, including drainage of wetlands, changes in hydrology, land clearing, agricultural and forestry activity, and the construction of structures that "harden" the coast. Sea-level rise and the changing frequency of extreme events associated with climate change are now further degrading the capacity of those ecological and social systems to remain resilient. As custodians of ecological goods and services valued by society, coastal USFWS National Wildlife Refuges have an especially important role to play in helping socioecological systems adapt to global-change processes. To help refuges address this challenge, research scientists articulated a two-track decision problem faced by coastal refuge managers. The first track focuses on efficient allocation of limited staff time and budgets for management of existing programs under the current refuge design. The second track recognizes the negative impacts of global-change processes on the ability to maintain societal values derived from the existing refuge configuration. Over the long term, refuge managers must decide when and where to acquire or protect new land/habitat to supplement or replace the existing refuge footprint to sustain individual coastal USFWS National Wildlife Refuge values as the system evolves over time. Each track suggests a unique set of alternatives to represent differences in the identity of the decision maker(s) and in the spatial, temporal, and governance scales of the decision problem. The research team developed a prototype decision structure by describing how a hierarchical set of objectives and alternative actions can be used to explore the tradeoffs inherent in making short- and long-term adaptation decisions. The prototype attempts to characterize a balance between decisions within the purview of the refuge itself and decisions made at higher organizational levels concerning reconfiguration of the refuge, which may be required to ensure the long-term persistence of societal values.

Key terms: sea-level rise; decision makers; migratory waterbirds

\section{Products}

\section{- Publications:}

- Final project memorandum-Understanding conservation management decisions in the face of sea-level rise along the U.S. Atlantic Coast (Johnson and Eaton, 2014)

- Maximizing the social and ecological value of Cape Romain National Wildlife Refuge (Nilius and others, 2014) 


\section{Fiscal Year 2014}

\section{Forests of the Future: Integrated Assessment of Climate Change and Ecosystem Diversity}

\section{PI: Robert Dunn (North Carolina State University)}

\section{Project Completion: July 2016}

\section{Project Summary}

What are the consequences of climate change on biodiversity and ecosystem processes? Using open-top warming chambers, researchers are manipulating climate experimentally to understand how climate change affects insect communities and the processes they mediate. Built in 2009 at both Duke Forest in North Carolina and Harvard Forest in Massachusetts, the warming chambers consisted of 12 open-top warming chambers that were pumped with warm air to simulate predicted environmental changes. The experiment was one of the largest, most robust warming experiments in the world and ran through summer 2015. Researchers monitored population dynamics, species composition, phenology, and behavior of ants and other arthropods occupying these experimental chambers. This experiment is an ongoing long-term ecological study that provides opportunities for collaborations across a broad spectrum of ecologists, including those studying biogeochemical, microbial, and plant responses to warming. The warming chambers ran through the summer of 2015 and SE CSC funds are supporting a post-doctoral student who will be analyzing data and writing papers through 2016.

\section{Products}

\section{- Media coverage:}

- Researchers Seek Sneak Peek Into the Future of Forests (Shipman, 2015)

- Researchers Seek a Sneak Peek Into the Future of Forests (Shipman and Varela Minder, 2015)

- NC State researchers explore future of climate change on ecosystems (Schrader and Stout, 2015)

- Scientists Create Tiny Zones of Climate Change (National Geographic, 2015)

\section{The Global Change Monitoring Portal}

\section{PI: Ryan Boyles (North Carolina State University)}

\section{Project Completion: September 2016. This is Phase II of Assessment of terrestrial and aquatic} monitoring programs.

\section{Project Summary}

The objective of this project is to provide scientists and the general public with access to information about the existence and operation of programs that monitor the effects of global change processes, such as climate and land use change, on important air, land, and water resources. This is a public service project intended to support both education and decision making by providing comprehensive "one stop" access to information about hundreds of monitoring programs in North Carolina and throughout the Southeast. This work will provide additional development of the Global Change Monitoring Portal, which is currently in the pilot phase.

\section{Tasks will include:}

- Compile, inventory, and map geographically, additional sources (Federal, State, local, and nongovernmental) of atmospheric, terrestrial, and water quality and quantity information in the region relevant to climate issues;

- Characterize the information sources in terms of the types of measurements made and data collected, sampling purpose, and other relevant metadata;

- Guide development of a user interface to allow display and search of data sources by measurement-specific and geographic criteria;

- Assess other attributes of the information sources, such as longevity and "depth," consistency over time, and types and quality of information;

- Assess currently available information for use in tracking regional trends, or running scenarios of interest to Federal, State and local resource managers; and,

- Identify key information gaps of concern to Federal, State, and local resource managers. 


\section{Hydrologic Modeling for Gulf Coastal Plains and Ozarks LCC}

\section{PI: Jacob LaFontaine (Georgia Water Science Center)}

\section{Project Completion: September 2016}

\section{Project Summary}

Through this project, researchers are working to expand the geographic extent of a multi-model synthesis proposal funded by the Gulf Coastal Plains and Ozarks Landscape Conservation Cooperative, to include the remainder of the Tennessee River Basin and the southeast gulf basins eastward, stopping at the Altamaha River Basin. Funding has been used for salary to QA/QC data and model inputs, finish the CONUS application of the Monthly Water Balance Model, and complete development/analysis of dynamic parameters using the annual land cover product produced by EROS for 1938-2100, and to develop the multi-model calibration strategy which will use Monthly Water Balance Model and statistical model outputs to inform the calibration of PRMS for the region. By leveraging funds from GCPO and the SECSC, a more consistent regional development of simulated hydrologic response is possible as a greater number of diverse regions is incorporated.

\section{Gulf of Mexico Avian Monitoring Network: A Forum to Facilitate Integrated and Complementary Data Collection for Avian Populations and Their Habitats}

\section{PI: Mitch Eaton (U.S. Geological Survey)}

\section{Project Completion: May 2016}

\section{Project Summary}

The Deepwater Horizon oil spill directly impacted birds and their habitats at an unprecedented scale within the Gulf of Mexico. Early efforts to determine pre-spill baseline conditions for avian resources highlighted the lack of adequate data to inform decision-makers, as well as the lack of any comprehensive, integrated approach that would permit evaluation of realized damages or response to future on-the-ground restoration efforts. However, this environmental disaster has also resulted in an equally unprecedented focus on the Gulf ecosystem and resources to support its restoration and recovery. Designing a coordinated, integrated, and collaborative avian monitoring program for this system has many challenges: (1) the scope and scale of the Gulf ecosystem, (2) the number of partners, stakeholders, and required expertise; and (3) the amount of funding required to successfully design and implement a Gulf-wide avian monitoring program. Yet meeting this challenge is imperative to understanding population trends and cause and effect relationships that underscore demographic processes that drive trends; as well as providing a basis for judging success of Gulf restoration efforts.

Over the last 2 years, an ad-hoc working group of conservation partners representing more than 20 agencies and organizations have been utilizing a Structured Decision Making framework to identify and agree upon a set of core values and fundamental objectives that underpin avian monitoring needs within the Gulf of Mexico. 


\section{Fiscal Year 2015}

\section{Climate Change Adaptation for Coastal National Wildlife Refuges}

\section{PI: Mitchell Eaton (U.S. Geological Survey) and Jennifer Costanza (North Carolina State University)}

\section{Project Completion: September 2018}

\section{Project Summary}

Coastal ecosystems in the Eastern U.S. have been severely altered by processes associated with human development, sea-level rise, and the increased frequency of extreme events related to climate change. These influences are degrading the capacity of both ecological and human social systems to remain resilient in the face of global change. USFWS National Wildlife Refuges along the east coast protect critical habitat and ecosystems for a host of wildlife species, and also contribute to essential goods and services that benefit coastal communities, businesses, and individuals. Storm-surge protection, increased water quality, nurseries for commercially important fin and shellfish, and recreational opportunities are only some of the benefits to society contributed by coastal wildlife refuges. Faced with sea-level rise and climate change, the role of coastal refuges to protect our nation's natural resources and provide ecosystem services is in jeopardy. The USGS is supporting a management-research collaboration with coastal refuges to assist in planning for and adapting to sea-level rise and other global change processes. This collaboration will integrate the expertise of specialists in global-change science, coastal dynamics, resource economics, and decision science to address management policies that will benefit both human and wildlife interests into the future.

\section{Connecting Landscape Adaptation and National Cultural Resource Policy to Climate Change and Cultural Resource Adaptation Decisions}

\section{PI: Erin Seekamp (North Carolina State University)}

\section{Project Completion: August 2016}

\section{Project Summary}

This project brings cultural resource management into local and regional decision contexts for climate change planning. Cultural resources hold multiple and diverse values to local communities, visitors, and the public. Yet, sea-level rise and episodic storm events threaten many coastal cultural resources. Strategies for climate adaptation or mitigation need to emerge from values-based decision processes that enable evaluations of the vulnerability and uniqueness of resources on a landscape. Such efforts will facilitate the prioritization of specific cultural resource management actions (move, stabilize, or document a resource). This project will use structured decision making (SDM) with National Park Service personnel and other key stakeholders to assist National Park Service managers assess strategies for managing cultural resources within Portsmouth Village and Lookout Village at Cape Lookout National Seashore. 


\section{Consequences of Urbanization and Climate Change on Human and Ecosystem Health}

\section{PI: Steven D. Frank and Robb Dunn (North Carolina State University)}

\section{Project Completion: August 2017}

\section{Project Summary}

In this project researchers will investigate how tree selection at the local scale affects biodiversity and ecosystem services. Then researchers will look regionally to determine the extent to which trees in cities can be used to predict heatrelated threats to rural forests. Ongoing investigations of heat-related stress and pest outbreaks in urban and rural forests will be considered to develop management recommendations for both systems. These ongoing projects provide knowledge-based, infrastructure (for example, study sites), equipment (for example, Li-Cor Photosynthesis System), and outreach opportunities that will extend the impact of this project. Researchers will also convene a working group to assess how urban environmental changes and tree cover affect human behavior and health. Specifically, the working group objectives are to (1) Determine tree (and arthropod) characteristics that affect tree-dependent biodiversity, tree herbivory, and resilience of both trees and biodiversity to warming; (2) Understand how urbanization (and heat) influences pest populations in order to predict future distributions of pests (and loss of biodiversity) in natural forests; (3) Integrate effects of warming and urbanization on tree health with effects on human health.

\section{Conservation Adaptation Planning for Landscape and Climate Changes in the Southeast}

\section{PI: Nils Peterson (North Carolina State University)}

\section{Project Completion: September 2018}

\section{Project Summary}

The Southeast is currently undergoing high rates of population growth, urbanization, and land use change while also experiencing climatic changes. These changes are expected to continue to threaten wildlife and their habitats. Most existing conservation programs and activities, however, focus on maintaining systems in their current condition, or returning them to a historic state, rather than enabling systems to adapt to projected changes. Recognizing this problem, State fish and wildlife agencies, together with the USFWS and others, have initiated the Southeastern Conservation Adaptation Strategy (SECAS). This project will support the SECAS effort, which aims to develop a collaborative network of conservation partners, shared conservation goals, and regional strategies to manage fish, wildlife, and other natural resources into the future. To help accomplish these goals, the project team will evaluate existing conservation plans and expected land and climate change impacts, and, in collaboration with the Southeast conservation community, identify opportunities to incorporate landscape and climate change considerations into State and regional conservation actions. Issues facing selected focal systems, including pine savannah, will be addressed through structured workshops and decision analysis processes. Project information and reports will be available through the SE CSC Global Change Forum Web site. 
Implementing a Values-Based Approach to Landscape Conservation Design in the U.S. Caribbean

\section{PI: Gerard McMahon (U.S. Geological Survey) and William Gould (U.S. Forest Service)}

\section{Project Completion: May 2016}

\section{Project Summary}

The Caribbean Landscape Conservation Cooperative (CLCC) Steering Committee (SC) recently made two landmark decisions providing direction for collaborative conservation efforts. The SC agreed to pursue landscape conservation design (LCD) as a major emphasis of collaborative work and they agreed to adopt a values-focused, structured decision making (SDM) process to guide conservation design development and implementation for the CLCC. Developing both a strategic plan and an implementation approach using a values focused LCD framework will have several advantages. This effort will complement existing conservation efforts in Puerto Rico and the U.S. Virgin Islands conducted by Federal territorial and nongovernmental organizations. This approach is focused by the values and priorities of organizations that are partners of the CLCC. One of the products of the LCD effort will be spatially explicit mapped information (geologic, ecologic, socio economic, climate, and vulnerabilities and threats) served by way of a Web-based interface - the Caribbean Atlas for Management and Planning Options (el CAMPO). Geospatial information will be developed and delivered with the guiding principle that managers, decision makers, and the general public can make decisions that foster the accomplishment of the values, priorities, and objectives that lie at the heart of the CLCC LCD project.

\section{Climate Change and Patch Dynamics: Implications for the Conservation of Amphibians in Tropical Environments \\ PI: Jessica Stocking (North Carolina Cooperative Fish and Wildlife Research Unit), Jaime A. Collazo (North Carolina Cooperative Fish and Wildlife Research Unit), and Adam Terando (U.S. Geological Survey)}

\section{Project Completion: August 2019}

\section{Project Summary}

Climate and land use change can strongly affect tropical island ecosystems and trust species. With limited land surface area, high rates of endemism, and maximal average planetary temperatures, the risks of significant negative impacts are likely to be higher in these systems than in many temperate, mid-latitude regions of the Earth. Complicating adaptation efforts is the lack of climate change guidance for decision makers due to the dearth of (1) reliable climate change projections and (2) species-specific climate sensitivity information. In FY13, the SE CSC began to address this need with the funded project, "Developing multi-model ensemble projections of ecologically relevant climate variables for Puerto Rico and the US Caribbean." This project is laying the foundation for more reliable climate change information by producing dynamically downscaled climate projections. These projections include fine-scale atmospheric processes that will mediate the local response to the global anthropogenic climate forcing. In addition, through the USGS Science Support Program, occupancy data have been collected for several amphibian species located in a target strategic habitat conservation region in the western portion of Puerto Rico. These data, along with data from two other taxa (avian, insect pollinators) will serve as the ecological input for an optimal decision-making framework for strategic habitat conservation sponsored by the Puerto Rico Department of Natural and Environmental Resources. This agency, in conjunction with the USFWS, could implement a strategic habitat conservation strategy to ensure the long-term persistence of amphibians and reptiles in Puerto Rico in the advent of climate change. These agencies are seeking to recover 11 species of terrestrial amphibians and reptiles with Federal or State designations, but also to prevent listing additional species that might become at risk.

Before specific climate-ready strategies can be developed for allocating scarce resources, further work is needed to better understand the level of dependence and key uncertainties between climate (particularly moisture-related variables) and the distribution and persistence of the species of conservation concern. The effects of climate on the distribution and persistence of several amphibian species on the island of Puerto Rico will be quantified. 


\section{Conclusion}

Since it began operation in 2010, the DOI Southeast Climate Science Center has been organized to accomplish three goals:

4. Provide decision-focused, research-based information that supports transparent global change adaptation decisions;

5. Convene conversations among decision makers, scientists, and managers about key ecosystem adaptation decisions;

6. Build the capacity of natural resource professionals, university faculty, and students to understand and frame natural resource adaptation decisions and develop and use research-based information to make adaptation decisions.

Because no single organization in the Southeast has the responsibility to carry out this convening function, SE CSC efforts to foster communication and coordination among diverse partners have helped address one of the biggest challenges to effective and efficient climate adaptation activities. Between FY11-15, the SE CSC has supported 45 NCSU graduate and post-doctoral Global Change Fellows and has also supported training for graduate students and conservation professionals in areas that include decision analysis and science communication.

The focus of this report has been on summarizing research projects supported by the SE CSC. The SE CSC has awarded more than $\$ 5$ million in research funding through 30 awards to scientists at NCSU and the USGS. More than 90 publications have been produced as a result of projects supported by the SE CSC.

These three goals shape what can be thought of as the SE CSC effort to produce "actionable science." All three activities are needed to define a knowledge production process that informs or fosters adaptation action by those with an interest in the impacts of global change processes. SE CSC actionable science is characterized by co-production, involving collaborations between scientists, decision makers, and other stakeholders to frame research questions, decide how to answer the questions, execute needed science activities, and communicate the findings.

\section{References Cited}

Advisory Committee on Climate Change and Natural Resource Science (ACCCNRS), 2015, Report to The Secretary of the Interior, accessed December 1, 2015, at https://nccwsc.usgs.gov/sites/default/files/files/ACCCNRS Report_2015.pdf.
Barsugli, J.J., Guentchev, G., Horton, R.M., Wood, A., Mearns, L.O., Liang, X., Winkler, J.A., Dixon, K., Hayhoe, K., and Rood, R., 2013, The practitioner's dilemma-How to assess the credibility of downscaled climate projections: Eos, Transactions American Geophysical Union, v. 94, no. 46, p. 424-425.

Baustian, J.J., Mendelssohn, I.A., and Hester, M.W., 2012, Vegetation's importance in regulating surface elevation in a coastal salt marsh facing elevated rates of sea level rise. Global Change Biology, v. 18, no. 11, p. 3377-3382.

Belyea, C.M., 2012, Dataset for urban growth projection for Southeast Regional Assessment Project, accessed May 5, 2016, at https://www.sciencebase.gov/catalog/ item/5438004ce4b08a816ca636fb.

Belyea, C.M., and Terando, A.J., 2013, Urban growth modeling for the SAMBI Designing Sustainable Landscapes Project, accessed May 5, 2016, at http://www.basic.ncsu. edu/dsl/urb.html.

Bhat, K.S., Haran, M., and Goes, M., 2010, Computer model calibration with multivariate spatial output - A case study: Frontiers of statistical decision making and Bayesian analysis, p. 168-184.

Bhat, Sham, Haran, M., Olson, R., and Keller, K., 2012, Inferring likelihoods and climate system characteristics from climate models and multiple tracers: Environmetrics, v. 23 , no. 4 , p. $345-362$.

Bhat, K.S., Haran, M., Terando, A., and Keller, K., 2011, Climate projections using Bayesian model averaging and space-time dependence: Journal of Agricultural, Biological, and Environmental Statistics, v. 16, no. 4, p. 606-628.

Blodgett, D.L., Booth, N.L., Kunicki, T.C., Walker, J.I., and Viger, R.J., 2011, Description and testing of the Geo Data Portal—Data integration framework and Web processing services for environmental science collaboration: U.S. Geological Survey Open-File Report 2011-1157, 9 p., accessed June 20, 2016, at http://pubs.usgs.gov/ of/2011/1157/

Boyles, Ryan, 2015, Final memorandum-Synthesis of climate model downscaling products for the Southeastern United States, accessed June 20, 2016, at https://www. sciencebase.gov/catalog/item/560c2e66e4b058f706e54107.

Burt, M.A., Dunn, R.R., Nichols, L.M., and Sanders, N.J., 2014, Interactions in a warmer world-Effects of experimental warming, conspecific density, and herbivory on seedling dynamics: Ecosphere, v. 5, no. 1, 12 p. 
Caldwell, P.V., Kennen, J.G., Sun, G., Kiang, J.E., Butcher, J.B., Eddy, M.C., Hay, L.E., LaFontaine, J.H., Hain, E.F., and Nelson, S.A.C., 2015, A comparison of hydrologic models for ecological flows and water availability: Ecohydrology, v. 8, no. 8, p. 1525-1546.

Cammarano, D., Stefanova, L., Ortiz, B.V., Ramirez-Rodrigues, M., Asseng, S., Misra, V., Wilkerson, G., Basso, B., Jones, J.W., and Boote, K.J., 2013, Evaluating the fidelity of downscaled climate data on simulated wheat and maize production in the southeastern U.S.: Regional Environmental Change, v. 13 , no. 1, p. 101-110.

Cartwright, J.M., and Wolfe, W.J., 2016, Insular ecosystems of the southeastern United States-A regional synthesis to support biodiversity conservation in a changing climate: U.S. Geological Survey Professional Paper 1828, 162 p., accessed June 20, 2016, at http://dx.doi.org/10.3133/pp1828.

Cayton, H.L., Haddad, N.M., Gross, K., Diamond, S.E., and Ries, L., 2015, Do growing degree days predict phenology across butterfly species?: Ecology, v. 96, no. 6, p. 1473-1479.

Collazo, J.A., 2012, Dataset for developing long-term urbanization scenarios for the Caribbean LCC as part of the Southeast Regional Assessment Project, accessed June 20, 2016, at https://www.sciencebase.gov/catalog/ item/5425b4b6e4b0e641df8c7475.

Collazo, J.A., 2014, Final project memorandum-Assessing climate-sensitive ecosystems in the Southeastern U.S., accessed June 20, 2016, at https://www.sciencebase.gov/ catalog/item/5525808ce4b027f0aee3d5ea.

Costanza, Jennifer, 2014a, Climate sensitivity, exposure, and adaptive capacity results for twelve ecosystems in the Southeastern U.S., accessed June 20, 2016, at https://www. sciencebase.gov/catalog/item/5440048be4b065f4ad22d2aa.

Costanza, Jennifer, 2014b, Habitat Climate Change Vulnerability Index (HCCVI) analysis results for two ecosystems in the Southeastern U.S., accessed June 20, 2016, at https://www. sciencebase.gov/catalog/item/5440040ce4b065f4ad22d2a8.

Costanza, J.K., Beck, S., Pyne, M., Terando, A., Rubino, M., White, R., and Collazo, J., 2016, Assessing climatesensitive ecosystems in the Southeastern United States: U.S. Geological Survey Open-File Report. 2016-1073, , accessed August 15, 2016, at http://dx.doi.org/10.3133/ ofr20161073.

Costanza, J.K., Hulcr, J., Koch, F.H., Earnhardt, T., McKerrow, A.J., Dunn, R.R., and Collazo, J.A., 2012, Simulating the effects of the southern pine beetle on regional dynamics 60 years into the future: Ecological Modelling, v. 244, p. 93-103.
Costanza, J.K., Terando, A.J., McKerrow, A.J., and Collazo, J.A., 2015, Modeling climate change, urbanization, and fire effects on Pinus palustris ecosystems of the Southeastern U.S.: Journal of Environmental Management, v. 151, p. 186-199.

Cregger, M.A., Sanders, N.J., Dunn, R.R., and Classen, A.T., 2014, Microbial communities respond to experimental warming, but site matters: PeerJ, v. 2.

Dale, A.G., and Frank, S.D., 2014a, The effects of urban warming on herbivore abundance and street tree condition: PloS one, v. 9, no. 7, p. e102996.

Dale, A.G., and Frank, S.D., 2014b, Urban warming trumps natural enemy regulation of herbivorous pests: Ecological Applications, v. 27, p. 7, p. 1596-1607.

Dalton, M.S., and Jones, S.A., comps., 2010, Southeast Regional Assessment Project for the National Climate Change and Wildlife Science Center: U.S. Geological Survey Open-File Report 2010-1213, 38 p. , accessed June 20, 2016, at http://pubs.usgs.gov/of/2010/1213/.

Diamond, S.E., Cayton, H., Wepprich, T., Jenkins, C.N., Dunn, R.R, Haddad, N.M., and Ries, L., 2014, Unexpected phenological responses of butterflies to the interaction of urbanization and geographic temperature: Ecology, v. 95, no. 9, p. 2613-2621.

Diamond, S.E., Nichols, L.M., McCoy, N., Hirsch, C., Pelini, S.L., Sanders, N.J., Ellison, A.M., Gotelli, N.J., and Dunn, R.R., 2012, A physiological trait-based approach to predicting the responses of species to experimental climate warming: Ecology, v. 93, no. 11, p. 2305-2312.

Diamond, S.E., Penick, C.A., Pelini, S.L., Ellison, A.M., Gotelli, N.J., Sanders, N.J., and Dunn, R.R., 2013, Using physiology to predict the responses of ants to climatic warming: Integrative and Comparative Biology, v. 53, no. 6, p. $965-974$.

Diamond, S.E., Sorger, D.M., Hulcr, J., Pelini, S.L., Toro, I.D., Hirsch, C., Oberg, E., and Dunn, R.R., 2012, Who likes it hot? A global analysis of the climatic, ecological, and evolutionary determinants of warming tolerance in ants: Global Change Biology, v. 18, no. 2, p. 448-456.

Doyle, T.W., 2015, Final memorandum-A handbook for resource managers to understand and utilize sealevel rise and coastal wetland models for ecosystem management under future conditions, accessed June 20, 2016, at https://www.sciencebase.gov/catalog/ item/560c29c2e4b058f706e540f9.

Doyle, T.W., Chivoiu, B., and Enwright, N.M., 2015, Sea-level rise modeling handbook-Resource guide for coastal land managers, engineers, and scientists: U.S. Geological Survey Professional Paper 1815, 76 p., accessed June 20, 2016, at https://pubs.er.usgs.gov/publication/pp1815. 
Dunn, R.R., and Fitzpatrick, M.C., 2012, Every species is an insect (or nearly so) - On insects, climate change, extinction, and the biological unknown, in Hannah, Lee (ed.), Saving a million species: Springer, p. 217-237.

Dunn, Rob, Frank, Steven, and Haddad, Nick, 2015, Final memorandum - Integrating the effects of global and local climate change on wildlife in North America and Tree eaters-Predicting the response of herbivores to the integrated effects of urban and global change, accessed June 20, 2016, at https://www.sciencebase.gov/catalog/ item/566efb43e4b09cfe53ca7715 and https://www.sciencebase.gov/catalog/item/566ef835e4b09cfe53ca76f9.

Eaton, Mitchell, and Costanza, Jennifer, 2015, Climate change adaptation for coastal National Wildlife Refuges, accessed June 20, 2016, at https://www.sciencebase.gov/catalog/ item/553fddf0e4b0a658d7938ef5.

Elliott, C.M., Jacobson, R.B., and Freeman, M.C., 2014, Stream classification of the Apalachicola-ChattahoocheeFlint River System to support modeling of aquatic habitat response to climate change: U.S. Geological Survey Scientific Investigations Report 2014-5080, 79 p., accessed June 20, 2016, at http://dx.doi.org/10.3133/sir20145080.

Frank, S.D., 2014, Bad neighbors: urban habitats increase cankerworm damage to non-host understory plants: Urban Ecosystems, v. 17, no. 4, p. 1135-1145.

Freeman, M.C., Buell, G.R., Hay, L.E., Hughes, W.B., Jacobson, R.B., Jones, J.W., Jones, S.A., LaFontaine, J.H., Odom, K.R., and Peterson, J.T., 2013, Linking river management to species conservation using dynamic landscape-scale models: River Research and Applications, v. 29, no. 7, p. 906-918.

Ganguly, A.R., Kodra, E.A., Agrawal, A., Banerjee, A., Boriah, S., Chatterjee, S.N., Chatterjee, S.O., Choudhary, A., Das, D., and Faghmous, J., 2014, Toward enhanced understanding and projections of climate extremes using physicsguided data mining techniques: Nonlinear Processes in Geophysics, v. 21, no. 4, p. 777-795.

Goes, M., Urban, N.M., Tonkonojenkov, R., Haran, M., Schmittner, A., and Keller, K., 2010, What is the skill of ocean tracers in reducing uncertainties about ocean diapycnal mixing and projections of the Atlantic Meridional Overturning Circulation?: Journal of Geophysical Research-Oceans, v. 115, 12 p.

Guénard, B., Cardinal-De Casas, A., and Dunn, R.R., 2015, High diversity in an urban habitat - Are some animal assemblages resilient to long-term anthropogenic change?: Urban Ecosystems, v. 18, no. 2, p. 449-463.

Gutierrez, B.T., Plant, N.G., and Thieler, E.R., 2011, A Bayesian network to predict coastal vulnerability to sea level rise: Journal of Geophysical Research-Earth Surface, v. 116, no. F2.
Haddad, N.M., 2015, Final memorandum-Connectivity for climate change in the Southeastern United States, accessed June 20, 2016, at https://www.sciencebase.gov/catalog/ item/55a54045e4b0183d66e45477.

Haddad, N.M., Brudvig, L.A., Clobert, J., Davies, K.F., Gonzalez, A., Holt, R.D., Lovejoy, T.E., Sexton, J.O., Austin, M.P., Collins, C.D., Cook, W.M., Damschen, E.I., Ewers, R.M., Foster, B.L., Jenkins, C.N., King, A.J., Laurance, W.F., Levey, D.J., Margules, C.R., Melbourne, B.A., Nicholls, A.O., Orrock, J.L., Song, D.-X., and Townshend, J.R., 2015, Habitat fragmentation and its lasting impact on Earth's ecosystems: Science Advances, v. 1 , no. 2 .

Harris, N.C., and Dunn, R.R., 2013, Species loss on spatial patterns and composition of zoonotic parasites, Proceedings of the Royal Society of London B: Biological Sciences, v. 280 , no. 1771 .

Hart, K.M., Lamont, M.M., Sartain, A.R., Fujisaki, I., and Stephens, B.S., 2013, Movements and habitat-use of loggerhead sea turtles in the northern Gulf of Mexico during the reproductive period: PloS one, v. 8, no. 7.

Hart, K.M., Zawada, D.G., Fujisaki, I., and Lidz, B.H., 2013, Habitat use of breeding green turtles Chelonia mydas tagged in Dry Tortugas National Park-Making use of local and regional MPAs: Biological Conservation, v. 161, p. 142-154.

Hulcr, J., Rountree, N.R., Diamond, S.E., Stelinski, L.L., Fierer, N., and Dunn, R.R., 2012, Mycangia of ambrosia beetles host communities of bacteria: Microbial Ecology, v. 64 , no. 3 , p. $784-793$.

Iglecia, M.N., Collazo, J.A., and McKerrow, A.J., 2012, Use of occupancy models to evaluate expert knowledge-based species-habitat relationships: Avian Conservation and Ecology, v. 7, no. 2, 5 p.

Ignatius, A.R., and Jones, J.W., 2014, Small reservoir distribution, rate of construction, and uses in the upper and middle Chattahoochee Basins of the Georgia Piedmont, U.S.A., 1950-2010: ISPRS International Journal of GeoInformation, v. 3, no. 2, p. 460-480.

Intergovernmental Panel on Climate Change (IPCC), 2014, Climate Change 2014-Synthesis Report, in Pachauri, R.K., and Meyer, L.A. (eds.) [core writing team]: Geneva, Switzerland, IPCC, Contribution of Working Groups I, II, and III to the Fifth Assessment Report of the Intergovernmental Panel on Climate Change, 151 pp.

Irwin, B.J., and Conroy, M.J., 2013, Consideration of reference points for the management of renewable resources under an adaptive management paradigm: Environmental Conservation, v. 40, no. 4, p. 302-309. 
Irwin and others, 2016, Turning uncertainty into useful information for conservation decisions, SE CSC Fact Sheet 2016-02, accessed August 2, 2016, at https:/www. sciencebase.gov/catalog/file/get/579f9c44e4b0589fa1cd55 $8 \mathrm{e}$ ? $\mathrm{f}=$ _ disk_c1\%2F31\%2Fa3\%2Fc131a3920de4220adaf2 $1 \mathrm{a} 24 \mathrm{~d} 8 \mathrm{ea} 5 \mathrm{fbff} 836 \mathrm{a} 287$.

Johnson, F.A., and Eaton, Mitchell, 2014, Final project memorandum-Understanding conservation management decisions in the face of sea-level rise along the U.S. Atlantic coast, accessed June 20, 2016, at https://www.sciencebase. gov/catalog/item/55257575e4b027f0aee3d5ca.

Jones, S.A., and Dalton, M.S., comps., 2012, U.S. Department of the Interior Southeast Climate Science Center Science and Operational Plan: U.S. Geological Survey Open-File Report 2012-1034, 48 p., accessed June 20, 2016, at http://pubs.usgs.gov/of/2012/1034/.

Kennen, J., Caldwell, P, and others, 2015, Final memorandumHydrological modeling for flow-ecology science in the Southeastern U.S., accessed June 20, 2016, at https://www. sciencebase.gov/catalog/item/560e9cf0e4b0ba4884c5eb97.

Krauss, K.W., McKee, K.L., and Hester, M.W., 2014, Water use characteristics of black mangrove (Avicennia germinans) communities along an ecotone with marsh at a northern geographical limit: Ecohydrology, v. 7, no. 2, p. 354-365.

Krauss, K.W., McKee, K.L., Lovelock, C.E., Cahoon, D.R., Saintilan, N., Reef, R., and Chen, L., 2014, How mangrove forests adjust to rising sea level: New Phytologist, v. 202, no. 1, p. 19-34.

Kuffner, I.B., Hickey, T.D., and Morrison, J.M., 2013, Calcification rates of the massive coral Siderastrea siderea and crustose coralline algae along the Florida Keys (U.S.A.) outer-reef tract: Coral Reefs, v. 32, no. 4, p. 987-997.

LaFontaine, J.H., Hay, L.E., Viger, R.J., Markstrom, S.L., Regan, R.S., Elliott, C.M., and Jones, J.W., 2013, Application of the Precipitation-Runoff Modeling System (PRMS) in the Apalachicola-Chattahoochee-Flint River Basin in the Southeastern United States: U.S. Geological Survey Scientific Investigations Report 2013-5162, 118 p., accessed June 20, 2016, at http://pubs.usgs.gov/sir/2013/5162/.

LaFontaine, J.H., Hay, L.E., Viger, R.J., Regan, R.S., and Markstrom, S.L., 2015, Effects of climate and land cover on hydrology in the Southeastern U.S.-Potential impacts on watershed planning: Journal of the American Water Resources Association, v. 51, no. 5, p. 1235-1261.

Lemos, M.C., and Morehouse, B.J., 2005, The co-production of science and policy in integrated climate assessments: Global Environmental Change, v. 15, p. 57-68, accessed June 20, 2016, at http://dc.doi.org/10.1016/j.gloenvcha. 2004.09.004.
Markstrom, S.L., 2012, P2S-Coupled simulation with the Precipitation-Runoff Modeling System (PRMS) and the Stream Temperature Network (SNTemp) models: U.S. Geological Survey Open-File Report 2012-1116, 19 p., accessed June 20, 2016, at https://pubs.usgs.gov/ of/2012/1116/.

Meadow, A.M., Ferguson, D.B., Guido, Z., Horangic, A., Owen, G., and Wall, T., 2015, Moving toward the deliberate coproduction of climate science knowledge: Weather, Climate, and Society, v. 7, p. 179-191, accessed June 20, 2016, at http://dx.doi.org/10.1175/WCAS-D-1400050.1 .

Meineke, E.K., Dunn, R.R., and Frank, S.D., 2014, Early pest development and loss of biological control are associated with urban warming: Biology Letters, v. 10, no. 11.

Meineke, E.K., Dunn, R.R., Sexton, J.O., and Frank, S.D., 2013, Urban warming drives insect pest abundance on street trees: PloS one, v. 8 , no. 3 .

Menke, S.B., Harte, J., and Dunn, R.R., 2014, Changes in ant community composition caused by 20 years of experimental warming vs. 13 years of natural climate shift: Ecosphere, v. 5 , no. 1 .

Morrison, J.M., Kuffner, I.B., and Hickey, T.D., 2013, Methods for monitoring corals and crustose coralline algae to quantify in-situ calcification rates: U.S. Geological Survey Open-File Report 2013-1159, 11 p., accessed June 20, 2016, at http://pubs.usgs.gov/of/2013/1159/.

Mote, P.W., 2015, Multivariate adaptive constructed analogs (MACA) statistical downscaling method, accessed June 20, 2016, at https:/www.sciencebase.gov/catalog/ item/563b89d0e4b0d6133fe75f20.

Mote, P., and Rupp, D., and Abatzoglou, J., 2015, Final memorandum-Evaluation and downscaling of CMIP5 climate simulations for the Southeast U.S., accessed June 20, 2016, at https:/www.sciencebase.gov/catalog/ item/563a5ec2e4b0d6133fe7340f.

National Geographic, 2015, Scientists create tiny zones of climate change: National Geographic video, 2:43 min, posted July 27, 2015, accessed August 20, 2016, at http://video.nationalgeographic.com/video/news/150727news-warming-chambers-vin? source $=$ searchvideo.

Nilius, R., Dawsey, S., Eaton, M., Martin, J., Romanach, S., Baird, S., Bryant, M., Case, D., Johnson, F., and McMahon, J., 2014, Maximizing the social and ecological value of Cape Romain National Wildlife Refuge, South Carolina as the effects of global change processes increase.

Osland, M.J., 2014, Final memorandum-Ecological implications of mangrove forest migration in the Southeastern U.S., accessed June 20, 2016, at https://www.sciencebase.gov/ catalog/item/548885b2e4b02acb4f0c912f. 
Osland, M.J., Day, R.H., Larriviere, J.C., and From, A.S., 2014, Aboveground allometric models for freeze-affected black mangroves (Avicennia germinans) —Equations for a climate sensitive mangrove-marsh ecotone: PloS one, v. 9, no. 6 .

Osland, M.J., Enwright, N., Day, R.H., and Doyle, T.W., 2013, Winter climate change and coastal wetland foundation species: Salt marshes vs. mangrove forests in the southeastern United States: Global Change Biology, v. 19, no. 5, p. 1482-1494.

Osland, M.J., Enwright, N., and Stagg, C.L., 2014, Freshwater availability and coastal wetland foundation species: Ecological transitions along a rainfall gradient: Ecology, v. 95 , no. 10 , p. 2789-2802.

Pelini, S.L., Diamond, S.E., MacLean, H., Ellison, A.M., Gotelli, N.J., Sanders, N.J., and Dunn, R.R., 2012, Common garden experiments reveal uncommon responses across temperatures, locations, and species of ants: Ecology and Evolution, v. 2, no. 12, p. 3009-3015.

Penick, C.A., Savage, A.M., and Dunn, R.R., 2015, Stable isotopes reveal links between human food inputs and urban ant diets, Proceedings of the Royal Society B: Biological Sciences, v. 282, no. 1806.

Peterson, Nils, and Cubbage, Fred, 2015, Final memorandumDevelopment of a SECAS conservation decision guidance library, accessed June 20, 2016, at https://www.sciencebase. gov/catalog/item/564e3dcfe4b0112df6c631f4.

Peterson, J.T., and Shea, C.P., 2015, An evaluation of the relations between flow regime components, stream characteristics, species traits, and meta-demographic rates of warm-water-stream fishes-Implications for aquatic resource management: River Research and Applications, v. 31 , no. 10 , p. $1227-1241$.

Reich, C.D., Kuffner, I.B., Hickey, T.D., Morrison, J.M., and Flannery, J.A., 2013, Complexity of nearshore strontiumto-calcium ratio variability in a core sample of the massive coral Siderastrea siderea obtained in Coral Bay, St. John, U.S. Virgin Islands: U.S. Geological Survey Open-File Report 2013-1092, 12 p., accessed June 20, 2016, at http://pubs.usgs.gov/of/2013/1092/.

Romañach, S.S., 2015, Final memorandum-Dynamic reserve design in the face of climate change and urbanization, accessed June 20, 2016, at https://www.sciencebase.gov/ catalog/item/56609488e4b071e7ea545019.

Rupp, D.E., 2016, An evaluation of 20th century climate for the Southeastern United States as simulated by Coupled Model Intercomparison Project Phase 5 (CMIP5) global climate models: U.S. Geological Survey Open-File Report 2016-1047, 32 p., accessed June 20, 2016, at http://dx.doi.org/10.3133/ofr20161047.
Ryu, J., and Hayhoe, K., 2013, Understanding the sources of Caribbean precipitation biases in CMIP3 and CMIP5 simulations: Climate Dynamics, v. 42, p. 3233-3252.

Ryu, J., and Hayhoe, K., 2014, Regional and large-scale influences on seasonal to interdecadal variability in Caribbean surface air temperature in CMIP5 simulations: Climate Dynamics, v. 45, p. 455-475.

Saintilan, N., Wilson, N.C., Rogers, K., Rajkaran, A., and Krauss, K.W., 2014, Mangrove expansion and salt marsh decline at mangrove poleward limits: Global Change Biology, v. 20, no. 1, p. 147-157.

Shea, C.P., Peterson, J.T., Wisniewski, J.M., and Johnson, N.A., 2011, Misidentification of freshwater mussel species (Bivalvia:Unionidae) - Contributing factors, management implications, and potential solutions: Journal of the North American Benthological Society, v 30, no. 2, p. 446-458.

Shea, Damian, 2015, Final memorandum-Assessment of terrestrial and aquatic monitoring programs in the Southeastern United States, accessed June 20, 2016, at https://www.sciencebase.gov/catalog/ item/5644bef8e4b0aafbcd018602.

Shipman, Matt, 2015, Researchers seek sneak peek into the future of forests: NC State News, June 2, 2015, accessed August 20, 2016, at https://news.ncsu.edu/2015/06/ warming-chambers-2015/.

Shipman, Matt, and Varela Minder, Elda, 2015, Researchers seek a sneak peek into the future of forests: USGS Science Features-Top Story, July 7, 2015, accessed August 20, 2016, at https://www2.usgs.gov/blogs/features/ usgs_top_story/researchers-seek-a-sneak-peek-into-thefuture-of-forests/.

Schrader, Brian, and Stout, Jon, 2015, NC State researchers explore future of climate change on ecosystems: WRAL.com-Weather, accessed August 20, 2016, at http://www.wral.com/nc-state-researchers-explorefuture-of-climate-change-on-ecosystems/14714850/.

Steyer, G.D., 2015, Final memorandum-Structured decision making to facilitate multi-stakeholder coastal conservation and restoration under climate change uncertainties - Case study on barrier islands of the northern Gulf of Mexico, accessed June 20, 2016, at https://www.sciencebase.gov/ catalog/item/565e07b3e4b071e7ea5435d0.

Stoner, A.M.K., Hayhoe, K., Yang, X., and Wuebbles, D.J., 2013, An asynchronous regional regression model for statistical downscaling of daily climate variables: International Journal of Climatology, v. 33, no. 11, p. 2473-2494.

Stuble, K.L., Patterson, C.M., Rodriguez-Cabal, M.A., Ribbons, R.R., Dunn, R.R., and Sanders, N.J., 2014, Antmediated seed dispersal in a warmed world: PeerJ, v. 2. 
Stuble, K.L., Pelini, S.L., Diamond, S.E., Fowler, D.A., Dunn, R.R., and Sanders, N.J., 2013, Foraging by forest ants under experimental climatic warming - A test at two sites: Ecology and Evolution, v. 3, no. 3, p. 482-491.

Swain, S., and Hayhoe, K., 2015, CMIP5 projected changes in spring and summer drought and wet conditions over North America: Climate Dynamics, v. 44, p. 2737-2750.

Terando, A.J., Costanza, J., Belyea, C., Dunn, R.R., McKerrow, A., and Collazo, J.A., 2014, The southern megalopolis-Using the past to predict the future of urban sprawl in the Southeast U.S.: PloS one, v. 9, no. 7.

Vargo, E.L., Leniaud, L., Swoboda, L.E., Diamond, S.E., Weiser, M.D., Miller, D.M., and Bagnères, A., 2013, Clinal variation in colony breeding structure and level of inbreeding in the subterranean termites Reticulitermes flavipes and R. grassei: Molecular Ecology, v. 22, no. 5, p. 1447-1462.

Veran, S., Kleiner, K.J., Choquet, R., Collazo, J.A., and Nichols, J.D., 2012, Modeling habitat dynamics accounting for possible misclassification: Landscape Ecology, v. 27, no. 7, p. 943-956.

Viger, R.J., Hay, L.E., Jones, J.W., and Buell, G.R., 2010, Effects of including surface depressions in the application of the Precipitation-Runoff Modeling System in the Upper Flint River Basin, Georgia: U.S. Geological Survey Scientific Investigations Report 2010-5062, 36 p., accessed May 5, 2016, at http://pubs.usgs.gov/sir/2010/5062/.

Viger, R.J., Hay, L.E., Markstrom, S.L., Jones, J.W., and Buell, G.R., 2011, Hydrologic effects of urbanization and climate change on the Flint River Basin, Georgia: Earth Interactions, v. 15 , no. 20.

Warren, R.J., and Chick, L., 2013, Upward ant distribution shift corresponds with minimum, not maximum, temperature tolerance: Global Change Biology, v. 19, no. 7, p. 2082-2088.
Wilson, K.V., 2011, Sea-level rise visualization for Alabama, Mississippi, and Florida, accessed May 5, 2016, at https:/www.sciencebase.gov/catalog/item/54dd1e20e 4b08de9379b2fad.

Wootten, Adrienne, and Furiness, Cari, 2015, Downscaled climate projections for the Southeast-Evaluation and use for ecological applications: Southeast Climate Science Center Fact Sheet 2015-01, accessed June 20, 2016, at http://dx.doi.org/10.3133/ofr20141190.

Wootten, A., Smith, K., Boyles, R., Terando, A., Stefanova, L., Misra, V., Smith, T., Blodgett, D., and Semazzi, F., 2014, Downscaled climate projections for the Southeast United States-Evaluation and use for ecological applications: U.S. Geological Survey Open-File Report 2014-1190, 54 p., accessed June 20, 2016, at http://dx.doi.org/10.3133/ ofr 20141190 .

Wuebbles, D., Meehl, G., Hayhoe, K., Karl, T.R., Kunkel, K., Santer, B., Wehner, M., Colle, B., Fischer, E.M., and Fu, R., 2014, CMIP5 climate model analyses: climate extremes in the United States: Bulletin of the American Meteorological Society, v. 95, no. 4, p. 571-583.

Yando, E.S., Osland, M.J., Willis, J.M., Day, R.H., Krauss, K.W., and Hester, M.W., 2016, Salt marsh-mangrove ecotones: using structural gradients to investigate the effects of woody plant encroachment on plant-soil interactions and ecosystem carbon pools, Journal of Ecology, v. 104, no. 4, p. 1020-1031.

Youngsteadt, E., Dale, A.G., Terando, A.J., Dunn, R.R., and Frank, S.D., 2014, Do cities simulate climate change? A comparison of herbivore response to urban and global warming: Global Change Biology, v. 21, no. 1, p. 97-105.

Youngsteadt, E., Henderson, R.C., Savage, A.M., Ernst, A.F., Dunn, R.R., and Frank, S.D., 2015, Habitat and species identity, not diversity, predict the extent of refuse consumption by urban arthropods: Global Change Biology, v. 21, no. 3, p. 1103-1115. 


\section{Appendix 1. SE CSC Projects and Timeline of Events}

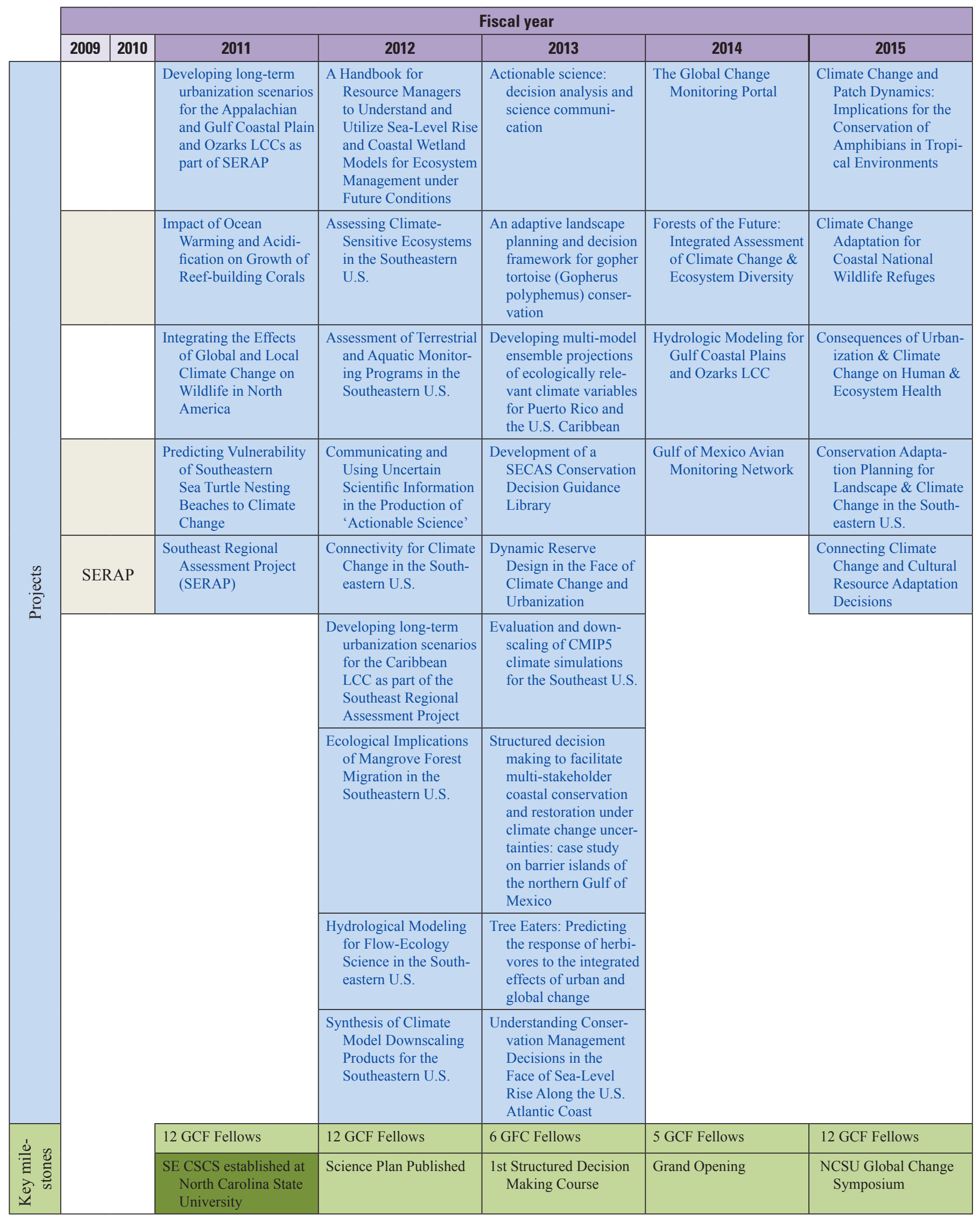




\section{Appendix 2. Southeast Climate Science Center Global Change Fellows}

The Global Change Graduate Fellowship is a program designed to provide financial, scientific, and professional development support for incoming graduate students (Masters, Ph.D.) and postdoctoral researchers who are interested in multidisciplinary research related to climate and global change. Sponsored by the SE CSC and NCSU, the program has supported 38 graduate fellows between FY11 and FY15. Their diverse research interests span several disciplines including wildlife and conservation biology; civil and environmental engineering; forestry; fisheries; marine, earth, and atmospheric sciences; and anthropology. All fellows have worked with advisers who are faculty affiliates to the SE CSC and (or) principle investigators to SE CSC-funded projects. The research of these fellows contributes to the SE CSC's science and management goals and responds to the science themes presented in the SE CSC's science plan.

\begin{tabular}{|c|c|c|c|c|c|}
\hline Fellow & $\begin{array}{l}\text { Fellowship } \\
\text { year(s) }\end{array}$ & $\begin{array}{l}\text { Degree } \\
\text { sought }\end{array}$ & $\begin{array}{l}\text { North Carolina State University } \\
\text { Department }\end{array}$ & $\begin{array}{c}\text { Science } \\
\text { theme }\end{array}$ & Research interest \\
\hline Rachel Atkins & 2015 & Ph.D. & $\begin{array}{l}\text { Marine, Earth and Atmospheric } \\
\text { Sciences }\end{array}$ & 2 & $\begin{array}{l}\text { Understanding how individuals learn in the } \\
\text { geosciences, with applications to improve } \\
\text { teaching strategies. }\end{array}$ \\
\hline Kristi Backe & 2015 & M.S. & Entomology & 4 & $\begin{array}{l}\text { Environmental factors mitigating the effects } \\
\text { of urban warming on tree pests, tree } \\
\text { health, and ecosystem services. }\end{array}$ \\
\hline Geneva Ely & 2015 & M.S. & $\begin{array}{l}\text { Marine, Earth and Atmospheric } \\
\text { Sciences }\end{array}$ & 1 & $\begin{array}{l}\text { Development of a consistent historical } \\
\text { climate dataset for eastern North Carolina. }\end{array}$ \\
\hline Kyle Garrison & 2015 & Ph.D. & $\begin{array}{l}\text { Forestry and Environmental } \\
\text { Resources }\end{array}$ & 4 & $\begin{array}{l}\text { Adaptation of coat color changing species to } \\
\text { climate change. }\end{array}$ \\
\hline Sean Giery & 2015 & Ph.D. & Applied Ecology & 4 & $\begin{array}{l}\text { Human influence on rapid evolutionary } \\
\text { change in an ecologically important fish } \\
\text { species of the Bahamas. }\end{array}$ \\
\hline $\begin{array}{l}\text { Amirhossein } \\
\text { Mazrooei }\end{array}$ & 2015 & Ph.D. & $\begin{array}{l}\text { Civil, Construction and Envi- } \\
\text { ronmental Engineering }\end{array}$ & 3 & $\begin{array}{l}\text { Probabilistic statistical downscaling methods } \\
\text { that utilize the ensemble of forecasts from } \\
\text { Global Climate Models to develop stream- } \\
\text { flow forecasts. }\end{array}$ \\
\hline Gabriella Pardee & 2015 & Ph.D. & Applied Ecology & 4 & $\begin{array}{l}\text { Studying the impacts of climate change on } \\
\text { plant-pollinator interactions in montane } \\
\text { regions of Colorado. }\end{array}$ \\
\hline Philip Patton & 2015 & M.S. & Applied Ecology & 4 & $\begin{array}{l}\text { Quantifying the effects, extent, and man- } \\
\text { agement implications of co-occurrence } \\
\text { among birds in Puerto Rico. }\end{array}$ \\
\hline Rene Valdez & 2015 & Ph.D. & $\begin{array}{l}\text { Forestry and Environmental } \\
\quad \text { Resources }\end{array}$ & 1 & $\begin{array}{l}\text { Integrating decision sciences to an emerging } \\
\text { wildlife conservation tool with global } \\
\text { implications in genetic pest management. }\end{array}$ \\
\hline Laura Villegas & 2015 & Ph.D. & $\begin{array}{r}\text { Agricultural and Natural } \\
\text { Resources Economics }\end{array}$ & 1 & $\begin{array}{l}\text { Integrating rapid environmental change into } \\
\text { the design of feasible and effective conser- } \\
\text { vation and agricultural policy instruments. }\end{array}$ \\
\hline $\begin{array}{l}\text { Liliana Velasquez } \\
\text { Montoya }\end{array}$ & 2014 & Ph.D. & Civil Engineering & 5 & $\begin{array}{l}\text { Coastal morphodynamics, inlets, sea-level } \\
\text { rise }\end{array}$ \\
\hline
\end{tabular}




\begin{tabular}{|c|c|c|c|c|c|}
\hline Fellow & $\begin{array}{l}\text { Fellowship } \\
\text { year(s) }\end{array}$ & $\begin{array}{l}\text { Degree } \\
\text { sought }\end{array}$ & $\begin{array}{c}\text { North Carolina State University } \\
\text { Department }\end{array}$ & $\begin{array}{c}\text { Science } \\
\text { theme }\end{array}$ & Research interest \\
\hline Michaela Foster & 2014 & M.F. & $\begin{array}{l}\text { Forestry and Environmental } \\
\text { Resources }\end{array}$ & 4 & $\begin{array}{l}\text { Decision making, longleaf pine ecosystems, } \\
\text { policy }\end{array}$ \\
\hline Nitin Singh & 2014 & Ph.D. & \begin{tabular}{|l|} 
Forestry and Environmental \\
Resources
\end{tabular} & 3 & $\begin{array}{l}\text { Carbon cycle, ecohydrology, watershed } \\
\text { hydrology }\end{array}$ \\
\hline Adam Dale & 2014 & Ph.D. & Entomology & 4 & $\begin{array}{l}\text { Entomology, urban ecology, urban forestry, } \\
\text { urban heat island }\end{array}$ \\
\hline Carlos Botero & $\begin{array}{l}2011 \\
2012 \\
2013\end{array}$ & Postdoc & Genetics & 4 & $\begin{array}{l}\text { Evolutionary biology and climate change } \\
\text { variability/models }\end{array}$ \\
\hline Michael Just & 2013 & Ph.D. & Plant and Microbial Biology & 2,4 & $\begin{array}{l}\text { Climate and fire impacts on wetland vegeta- } \\
\text { tion in longleaf pine landscapes }\end{array}$ \\
\hline Ayse Karanci & 2013 & Ph.D. & Civil Engineering & 5 & $\begin{array}{l}\text { Impacts of sea-level rise and vulnerability on } \\
\text { coastal landforms }\end{array}$ \\
\hline Jennifer Niemuth & 2013 & Ph.D. & $\begin{array}{l}\text { Wildlife and Aquatic Health/ } \\
\text { Fisheries, Wildlife \& Conser- } \\
\text { vation Biology Program }\end{array}$ & 4,5 & Physiologic basis of cold stun in sea turtles \\
\hline Tyson Wepprich & $\begin{array}{l}2013 \\
2012 \\
2011\end{array}$ & Ph.D. & Biological Sciences/Zoology & 4 & $\begin{array}{l}\text { Insect response to climate change and urban- } \\
\text { ization }\end{array}$ \\
\hline $\begin{array}{l}\text { Lauren Charles } \\
\text { Smith }\end{array}$ & $\begin{array}{l}2012 \\
2011\end{array}$ & Ph.D. & $\begin{array}{l}\text { Clinical Sciences/Fisheries, } \\
\text { Wildlife \& Conservation } \\
\text { Biology Program }\end{array}$ & 4 & $\begin{array}{l}\text { Impact of extreme weather events on select } \\
\text { wildlife diseases }\end{array}$ \\
\hline Sarah Fritts & $\begin{array}{l}2012 \\
2011\end{array}$ & Ph.D. & $\begin{array}{l}\text { Forestry and Environmental } \\
\text { Resources/Fisheries, Wildlife } \\
\text { and Conservation Biology } \\
\text { Program }\end{array}$ & 2 & $\begin{array}{l}\text { Effects of biomass harvesting guidelines on } \\
\text { ground-dwelling wildlife habitat }\end{array}$ \\
\hline Ernest Hain & $\begin{array}{l}2012 \\
2011\end{array}$ & Ph.D. & $\begin{array}{l}\text { Forestry and Environmental } \\
\text { Resources/Fisheries, Wildlife } \\
\text { and Conservation Biology } \\
\text { Program }\end{array}$ & 2 & Woody biomass for green energy feedstock \\
\hline Guofang Miao & 2012 & Ph.D. & $\begin{array}{l}\text { Forestry and Environmental } \\
\text { Resources }\end{array}$ & 4,5 & $\begin{array}{l}\text { Carbon cycle in forested wetlands under } \\
\text { climate change }\end{array}$ \\
\hline Jessica Osborne & $\begin{array}{l}2012 \\
2011\end{array}$ & M.A. & $\begin{array}{l}\text { Sociology and Anthropology/ } \\
\text { Archaeology }\end{array}$ & 6 & Mortuary analysis of Caribbean islands \\
\hline Aaron Poteate & $\begin{array}{l}2012 \\
2011\end{array}$ & M.A. & $\begin{array}{l}\text { Sociology and Anthropology/ } \\
\text { Archaeology }\end{array}$ & 6 & $\begin{array}{l}\text { Human subsistence strategies in face of } \\
\text { environmental change }\end{array}$ \\
\hline Elizabeth Warren & 2012 & M.A. & $\begin{array}{l}\text { Sociology and Anthropology/ } \\
\text { Archaeology }\end{array}$ & 6 & \\
\hline
\end{tabular}




\begin{tabular}{|c|c|c|c|c|c|}
\hline Fellow & $\begin{array}{l}\text { Fellowship } \\
\text { year(s) }\end{array}$ & $\begin{array}{l}\text { Degree } \\
\text { sought }\end{array}$ & $\begin{array}{c}\text { North Carolina State University } \\
\text { Department }\end{array}$ & $\begin{array}{c}\text { Science } \\
\text { theme }\end{array}$ & Research interest \\
\hline Adrienne Wootten & 2012 & Ph.D. & $\begin{array}{l}\text { Marine, Earth and Atmospheric } \\
\text { Sciences }\end{array}$ & 1 & $\begin{array}{l}\text { Weather generator techniques for down- } \\
\text { scaling precipitation }\end{array}$ \\
\hline Nathan Putnam & 2011 & $\begin{array}{c}\text { Postdoc- } \\
\text { toral }\end{array}$ & $\begin{array}{l}\text { Marine, Earth and Atmospheric } \\
\text { Sciences }\end{array}$ & 4,5 & $\begin{array}{l}\text { Behavioral ecology, migration dispersal in } \\
\text { marine environments }\end{array}$ \\
\hline Corey Davis* & 2011 & M.S. & $\begin{array}{l}\text { Marine, Earth and Atmospheric } \\
\text { Sciences }\end{array}$ & 5 & Climate impacts on local fire risk \\
\hline $\begin{array}{l}\text { Daniela Magda- } \\
\text { lena Sorger* }\end{array}$ & 2011 & Ph.D. & Biology & 4 & $\begin{array}{l}\text { Diversification of ants; climate change and } \\
\text { evolutionary biology }\end{array}$ \\
\hline Siyao, Zhang* & 2011 & Ph.D. & $\begin{array}{l}\text { Forestry and Environmental } \\
\text { Resources }\end{array}$ & 4 & $\begin{array}{l}\text { Soil organic carbon cycling affected by } \\
\text { climate change, hydrology, management }\end{array}$ \\
\hline
\end{tabular}

*No Weblink available for these fellows.

Training opportunities organized by the SE CSC are intended to prepare these fellows for careers conscience of global change and decision makers. Previous opportunities include

\begin{tabular}{|l|l|}
\hline \multicolumn{1}{|c|}{ Training opportunity } & \multicolumn{1}{c|}{ Purpose } \\
\hline $\begin{array}{l}\text { National Conservation Training Center: } \\
\text { Structured Decision Making course }\end{array}$ & $\begin{array}{c}\text { Provides the skills to develop structured approaches in order to make a } \\
\text { complicated decision-making process more explicit, transparent, and clear. } \\
\text { It teaches practical approaches to critical thinking, logic, reasoning, and } \\
\text { structuring decisions that support day-to-day work. }\end{array}$ \\
\hline Seminar Lecture Series & $\begin{array}{l}\text { Invited guest speakers share their research and (or) management experience } \\
\text { with the fellows and allow for open discussion about their work. }\end{array}$ \\
\hline Science video training workshop & $\begin{array}{c}\text { A combination of lecture, discussion, and hands-on exercises to train scien- } \\
\text { tists on how to make videos that communicate their science. }\end{array}$ \\
\hline Science Communication Workshop & $\begin{array}{l}\text { Gain knowledge of basic communication principles, review good/not good } \\
\text { examples of effective science communication. }\end{array}$ \\
\hline National Conservation Training Center: & $\begin{array}{l}\text { This course was designed to cover the fundamentals of climate science, } \\
\text { provide tools and resources for climate adaptation, increase climate literacy } \\
\text { and communication, and provide guidance for maintaining literacy using } \\
\text { shared online resources. }\end{array}$ \\
\hline
\end{tabular}


The Fellows also contribute to science through their published work on their research and findings. Fellows' publications (whose names are in bold) include:

Hydro-Climatological Influences on Long-Term Dissolved Organic Carbon in a Mountain Stream of the Southeastern United States, Singh, N.K., Reyesa, W.M., Bernhardt, E.S., Bhattacharyaa, R., Meyerc, J.L., Knoeppd, J.D., Emanuela, R.E., 2016, Journal of Environmental Quality, Science Theme: 3

Forecasting the Effects of Heat and Pests on Urban Trees Impervious Surface Thresholds and the 'Pace-to-Plant' Technique, Dale, A.G.,Youngstead, E., and Frank, S.D., 2016, Arboriculture \& Urban Forestry, Science Theme: 4

High Fitness Costs of Climate Change Induced Camouflage Mismatch, Zimova, M., Mills, L.S., Nowak, J.J., 2016, Ecology Letters, Science Theme: 4

Point-count methods to monitor butterfly populations when traditional methods fail: A case study with Miami blue butterfly, Henry, E.H., Haddad, N.M., Wilson, J., Hughes, P., and Gardner, B., 2015, Journal of Insect Conservation, Science Theme: 4

Habitat restoration as a recovery tool for a disturbancedependent butterfly, the endangered St. Francis' satyr, Cayton, H., Haddad, N.M., Ball, B., Henry, E.H., and Aschehoug E., 2015, Butterfly Conservation in North America, Science Theme: 4

Environmental harshness is positively correlated with intraspecific divergence in mammals and birds, Botero, C.A., Dor, R., McCain, C.M. and Safran, R.J., 2014, Molecular Ecology, Science Theme: 4

Fluctuating environments, sexual selection and the evolution of flexible mate choice in birds, Botero, C.A., and Rubenstein D.R., 2012, PLoS ONE, Science Theme: 1,4

Urban warming trumps natural enemy regulation of herbivorous pests, Dale, A., and Frank, S.D., 2014, Ecological Society of America, Science Theme: 4

The effects of urban warming on herbivore abundance and street tree condition, Dale, A., and Frank, S.D., 2014, PLOS ONE, Science Theme: 2, 4

Do cities simulate climate change? A comparison of herbivore response to urban and global warming, Youngsteadt, E., Dale, A., Terando, A.J., Dunn, R.R., and Frank S.D., 2014, Global Change Biology, Science Theme: 2, 4

Shrew response to variable woody debris retention: Implications for sustainable forest bioenergy, Fritts, S.R., Moorman, C.E., Grodsky, S.M., Hazel, D.W., Homyack, J.A., Farrell, C.B., and Castleberry, S.B., 2014, Forest Ecology and Management, Science Theme: 2, 4
Biomass harvesting guidelines affect downed woody debris retention, Fritts, S.R., Moorman, C.E., Hazel, D.W., and Jackson B.D., 2014, Biomass and Bioenergy, Science Theme: 2,4

Regional analysis of wind turbine-caused bat mortality, Drake, D., Jennelle, C.S., Lui, J.N., Grodsky S.M., Schumaker, S., and Sponsler, M., 2015, Regional analysis of wind turbine-caused bat mortality, Acta Chiropterologica, Science Theme: 2

Interpopulation variation in a condition-dependent signal: predation regime affects signal intensity and reliability, Giery, S.T., and Layman, C.A., 2015, The American Naturalist, Science Theme: 4, 5

Anthropogenic ecosystem fragmentation drives shared and unique patterns of sexual signal divergence among three species of Bahamian mosquitofish, Giery, S.T., Layman, C.A., and Langerhans, R.B., 2015, Evolutionary Applications, Science Theme: 4, 5

Does hydrological fragmentation affect coastal bird communities? A study from Abaco Island, The Bahamas, Chacin, D.H., Giery, S.T., Yeager, L.A., Layman, C.A., and Langerhans, R.B., 2015, Wetland Ecology and Management, Science Theme: 4

A primer on the history of food web ecology: Fundamental contributions of fourteen researchers, Layman, C.A., Giery, S.T., Buhler, S., Rossi, R., Penland, T., Henson, M.N., Bogdanoff, A.K., Cove, M.V., Irizarry, A.D., Schalk, C.M., and Archer, S.K., 2015, Food Webs, Science Theme: 4,5

Differing nutritional constraints of consumers across ecosystems, Lemoine, N.P., Giery, S.T., and Burkepile, D.E., 2014, Oecologia, Science Theme: 4, 5

Ecosystem fragmentation drives increased diet variation in an endemic live-bearing fish of the Bahamas, Araujo, M.S., Langerhans, R.B., Giery, S.T., and Layman, C.A., 2014, Ecology and Evolution, Science Theme: 4, 5

Evolved for extinction: The cost and conservation implications of specialization in hammerhead sharks, Gallagher, A.J., Hammerschlag, N., Shiffman, D.S., Giery, S.T., 2014, BioScience, Science Theme: 4, 5

Commonly rare and rarely common: Comparing population abundance of invasive and native aquatic species, Hansen, G.J.A., Vander Zanden, M.J., Blum, M.J., Clayton, M.K., Hain, E.F., and others, 2013, PLoS ONE, Science Theme: 4,5

Where fire stops: Vegetation structure and microclimate influence fire spread along an ecotonal gradient, Just, M.G., Hohmann, M.G., and Hoffmann, W.A., 2015, Plant Ecology, Science Theme: 2,4 
Global biogeographic regions in a human-dominated world: The case of human diseases, Just, M.G., Norton, J.F., Traud, A.L., Antonelli, T., Poteate, A.S., Backus, G.A., Snyder-Beattie, A., Sanders, R.W., and Dunn, R.R., 2014, Ecosphere, Science Theme: 2

Size dependency of post-disturbance recovery of multistemmed resprouting trees, Schafer, J.L., and Just, M.G., 2014, PLOS ONE, Science Theme: 4

Decomposition of sources of errors in seasonal streamflow forecasting over the U.S. Sunbelt, Mazrooei, A., Sinha, T., Sankarasubramanian, A., Kumar, S., and Peters-Lidard, C.C., 2015, Journal of Geophysical Research, Science Theme: 3

The effect of water table fluctuation on soil respiration in a lower coastal plain forested wetland in the Southeastern U.S., Miao, G., Noormets, A., Domec, J.C., Trettin, C.C., McNulty, S.G., Sun, G., and King, J.S., 2013, Journal of Geophysical Research: Biogeosciences, Science Theme: 2, 5

Effects of processing time on blood and plasma samples from loggerhead sea turtles (Caretta caretta) for1H-NMR-based metabolomics, Niemuth, J.N., Harms, C.A., and Stoskopf, M.K., 2015, Herpetological Conservation and Biology, Science Theme: 4

Hepatic metabolomic investigation of the North American black bear (Ursus americanus) using 1H-NMR spectroscopy, Niemuth, J., and Stoskopf, M., 2014, Wildlife Biology in Practice, Science Theme: 4

Nephrolithiasis in free-ranging North American river otter (Lontra canadensis) in North Carolina, U.S.A., Niemuth, J.N., Sanders, C.W., Mooney, C.B., Olfenbuttel, C., DePerno, C.S., and Stoskopf, M.K., 2014, Journal of Zoo and Wildlife Medicine, Science Theme: 4, 5
Malignant hypertension and retinopathy in a western lowland gorilla (Gorilla gorilla gorilla), Niemuth, J.N., De Voe, R.S., Jennings, S.H., Loomis, M.R., and Troan, B.V., 2014, Journal of Medical Primatology, Science Theme: 4

Ventricular habronemiasis in aviary passerines, Niemuth, J.N., Allgood J.V., Flowers J.R., De Voe R.S., and Troan B.V., 2013, Case Reports in Veterinary Medicine, Science Theme: 4

Who likes it hot? A global analysis of the climatic, ecological, and evolutionary determinants of warming tolerance in ants, Diamond, S.E., Sorger, D.M., Hulcr, J., Pelini, S.L., Del Toro, I., Hirsch, C., Oberg, E., and Dunn, R.R., 2012, Global Change Biology, Science Theme: 1, 4

Unexpected phenological responses of butterflies to the interaction of urbanization and geographic temperature, Diamond, S.E., Cayton, H., Wepprich, T., Jenkins, C.N., Dunn, R.R., Haddad, N.M., and Ries, L., 2014, Ecology, Science Theme: 2, 4

Downscaled climate projections for the Southeast United States: Evaluation and use for ecological applications, Wootten, A., Smith, K., Boyles, R., Terando, A., Stefanova, L., Misra, V., Smith, T., Blodgett, D., and Semazzi, F., 2014, U.S. Geological Survey Open-File Report, Science Theme: 1

High fitness costs of climate change induced camouflage mismatch, Zimova, M., Mills, L.S., and Nowak, J.J., 2016, Ecology Letters, Science Theme: 4

Snowshoe hares display limited phenotypic plasticity to mismatch in seasonal camouflage, Zimova, M., Mills, L.S., Lukacs, P.M., and Mitchell, M.S., 2014, Proceedings of the Royal Society, Science Theme: 4 


\section{Appendix 3. FY12 SE CSC Science Priorities}

In Fiscal Year 2012, the SE CSC invited Statements of Interest (SOI) that addressed the following five priority science needs:

1. Synthesis of the state of the science regarding six topics important to the LCC efforts to manage sustainable landscapes:

a. regional downscaling of global climate models;

b. ecohydrology;

c. sea-level rise;

d. modeling of urban growth;

e. unique climate-vulnerable; and,

f. climate-sensitive ecosystems; and the communication of scientific uncertainty to decision makers.

2. Terrestrial connectivity analysis across the entire SE region.

3. Conceptual model for regional-scale sustainable landscapes.

4. Impact of mangrove migration on coastal ecosystems.

5. Snowfall and snow depth projections for the Eastern United States.

These priority science needs were defined and approved by the SE CSC's SIP in FY12. The description of these priorities follows:

\section{Synthesis of the State of the Science}

As stated in the call for proposals, the goal for each of the individual topics listed below is to generate a synthesis of the current state of the science for the topic in relation to the information needs of the LCCs in the Southeast (SE). In general, these information needs are associated with the LCC objective of developing conservation adaptation strategies that support regional scale sustainable landscapes. The emphasis in these syntheses is the development of "actionable scientific information" that can support LCC management activities and future investment of CSC and (or) LCC dollars. Investigators will be expected to collaborate with the LCCs in the identification of priority information needs. The syntheses of the state of the science of scientific approaches should broadly reflect awareness of these needs and result in a deliverable product that is suitable for distribution to a broad range of stakeholders within the conservation community (scientists, managers, and administrators).

Regional downscaling of global climate models: The need for projections of future climate change at the scale of management and decision making has resulted in the advancement of numerous downscaling methodologies and datasets. This proliferation of model results, broadly categorized within statistical and dynamical downscaling frameworks, can provide important insights in regards to future regional impacts of climate change. However, the large number of methods involved, different downscaling approaches, resolutions, time periods, and focal variables limits the ability to quickly form robust conclusions that reflect the breadth of modeling efforts. The goal of this task is to synthesize the state of the science for different downscaling methodologies and to compare the results of downscaling efforts whose modeling extent covers the SE CSC region. The comparison should address the advantages and disadvantages of downscaling approaches in terms of the characterization of model-related uncertainties, the appropriateness of downscaled data for use in hydrologic and other models, and the ability of the models to simulate (or enable the derivation of) important derived variables such as potential evapotranspiration, relative humidity, wind speed and direction, and snow fall. The synthesis should provide an assessment of model accuracy but also should consider approaches that allow for pooling of model results to provide LCCs with a combined ensemble of downscaled climate projections. (Project limit: $\$ 40,000$, with completion in 1 year)

Ecohydrology: The body of scientific knowledge concerning ecological-hydrology relations has expanded greatly over the last decade, and many studies have identified hydrologic alteration as one of the most serious threats to the ecological sustainability of the world's streams and rivers and their associated biotic communities. A large number of hydrologic models have been developed - each with a very specific extent, temporal and spatial resolution, accuracy and precision, and appropriate application. The goal of this effort is to synthesize the state of the science regarding the use of the various existing rainfall-runoff and statistical hydrologic models to support investigations of the effects of climate and land cover change on stream ecology and hydrology. Because LCC management questions encompass multiple scales, ranging from stream reach (what is the effect of land use change on hydrology and the fish assemblage in a particular tributary?) to region (what is the relation between water use, stream characteristics and the sustainability of the human and natural landscape at the scale of a U.S. Environmental Protection Agency Level III ecoregion?) the synthesis should consider the advantages and disadvantages of each modeling approach at multiple scales and the potential for integration with models of lentic (lake or reservoir), coastal wetland, and marine aquatic systems. The synthesis should also provide information about the capabilities of each model to portray uncertainty in model parameters and model predictions. Consideration should be given to coordination of this synthesis with a regional model comparison project currently being 
conducted by the Office of Surface Water at USGS (Project limit: $\$ 40,000$, with completion in 1 year)

Sea-level rise: Coastal areas are highly complex systems, vulnerable to abrupt change, and stressed by human development activities. Future sea-level rise, coupled with changes in storm intensity and freshwater runoff, may result in dramatic changes in coastal systems, effecting natural and built habitats. The goal of this task is to synthesize the state of the science in two areas, including: (a) approaches for predicting sealevel rise, and (b) tools and other methods to assist coastal communities and natural resource managers in anticipating, understanding, and applying information on the effects of sea-level rise and associated climate related hydrologic effects (and their uncertainty) on natural and human communities. An important outcome of this work will be a base of knowledge that managers and scientists in the area served by the SE CSC can use to plan future management and scientific activities. (Project limit: $\$ 40,000$, with completion in 1 year)

Modeling urban growth: Rapid urbanization in the SE complicates the ability of managers and decision makers to plan for and adapt to a changing climate. Urban growth models can aid the decision process by identifying areas that are likely to continue to experience urban growth. They also can aid managers through the development of scenarios that show the consequences of future land use planning strategies. However, the existing suite of urban models spans a wide range of scales, data requirements, assumptions, and approaches. The goal of this task is to synthesize the state of the science of urban growth models and to compare results from projects previously undertaken across the region. Parcelbased approaches versus dynamic modeling and empirical approaches should be evaluated with respect to their ability to capture future local, sub-regional, and regional urban growth (and decay) scenarios that conflict with strategies to adapt to climate change. Model capabilities to represent uncertainty in model predictions should be assessed. (Project limit: $\$ 40,000$, with completion in 1 year)

Identify unique climate-vulnerable and climate-sensitive ecosystems, their key stressors, and adaptation/mitigation options: The regional landscape encompassed by the SE CSC contains some of the most diverse and biologically rich temperate ecosystems that occur anywhere in the world, with numerous endemic species of flora and fauna. The goal of this task is to synthesize the state of the science regarding what is known about several unique and important ecosystems in this region that are especially sensitive to climate-related impacts: high elevation systems (shaped by the complex relation among unique geological formations and non-precipitant moisture such as mist, fog; examples include cloud forests, coves, balds, flatrock communities; elfin forests in Puerto Rico; pocosins; vernal pools; pine flatwoods; xeric maritime scrub communities; and karst-related systems such as glades; Highland Rim karst swamps; lime sinks. The emphasis should be on systems-level understanding of these ecosystems, rather than a focus on a particular species or assemblage. The synthesis should catalog the general locations of these systems across the area of the 7 LCCs, describe what is known about the factors that control their distribution, including geologic and climatic settings and hydrology, describe the likely effect of climate and land use change on the condition of these systems, and the current suite of conservation strategies used to protect these systems or otherwise mitigate the effects of processes that degrade these systems. (Project limit: $\$ 40,000$, with completion in 1 year)

\section{Communicating and using uncertain scientific}

information: Uncertainty is a fundamental characteristic of the science used to describe and understand the world we live in. This is particularly the case for climate change science, where predictions regarding climate factors and the associated ecological responses range from the whole planet to local habitats. Moreover, climate change predictions carry differing degrees of uncertainty; for example, we have a high degree of certainty that carbon dioxide concentrations in the atmosphere will continue to rise, but a lower degree of certainty in predicting how plant community dynamics will change with this increased $\mathrm{CO}_{2}$. For many policy makers and resource managers, a misunderstanding about the meaning of scientific uncertainty may inhibit or even distort decision making critical for mitigating or adapting to climate-associated risks. The goal of this task is to bring climate scientists together with social scientists (particularly specialists in the areas of risk communication and public policy) to (a) synthesize the state of the science about uncertainty in predicted climate factors and ecological responses, particularly with emphasis on conservation adaptive strategies in the Southeastern U.S.; and (b) develop and implement a strategy to improve decisionmakers' understanding of the uncertainty in climate prediction (particularly as it pertains to risks, vulnerabilities, and proposed mitigation/adaptation activities in the SE) as well as climate scientists' capabilities to effectively communicate about climate risk and uncertainty. (Project limit: \$40,000, with completion in 1 year)

\section{Terrestrial Connectivity Analysis Across the Entire SE Region}

The goal of this task is to improve the capacity to predict patterns of terrestrial habitat connectivity necessary to sustain natural resources, with consideration given to the approach used by Washington Wildlife Habitat Connectivity Working Group (http://waconnected.org). Models and other approaches developed as part of this task should cover the entire SE region and be capable of producing measurable predictions of the impacts of changes in connectivity based on future landscape conditions and potential conservation actions. Models should be capable of identifying where to conserve and restore habitat connectivity for priority or idealized species of interest across the LCCs and natural landscapes across the SE to ensure the long-term viability of the region's wildlife populations. 
Predictions of future landscape conditions and potential actions are complete or under development for the SE region and will be provided to PIs where available. PIs can also be provided with idealized species of interest.

\section{Conceptual Model for Regional-Scale Sustainable Landscapes}

A sustainable regional landscape can be thought of as an ensemble of stable and productive human and natural ecosystems that maintain important physical, chemical, and biological processes characteristic of that landscape. This broad concept of "sustainable landscapes" is focused on sustainable levels of fish, wildlife, and other resources desired by the public, and represents a reasonable general endpoint for adaptive management of these ecosystems in the face of global changes in climate and land use. The concept of a sustainable regional landscape is, however, not well understood and agreed upon by the scientific and management communities. Common agreement is also lacking about the identity and measurement of the attributes of a sustainable regional landscape, as well as the identity and role of factors that influence the condition of regional landscapes.

There are three goals related to this task: (a) Frame a conceptual model that links the concept of a sustainable landscape, at the scale of individual level III ecoregions in the SE United States that coincide with the boundary of the $7 \mathrm{SE} \mathrm{LCCs},{ }^{2}$ to the drivers and stressors that affect the sustainability of that landscape. This effort should involve a synthesis of the state of the current scientific and management thinking about the concepts that are part of this framework and how these concepts can be operationalized and measured. (b) The conceptual model from (a) will be used, in consultation with the LCCs, to identify potential adaptive management strategies that may not now be commonly used in the SE; these adaptive strategies will be incorporated into the overall conceptual model as factors that can shape a sustainable landscape.

(c) Because this conceptual model represents a hypothesis about the functioning of key natural and human ecosystems in these ecological regions, the conceptual model derived from (a) and (b) will serve as the basis for identifying important knowledge gaps and research priorities.

\footnotetext{
${ }^{2}$ U.S. Environmental Proection Agency (EPA) Level III ecoregions 34, 35, 36, 37, 38, 39, 45, 63, 65, 66, 67, 68, 69, 71, 73, 74, 75, 76; see ftp://ftp.epa.gov/wed/ecoregions/us/Eco_Level_III_US_pg.pdf for Level III ecoregion map.
}

\section{Impact of Mangrove Migration on Coastal Ecosystems}

Use recently completed predictions of mangrove migration for the Atlantic and Gulf of Mexico coasts to predict the impacts of that migration on coastal ecosystems and the natural and (or) cultural resources that depend on them. The goal of this task is to understand what the impacts of a transition to mangrove communities means for terrestrial and aquatic flora and faunal communities, as well as impacts of this transition on broader coastal ecosystems. The project should cover the Gulf Coast states and the Atlantic Coast up to southern South Carolina. Predictions of mangrove migration will be provided to the PIs.

\section{Snowfall and Snow Depth Projections for the Eastern United States}

In North America, the life history strategies of many fish and wildlife species are influenced by the timing and intensity of snow events. Seasonal snow patterns greatly influence fish and wildlife survival, mobility, and access to food. In order to better evaluate and plan for potential fish and wildlife responses to snow-related winter climate change, natural resource scientist and managers require easily accessible highresolution daily downscaled snowfall and snow depth projections. Additionally, snow water equivalent is needed in many hydrologic models. Statistical downscaling products for the conterminous U.S. currently lack these snow-related variables. Projects should address these gaps as described below:

Desired variables: snowfall $(\mathrm{cm})$, snow depth $(\mathrm{cm})$, snow water equivalent

Temporal extent: daily projections through 2100

Number of models: as many as possible using the statistically downscaled projections already produced by Hayhoe and Stoner

Spatial extent of projections: at a minimum, the Eastern United States

Resolution: $\sim 1 / 8$ degree

Accessibility: via the Center for Geospatial Data Analysis GeoDataPortal ${ }^{3}$

\footnotetext{
${ }^{3}$ http://cida.usgs.gov/gdp/.
} 


\section{Appendix 4. FY13/14 SE CSC Science Priorities}

These science priorities appeared as follows in the Funding Opportunity Announcement for the Department of Interior Climate Science Centers (CSC) for Fiscal Years 2013 and 2014, released January 9, 2013:

\section{Science Needs:}

The Southeast Climate Science Center (SE CSC) is soliciting proposals for projects that show evidence of a clear linkage between proposed science and climate change adaptation decisions that affect the sustainability of fish, wildlife, and other natural and cultural resources. Two types of climaterelated management decision problems have been identified as priority SE CSC concern in FY13/14.

1. Conservation and water governance-Water governance decisions are often characterized by conflicts over how to prioritize and balance diverse societal water uses with the needs of fish and wildlife resources (and the services they provide). This has been especially true in the Southeast, a region that has seen limited success reconciling conservation of fish and wildlife resources with other water uses despite over four feet of annual rainfall. Proposed research should address the challenges of incorporating fish and wildlife conservation into the larger context of water governance at the river basin scale, which encompasses a broad range of social, economic, and aesthetic values.

2. Local-scale climate adaptation decision problemThe southeastern U.S. has an abundance of public properties devoted to the conservation of natural and cultural resources, such as National and State Parks, National Wildlife Refuges, State Wildlife Management Areas, and many others. Managers of these areas face the difficult challenge of understanding the potential impacts of climate change on the resources they are charged to protect, and of formulating effective mitigation and adaptation strategies. Proposed research should indicate how structured decision making will be used to frame a specific decision problem, identify objectives, and define alternatives and tradeoffs necessary to identify effective mitigation or adaptation strategies. The research may be focused on a single conservation area or on a common problem shared by multiple preserves. 


\section{Appendix 5. FY15 SE CSC Science Priorities}

These science priorities appeared as follows in the Funding Opportunity Announcement for the Department of Interior Climate Science Centers (CSC) - Fiscal Year 2015, released April 30, 2014:

\section{FY15 Science Needs:}

The Southeast Climate Science Center (SE CSC) is soliciting Statements of Interest (SOI) for two projects that support development and implementation of a Southeast Conservation Adaptation Strategy (SECAS). Additional details about these FY15 science needs are available and should be reviewed before submitting a statement of interest or proposal (http://globalchange.ncsu.edu/SECSC/wp-content/uploads/ SE CSC_FY15_call_description_041414.pdf)

1. SECAS framework development: The lands and waters of the Southeastern United States have experienced tremendous change, particularly during the 20th Century, and yet have remained remarkably resilient in their capacity to sustain some of the most diverse natural resources found on the North American continent (Master and others, 1998; White and others, 1998). These resources, which can be recognized at many scales - species/assemblages (fish, wildlife, and plants); ecosystems; and landscapes, also support diverse and productive human activities.

Serious unanswered questions exist about the degree to which past successful conservation strategies can sustain all aspects of these diverse, natural resources in the face of unprecedented changes (and interactions) broadly expected to occur as a result of both climate and land use change. Preserving all natural resources "as is" will not be possible with the large-scale ecological changes anticipated under pervasive and interacting climate and land use change (Dunlop and others, 2013).

Those whose decisions shape the SE landscape and the status of these natural resources will need to account for at least three challenges: (1) the unprecedented degree of change in large scale stressors (climate and land use change) and the impacts of these stressors on services provided by these resources at multiple scales; (2) the potential mismatch between the scales at which changing physical and biological processes affect valued natural resources and scales at which governance of these resources is exercised; and (3) articulation of objectives that adequately reflect the values and priorities of multiple stakeholders who have an interest in these resources at a variety of spatial and temporal scales. It is likely that sustaining natural resources in the SE into the future will require a re-thinking of conservation objectives, principles, and decision making processes.

Recognizing these challenges and needs, in 2011 the Directors of the Southeastern Association of Fish and Wildlife Agencies (SEAFWA; http://www.seafwa.org/index.php) initiated a process to develop a Southeast Conservation Adaptation
Strategy (SECAS) that will define a "future conservation landscape in the Southeast United States." This element of the FY15 SE CSC science needs contributes directly to this initiative.

The overall goals of this "SECAS Development Project" are to produce a report and a Web site that will support this initiative. We are seeking proposals for research efforts that accomplish the following goals:

(1) Review and summarize the objectives and management actions contained in existing Federal, State, and local plans and other strategic documents that guide management decisions about three key dimensions of SE natural resources: species (such as fish, wildlife, and plants); priority ecosystems (including, at least, coastal and upland wetlands, and forests); and landscape-scale systems (such as open space and corridors, the interface between urban and non-urban areas, and water quantity and quality associated with meeting conservation objectives). These objectives represent the values and priorities on the books now for assessing alternative actions that will determine the future of these key SE resources. At a minimum, reviewed plans should include: state wildlife action plans and open space and habitat connectivity plans for all member states of SEAFWA; open space plans for large metropolitan areas in each SEAFWA state; and forest plans.

(2) Using existing climate and land use change-related impact assessment products, assess the impacts of expected climate and land use change on the objectives and priorities associated with these key resources. Examples of such an assessment are contained in Dunlop and others (2012a, b).

(3) In collaboration with LCCs, develop and articulate a small number (3-5) of high-level guiding principles or propositions to guide natural resource decisions in the SE in the face of changing climate and land use. Examples of such broad propositions are contained in Dunlop and others (2013).

Specific objectives of this project include:

(a) Increase the understanding, for both the general public and those whose decisions shape the SE landscape, about the scientifically complex and politically charged set of topics that include: what matters to the public and decision makers about these key natural resources, as reflected in planning documents and other resources? and how are the things that matter about these resources threatened by climate and land use change?

(b) Provide a one-stop place to get introductory and more advanced information about natural resources-related planning objectives and priorities, and climate and land use change-related impacts, including impacts on attaining these resource objectives.

(c) Enable users of the report and Web site to visualize the trajectory of climate and land use change and risks to natural resources in the Southeast, where risks are expressed in terms of the vulnerability of the resource-related objectives and priorities. 
(d) Use information about current objectives and values placed on natural resources as a context to advance the conversation about defining the desired conservation landscape of the future.

Audience: The primary audiences for these products are those whose decisions shape the SE landscape now and in the future and the technical staff that support the decision makers. These include decision makers of land units at the scale of a park, refuge, or reserve, as well as larger landholders, including private landowners and nongovernmental organizations. Because decision makers are not necessarily disciplinary experts in all facets of the scientific issues that should be brought to bear on making these decisions, the products should be understandable and useful to non-technical experts that have a strong interest in these topics.

The proposed report should include sections that accomplish the following three tasks:

(a) Review objectives and management actions that underlie natural resource decisions that will be affected by climate and land use change in the SE:

Objectives are concise statements of the fundamental interests that could be affected by a decision, reflecting the things that matter to people making the decision. These objectives provide a key frame of reference for creating and evaluating alternative management actions (Gregory and others, 2012). Conservation decisions about natural resources affected by climate change are likely to consider objectives that reflect what matters both to decision makers and to broader groups with an interest in the resource.

This review should identify natural resources objectives and the menu of management actions contained in existing planning documents and present these objectives and actions organized by three key dimensions of these natural resources: species/assemblages (fish, wildlife, and plants); ecosystems; and landscapes.

In choosing natural resource plans for review place a priority on: (a) state wildlife action plans; (b) open space and habitat connectivity plans for all member states of SEAFWA; (c) open space plans for large metropolitan areas in each SEAFWA state; and (d) forest plans at Federal, State, and private levels. Work with LCCs to identify plans and build on existing summaries prepared by LCCs.

Identify and discuss any scale mismatches between the objectives and priorities related to the management of these natural resources and the scale of governance activities that currently can be brought to bear to achieve these priorities.

Analyze and assess the apparent challenge that despite the awareness that conservation frameworks will need to account for the impacts of broad-scale climate and land use change processes, very little has been articulated about how these broad scale processes affect the definition of local and broad scale objectives, values, and priorities related to these resources.

In addition to this review of objectives and management actions over a broad range of resources and plans, a more detailed assessment will be completed on the objectives found in a sample of legislation, plans, and regulatory documents associated with a few key resources in the SEAFWA region. Proposals should suggest 2-3 types of natural resources that will be the focus of this more in-depth analysis (from among important SE resources such as open pine systems; black bears; coastal wetland; migratory waterbirds; open space/ habitat connectivity, etc.) and, using a sample of legislation, planning documents, and promulgated regulations, propose an approach for assessing the quality of the objectives indicated in these documents, using properties for "good" objectives such as those described in Gregory and others, (2012; e.g., complete, concise, sensitive, understandable, independent). The assessment should also determine, using tools such as textual analysis, how ambiguities and other problems in these written documents may hinder accomplishment of conservation outcomes. Examples of potential problems include: (1) poor program logic (e.g., confusing means and ends; confusing outcomes in one dimension of natural resources (e.g., species) with outcomes actually desired in another dimension (ecosystems or landscapes); (2) blurring concepts through use of language and terms that have different meanings to different audiences; (3) a mismatch between objectives and alternative actions (either the list of objectives in insufficient to assess the efficacy of all the alternative actions or the scope of alternative actions are insufficient to describe all the ways that the objectives can be achieved (ch 2. Keeney, 1992); and (4) scale mismatches between the planning objectives (which might reflect a set of priorities ranging from a local park or refuge scale to a continental/flyway scale) and the scale of governance activities that currently can be brought to bear on these priorities. This analysis should improve understanding of the ways in which the development, articulation, and use of objectives can promote or provide barriers to accomplishing what matters to those who value natural resources in the SE, and ways to surmount these barriers. Final selection of natural resources and a list of document analysis objectives will be done in cooperation with a project steering committee (see below).

Examples of the types of documents that may be useful for understanding and framing a proposal for this element of the SECAS project:

- Florida Forever Conservation Needs Assessment

- Range-Wide Conservation Plan for Longleaf Pine

- Connectivity approaches in state wildlife action plans

- Considering Climate Change in Florida's Wildlife Action Planning A Spatial Resilience Planning Approach

- National, state, and other forest plans

(b) Use available scientific literature to understand and describe the impacts of climate and land use change on these existing objectives and priorities:

Provide an overview of climate and land use change impacts in the SE, by LCC boundaries, reflected in temperature, precipitation, extreme climatic conditions, hydrology, 
soil moisture, and land use/cover. For the natural resources identified in part one of this project, used existing assessment literature to summarize expected impacts of climate and land use changes on the ability to achieve objectives. In collaboration with the project steering committee, identify resource types (e.g., long leaf pine; mangroves) where more detailed impact studies have been accomplished, and synthesize these study findings. Identify important knowledge gaps to understand the impacts of global change scenarios on SE natural resources objectives.

Potential documents that may be useful for understanding and framing a proposal for this element of the SECAS project:

- The implications of climate change for biodiversity conservation and the National Reserve System: Final Synthesis

- Implications for policymakers: Climate change, biodiversity conservation and the National Reserve System

- National Climate Assessment

- Climate of the Southeast United States: Variability, Change, Impacts, and Vulnerability

- Regional Climate Trends and Scenarios for the US National Climate Assessment: Part 2. Climate of the Southeast US

- Intergovernmental Panel on Climate Change Assessment Reports

- A Multi-disciplinary Assessment of the Southeastern United States Climate

- Integrating climate change vulnerability assessments into adaptation planning, Florida, 2011

(c) Articulate broad SECAS conservation principles and propositions:

Following Dunlop and others (2013), while the details are uncertain, anticipated future climate and land use changes in the SE will affect many, if not most, species, ecosystems, and landscapes in coming decades and centuries. Preserving these natural resources may not be possible under a regime of local to global ecological changes driven by climate and land use change (although preserving many associated ecosystem services may be). Because of the likely scope of ecological changes (unfolding over decades to centuries), current approaches to maintaining the form and function of natural resources may become increasingly ineffective. A fundamental challenge is to develop a statement of high-level principles to guide the formulation of more detailed objectives and plans for adapting to climate change in coming decades. Using what is known about how climate change will affect (at least broadly) the key SE natural resources listed above, and consultation with LCCs, develop climate and land use ready, broad scale principles to guide management of natural resources in the Southeast (Dunlop and others, 2013).

Potential documents that may be useful for understanding and framing a proposal for this element of the SECAS project:
- Climate-ready conservation objectives: a scoping study

- National Fish, Wildlife and Plants Climate Adaptation Strategy

The proposed companion Web site developed as part of this proposal should enable users to visualize the trajectory of climate and land use change and other threats and risks associated with global change. This site might integrate some existing LCC GIS data and capabilities, along with new data (e.g., climate-related scenarios that can be portrayed on user selected geographies?). One example of such a Web resource is the Cal Adapt Web site (http://cal-adapt.org/), which enables members of the public to examine and explore the impacts of climate change on things that matter to them.

Additional information: It is anticipated that project funding will begin in fall 2014, or as soon as the FY15 USGS appropriation is complete, and that the project may take 2-3 years to complete, in an iterative manner. A first iteration of the report and Web site should be prepared by January 2016. Project team members should be prepared to use the draft framework to assist in the planning of a SECAS summit planned for summer 2016. It is anticipated that the summit planning process and the summit will produce information that can inform a second iteration of some or all of the project products. The final project report and Web site should be completed by no later than June 2017.

SE CSC and LCCs will provide assistance in identifying members of an advisory group for the project. Full proposals should indicate how an advisory group would be used in scoping, reviewing, and finalizing all project-related products. Teams invited to submit proposals are encouraged to identify and include as project team members scientists that have experience in developing large scale natural resource climate adaptation plans (e.g., Dunlop and others, 2012a and b) as well as scientists with expertise in decision analysis approaches such as structured decision making.

2. Cultural resources. Climate and land use change are already having a broad set of adverse impacts on cultural resources. Sea level rise, extreme storms, and coastal flooding threaten coastal resources like shell middens and historic structures. Land use change (particularly urbanization) near historic sites is altering the physical and cultural setting within which these resources are viewed and experienced. Rising temperatures are leading to introduced climate control systems like air conditioning at historic destinations like houses, buildings, and boats, again altering the experience of visitors. Additionally, new temperature and precipitation combinations may lead to altered behavior affecting visitation to historic sites and resources. The combined stressors of climate and land use change can create substantial problems for maintaining the values associated with cultural resources.

Three key features of cultural resources in the Southeast are of particular value: significance, association, and integrity. To be significant, a cultural resource must have important historical, cultural, scientific, or technological meaning and this meaning must be connected or associated with a physical 
place or form. For purposes of this project, every cultural resource must have a connection with the history or prehistory of the United States, or it must have value for a particular ethnic group. Integrity addresses the degree to which socially valued behavior and ideas are manifested in the form and substance of a resource. A cultural resource has integrity if it retains material attributes connected with its social values.

Virtually all problems in resource management require decisions involving choices that must be made among alternative actions to achieve one or more objectives; this is true for cultural resources, as well (Conroy and Peterson, 2013). While this appears like a straightforward task requiring little more than the application of common sense, protecting the values associated with significant cultural resources requires managers to make challenging decisions under considerable uncertainty, complexity, and potential conflict, assessing and weighing a variety of values, objectives, risks, stressors, and other challenges to sustainable management.

Managers are seeking objective, replicable, and transparent ways to make wise decisions that will protect important values and objectives associated with cultural resources. Management options for protecting and preserving societal values associated with cultural resources have narrowed due to the stresses associated with climate and land use change, constraints associated with limited budgets, and increasing urgency for managing threatened resources. In these complex cultural resources decision-making settings, decision analytic approaches, such as structured decision making, can be useful in providing a "...formalization of common sense for decision problems which are too complex for informal use of common sense (Keeney, 1992)."

The overall goal of this project is to utilize a decisionanalysis-based approach to strengthen the ability of the agencies and organizations in the SE to make wise management choices about cultural resources, accounting for the stresses associated with climate and land use change (Thompson and others, 2013). This 1-2 year project will be a collaboration between staff at agencies responsible for managing the cultural resources and, as appropriate, collaborators from academia and elsewhere. The project will focus on three goals: (1) define an overall conceptual framework that articulates which cultural resources in the SE are important (significance, association, integrity) and why; (2) use this conceptual framework to define an overall decision context (in a decision analytic sense) applicable for cultural resource conservation decisions by an agency/organization; and (3) implement a decision analysis-based pilot project focused on an actual cultural resource management decision.

Conceptual framework: A theory-based conceptual framework will be developed that provides the rationale for understanding the significance, association, and integrity of cultural resources in the SE that are under the purview of the agencies and organizations that range from the NPS to a local historic preservation organization. The framework may be informed by and build on documents developed by the NPS, which is considered to be one of the preeminent national organization for management of cultural resources. Among these documents are Climate Change Response Strategy (2010), Climate Change Action Plan (2012), and a recently released policy memo, Climate Change and Stewardship of Cultural Resources (2014). This framework will provide answers to questions related to the significance, association, and integrity of cultural resources such as What matters about the cultural resources? to whom? and why? Why are these resources important for understanding the identity and importance of a place? What makes a "place" important to different stakeholders such as the general public, preservation professionals, and the academic community? What aspects of resources and place are important to preserve in the face of threats from climate and land use change? Why are these aspects important? What are the options for preserving the various elements of a place/resource? What is the basis for "giving up" on the physical preservation of a resource threatened by global change processes? Is there scalability of cultural significance; that is, does the significance of individual cultural sites in the SE "add up" in some way, or is the significance strictly local? Answers to such questions are needed to define the objectives and priorities that will guide cultural resources management decisions. Without understanding what is significant about these resources and why, there is no context for framing the decisions faced by an agency or organization nor, practically, is it possible to wisely allocate limited resources toward a portfolio of actions and an expectation of the best outcome.

Decision context: A decision context for cultural resource management decisions in the SE will be defined using the conceptual framework and an articulation of the key cultural resource decision problems facing organizations that manage cultural resources in the next 20-50 years; an articulation of the objectives of both decision makers and stakeholders in these cultural resource management decisions; an overall rationale for the key cultural resource management objectives in the SE of these decision makers and stakeholders, including their attitudes toward risk; and an articulation of an innovative portfolio of potential management strategies and actions. Understanding the decision context is a necessary step prior to any type of vulnerability assessment or choice of adaptation strategy, because the need to understand the vulnerability of a resource characteristic that is "at risk" arises out of the association of that resource characteristic with one or more management objectives.

Pilot project: Proposals should also define how structured decision making will be used to frame a specific cultural resource-related decision problem. The proposal should describe how decision makers and other stakeholders will frame a relevant decision problem, develop conservation objectives, identify possible mitigation or adaptation actions that are within the purview of the decision maker(s), evaluate the potential strategies for decision making, and design or re-design monitoring programs to assess the effectiveness of management actions (fig. 1). The research should be focused on a problem shared by multiple cultural resource 
locations and result in information (including the process of conducting such a study) that is informative and transferable for addressing similar management questions across the SE.

It is expected that the team of investigators for a proposal will include cultural resource experts from the resource management organization, researchers in fields such as cultural anthropology and geography, and experts in the field of decision analysis.

\section{References Cited*}

Conroy, M.J., and Peterson, J.T., 2013, Decision making in natural resource management-A atructured, adaptive approach: Wiley Blackwell, 474 p.

Dunlop, M., Hilbert, D.W., Ferrier, S., House, A., Liedloff, A., Prober, S.M., Smyth, A., Martin, T.G., Harwood, T., Williams, K.J., Fletcher, C., and Murphy, H., 2012a, The implications of climate change for biodiversity conservation and the National Reserve System-Final synthesis: A report prepared for the Department of Sustainability, Environment, Water, Population and Communities, and the Department of Climate Change and Energy Efficiency, CSIRO Climate Adaptation Flagship, Canberra.

Dunlop, M., Hilbert, D.W., Stafford Smith, M., Davies, R., James, C.D., Ferrier, S., House, A., Liedloff, A., Prober, S.M., Smyth, A., Martin, T.G., Harwood, T., Williams, K.J., Fletcher, C. and Murphy, H., 2012b, Implications for policymakers - Climate change, biodiversity conservation and the National Reserve System, CSIRO Climate Adaptation Flagship, Canberra.

Dunlop, M., Parris, H., Ryan, P., and Kroon, F., 2013, Climate-ready conservation objectives - A scoping study: Gold Coast, National Climate Change Adaptation Research Facility, 102 p.
Gregory, R., Failing, L., Harstone, M., Long, G., McDaniels, T., and Ohlson, D., 2012, Structured decision making-A practical guide to environmental management choices: Chichester, West Sussex, UK, Wiley-Blackwell.

Jarvis, J.B., 2014, Climate change and stewardship of cultural resources: National Park Service. Policy Memorandum 14-02, accessed August 23, 2016, at https://www.nps.gov/ policy/PolMemos/PM-14-02.htm.

Keeney, R.L., 1992, Values-focused thinking-A path to creative decisionmaking: Cambridge, Mass., Harvard University Press, $432 \mathrm{p}$.

National Park Service, 2010, National Park Service climate change response strategy: Fort Collins, Colo., National Park Service Climate Change Response Program, accessed August 23, 2016, at http://www.nature.nps.gov/climate change/docs/NPS_CCRS.pdf.

National Park Service, 2012, Climate change action plan 2012-2014: Fort Collins, Colo., National Park Service Climate Change Response Program, accessed August 23, 2016, at http://www.nature.nps.gov/climate change/docs/NPS_CCActionPlan.pdf.

Thompson, M.P., Marcot, B.G., Thompson, F.R., III, McNulty, Steven, Fisher, L.A., Runge, M.C., Cleaves, David, and Tomosy, Monica, 2013, The science of decision making-Applications for sustainable forest and grassland, Management in the National Forest System: U.S. Department of Agriculture General Technical Report WO-88.

\footnotetext{
*The References Cited section for appendix 5 is not part of the original FY15 Funding Opportunity Announcement document but is added here for the convenience of the reader.
} 


\section{Appendix 6. Southeast Climate Science Center Science Planning Meeting}

An overview of the SE CSC presentations and attendees to this meeting can be found on the SE CSC Web site. The agenda to this meeting follows:

USGS Coastal and Marine Science Center Office

600 4th Street South

St. Petersburg, FL

February 14-16, 2012

\section{Overall Meeting Objectives:}

- Lay the groundwork for a common vision of the Southeast Climate Science Center including its relationship, roles, and responsibilities with participating Federal agencies and the LCCs.

- Compile and organize information regarding science capabilities and expertise among the participants in the Southeast.

- Discuss research priorities for 2012 request for proposals.

\section{Tuesday, February 14, 2012: Overview of Context for Science Activities \& Theme 3: Impacts of Climate Change on Water Resources}

8:30 a.m. Welcome and Agenda Review

- Jerry McMahon, Director, DOI Southeast Climate Science Center will welcome the group and review desired meeting objectives.

- Linda Manning, facilitator, Council Oak, will assist with introductions and review the agenda.

8:45 a.m. $\quad$ SE CSC Science Planning Issues and Objectives

Jerry McMahon will provide an overview of the SE CSC and review the SE CSC Science and Operations Plan including key players, themes, challenges and opportunities.

9:15 a.m. North Carolina State University as Host of SE CSC (NCSU)

Damian Shea, (Principal Investigator, SE CSC, Professor, Department of Biology) will provide an overview of the role of NCSU as the host of the SE CSC and discuss the science capabilities at NCSU.

9:45 a.m. Break

10:00 a.m. Federal Partners \& Their Involvement in the SE CSC Science Partnership

Partner leads will provide an overview of the intended role of their organization in the SE CSC science partnership and how that fits in with their overall agency objectives, programs, activities, and foci.

10:00 a.m. National Oceanographic and Atmospheric Administration (NOAA)

Dave Brown (Director, Southern Region Climate Services)

10:20 a.m. U.S. Forest Service (USFS)

Jim Vose, (Project Leader, Forest Watershed Science)

10:40 a.m. National Park Service (NPS)

Sherri Fields (Chief, Natural Resources Division, Southeast Region)

11:00 a.m. U.S. Fish and Wildlife Service (USFWS)

Bill Uihlein, (Assistant Regional Director for Science Applications) 
11:20 a.m. Landscape Conservation Cooperative Panel Discussion on Science Needs/Agendas

12:00 p.m. Discussion of SE CSC and Partner Relationships and Programs

12:30 p.m. Working Lunch - Sandwiches

1:00 p.m. U.S. Geological Survey (USGS) Involvement in the SE CSC Science Partnership

1:00 p.m. Climate and Land Use Change Research \& Development

Deb Willard, Program Coordinator, will provide an overview of the USGS CLU R\&D program and describe how it supports the efforts of the SE CSC Science Partnership.

1:20 p.m. $\quad$ Eastern Geographic Science Center

Dave Kirtland, Director, will prove an overview of the Geographic Analysis and Monitoring Program and describe how it supports the efforts of the SE CSC Science Partnership.

1:40 p.m. USGS National Research Program

Jared Bales, Chief Scientist for Water, will provide a description of the USGS

National Research Program activities relevant to the SE CSC Science Partnership.

\section{2:00 p.m. Compile Science Capabilities in Relation to SE CSC Science Plan Themes}

This theme-by-theme discussion will be kicked off with brief presentations followed by a discussion by all participants. Presentations will focus on a summary of related research including key researchers and their findings, key questions, promising methods, knowledge gaps/challenges, and opportunities. They will also share an assessment of their center's plan for addressing key questions including staffing plans, ability to leverage resources and existing and future science partners, and where they see their center's focus/ niche in the coming 5-10 years.

Following the presentations for each theme, discussion questions will address:

- How does the research you have heard about answer some of the key management questions/needs you may have?

- Are there particular products or synthesis that could be developed from existing information/data that would be helpful?

- What are the key information needs that are not being addressed?

2:00 p.m. Science Plan Theme 3: Impacts of Climate Change on Water Resources

2:00 p.m. $\quad$ Lauren Hay, USGS National Research Program

2:20 p.m. $\quad$ Eric Swain, USGS Florida Water Science Center

2:40 p.m. Paul Conrads, USGS South Carolina Water Science Center

3:00 p.m. Break

3:15 p.m. Brian Hughes, USGS Georgia Water Science Center

3:35 p.m. Van Wilson, USGS Mississippi Water Science Center

3:55 p.m. Rodney Knight, USGS Tennessee Water Science Center

4:15 p.m. Nate Booth, USGS Center for Integrated Data Analytics

4:35 p.m. Discussion

5:30 p.m. Adjourn 


\section{Wednesday, February 15, 2012: Discussion of Themes 2, 4, and 5}

8:30 a.m. Day One Recap and Agenda Review - Linda Manning/Jerry McMahon

8:45 a.m. USGS National Wetlands Research Center

Dr. Phil Turnipseed, Director, will provide an overview of the USGS NWRC science capabilities and their relationship and cooperative efforts with both the Gulf Coast Prairie and Gulf Coastal Plain and Ozarks Landscape Conservation Cooperatives.

9:15 a.m. $\quad$ Science Plan Theme 5: Coastal \& Nearshore Marine Environments

9:20 a.m. Athena Clark, USGS Alabama Water Science Center

9:40 a.m. Amanda Demopoulos, USGS Southeast Ecological Science Center

10:00 a.m. Van Wilson, USGS Mississippi Water Science Center

10:20 a.m. Break

10:30 a.m. Ilsa Kuffner, USGS Coastal Marine Science Center

10:50 a.m. Chris Smith, USGS Coastal Marine Science Center

11:10 a.m. Brian Hughes, USGS Georgia Water Science Center

11:30 a.m. Nate Booth, USGS Center for Integrated Data Analytics

11:50 a.m. Discussion

12:30 p.m. $\quad$ Lunch $-B B Q$

1:15 p.m. USGS Florida Water Science Center

Bob Renken (Associate Director for Hydrologic Studies) will provide an overview of the South Florida Climate Compact and other examples of multi-agency Climate Compacts in Florida in order to inform participants about local scale management tool/agreements.

1:45 p.m. Science Plan Theme 4: Ecological Research and Modeling

1:45 p.m. Brian Hughes, USGS Georgia Water Science Center

2:05 p.m. Stephanie Romanach, USGS Southeast Ecological Science Center

2:25 p.m. Leslie Ries, University of Maryland

2:45 p.m. Eric Swain, USGS Florida Water Science Center

3:05 p.m. Discussion

3:30 p.m. Break

3:40 p.m. Science Plan Theme 2: Land Use and Land Cover Change Projections

3:40 p.m. John Barras, USGS Coastal Marine Science Center

4:00 p.m. Dave Sumner, USGS Florida Water Science Center

4:20p.m. Tom Smith, USGS Southeast Ecological Science Center

4:40 p.m. Nate Booth, USGS Center for Integrated Data Analytics

5:00 p.m. Discussion

5:30 p.m. Adjourn 
Thursday, February 16, 2012: Discussion of Themes 1 and 6 and Synthesis of Science Capabilities and Management Needs

8:30 a.m. $\quad$ Day Two Recap and Agenda Review - Linda Manning/Jerry McMahon

8:45 a.m. Science Plan Theme 6: Impacts of Climate Change on Cultural Heritage Resources

Dave Zawada, USGS Coastal Marine Science Center

9:05 a.m. Discussion

9:40 a.m. Science Theme 1: Develop Climate Projections and Determine Appropriate Projections to Use for Resource Management

9:40 a.m. Tom Smith, USGS Florida Water Science Center

10:00 a.m. $\quad$ Fred Semazzi, North Carolina State University

10:20 a.m. Break

10:40 a.m. Adam Terando, North Carolina State University

11:00 a.m. Dick Poore, USGS Coastal and Marine Science Center

11:20 a.m. Nate Booth, USGS Center for Integrated Data Analytics

11:40 a.m. Discussion

12:30 p.m. Lunch - Mediterranean

1:30 p.m. Synthesis of Science Capabilities and Management Information Needs

Discussion will focus on developing a summary and synthesis of the following topics:

1. Key LCC management information needs

2. Science capabilities in terms of these needs

3. Key gaps in science capabilities

4:00 p.m. Adjourn 

Manuscript approved August 15, 2016

Prepared by the USGS Science Publishing Network Reston Publishing Service Center Edited by Kay P. Naugle Layout by Caryl J. Wipperfurth

For more information concerning this report, please contact:

Director

U.S. Department of the Interior Southeast Climate Science Center North Carolina State University Campus Box 7617

Raleigh, NC 27695-7617 https://www.doi.gov/csc/southeast/ https://globalchange.ncsu.edu/secsc/ 
